University of San Diego

Digital USD

2004-05-01

\title{
Webquest Design Strategies: A Case Study Measuring the Effect of the Jigsaw Method on Students' Personal Agency Beliefs, Engagement, and Learning
}

James P. Frazee EdD

University of San Diego

Follow this and additional works at: https://digital.sandiego.edu/dissertations

Part of the Leadership Studies Commons

\section{Digital USD Citation}

Frazee, James P. EdD, "Webquest Design Strategies: A Case Study Measuring the Effect of the Jigsaw Method on Students' Personal Agency Beliefs, Engagement, and Learning" (2004). Dissertations. 872. https://digital.sandiego.edu/dissertations/872 Digital USD. It has been accepted for inclusion in Dissertations by an authorized administrator of Digital USD. For more information, please contact digital@sandiego.edu. 


\title{
WEBQUEST DESIGN STRATEGIES: A CASE STUDY MEASURING THE EFFECT OF THE JIGSAW METHOD ON STUDENTS' PERSONAL AGENCY BELIEFS, ENGAGEMENT, AND LEARNING
}

\author{
by \\ James P. Frazee
}

\begin{abstract}
A dissertation submitted to the faculty of
San Diego State University and the University of San Diego in partial fulfillment of the requirements for the degree of Doctor of Education
\end{abstract}

Dissertation Committee:

Bernard J. Dodge, Ph.D., Chair Susan M. Zgliczynski, Ph.D., Member

Marcie J. Bober, Ph.D., Member

David M. Sharpe, Ed.D., Member

May 2004 
C Copyright by James P. Frazee 2004

All Rights Reserved

Reproduced with permission of the copyright owner. Further reproduction prohibited without permission. 


\begin{abstract}
The WebQuest model continues to grow in popularity, with teachers from around the world and many teacher-educators and experts in the field of educational technology espousing its potential to extend content knowledge and promote higher level thinking. While the model is well received by teachers and students alike, most evidence of its effectiveness is anecdotal, and there is very little in the way of empirical research on the elements that make an effective WebQuest. Furthermore, rich descriptions of how students interact during a well-developed WebQuest are largely absent from the literature. In short, the WebQuest model suffers from a lack of scholarly research which may impede practitioners interested in using this approach to design and deliver effective Web-enhanced instruction.
\end{abstract}

Successful WebQuests must address three pedagogical design challenges: Enhancing students' personal agency beliefs; sustaining student engagement; and, promoting students' deep understanding and critical thinking. This dissertation was a comparative two-case case study that investigated how one cooperative learning method, Jigsaw, was adapted for use with a WebQuest about living with AIDS. The researcher compared two versions of the WebQuest, one with and one without the addition of the Jigsaw method, and showed how they addressed each design challenge.

Feedback from 89 students participating in two undergraduate history classes revealed significant differences by class in the following important areas: Students in the No Jigsaw class were more likely to use a negative statement to describe the quality of interaction with their teammates post-Jigsaw. Students in the Jigsaw class perceived more strengths and fewer weaknesses with the WebQuest than the No Jigsaw class, and shared 
more positive and fewer negative remarks regarding overall satisfaction with the WebQuest experience. Perhaps most importantly, students in the Jigsaw class spent significantly less time on task post-Jigsaw when controlling for Midterm Score and prior experience with the content domain. Finally, while students from both classes did equally well on the measures of content learned, the results suggested that the students from the Jigsaw classes were more efficient with the time they spent working on the WebQuest task outside of class. 


\section{DEDICATION}

To my dear mother who taught me the value of hard work, humility, and perseverance. Her deep love, good nature, and ceaseless encouragement helped me greatly on this long road to obtaining a doctoral degree. 


\section{ACKNOWLEDGEMENTS}

A number of people helped me complete this dissertation. My principal thanks go to my advisor, Dr. Bernie Dodge, who made a profound impact on the future of learning with his innovative WebQuest model. He is a continual source of inspiration for educators from around the world and he has long been an able cognitive guide to me.

I would also like to thank Dr. Susan Zgliczynski and Dr. Marcie Bober for their patience and for the amount of time they dedicated to painstakingly helping me with methodological design, data analysis, and interpretation. Dr. David Sharpe also deserves my gratitude for his generosity and calming presence, and for providing thoughtful insights that challenged me to step back and think carefully about the rigor of the study and presentation of results.

My thanks also go out to Frank Nobiletti for his willingness to take a risk in opening his classroom to me and this study. I would also like to express my appreciation to Charles Hurley and Donna Sneden for their support in making this study a reality.

Finally, I cannot adequately thank my wife and classmate, Rebecca, for her good humored support and never-ending love and kindness from the very start of this journey together. Her engineer's mind and musician's heart helped to make the process systematic yet fluid. 


\section{CONTENTS}

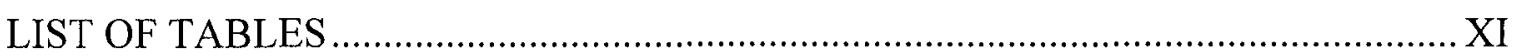

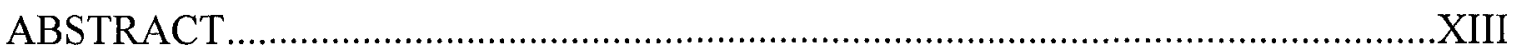

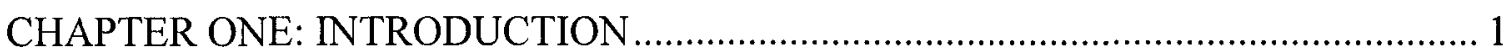

Introduction of the Problem.............................................................................. 1

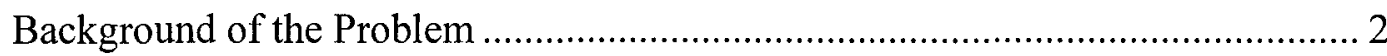

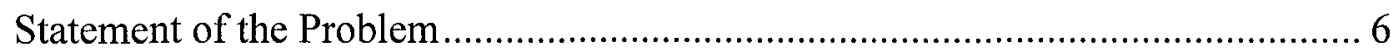

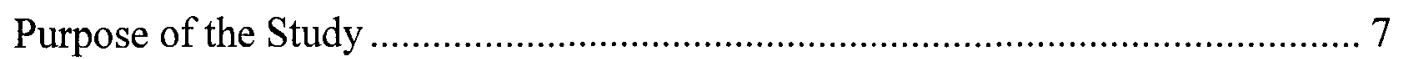

Research Questions .......................................................................................... 7

Rationale and Theoretical Framework for the Study ............................................ 9

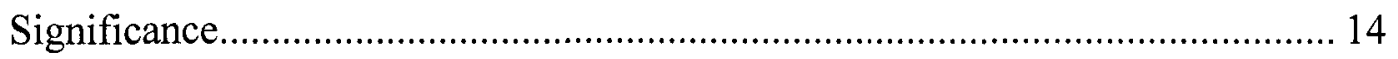

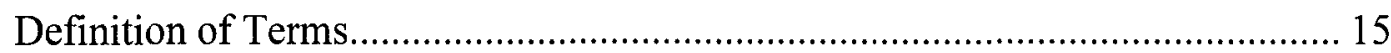

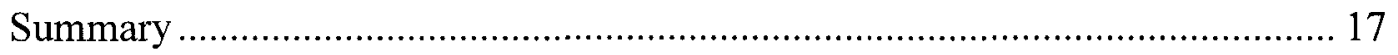

CHAPTER TWO: REVIEW OF THE LITERATURE ……………................................. 18

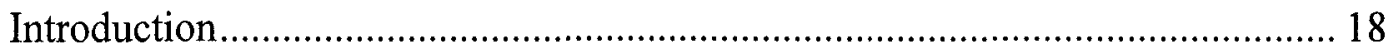

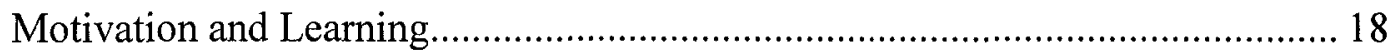

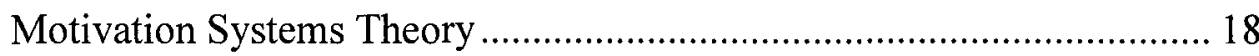

Personal Agency Beliefs ........................................................................ 20

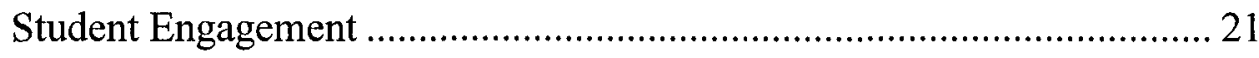

The Social Construction of Knowledge ............................................................... 22

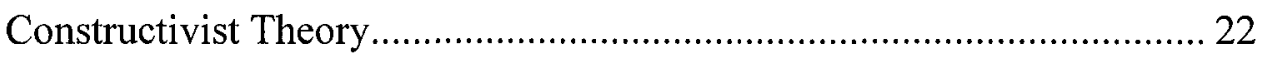

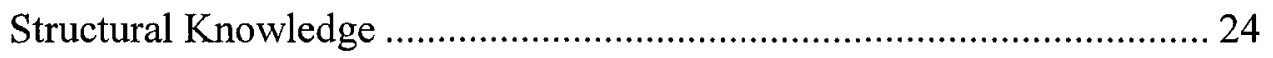

Cooperative Learning Strategies......................................................................... 27

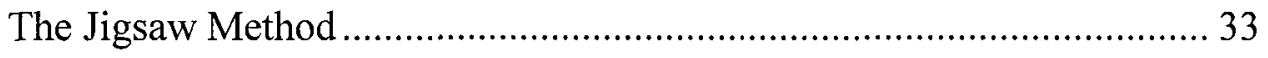

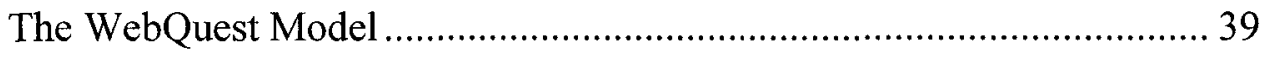




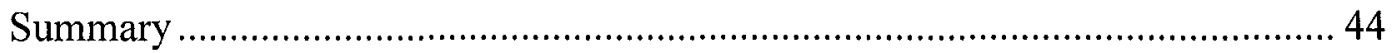

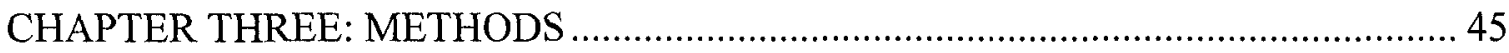

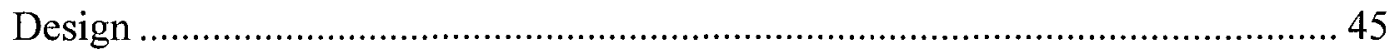

Sample and Population ...................................................................................... 46

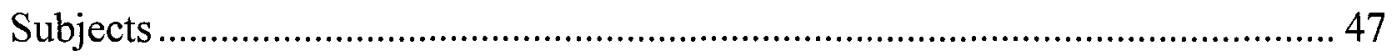

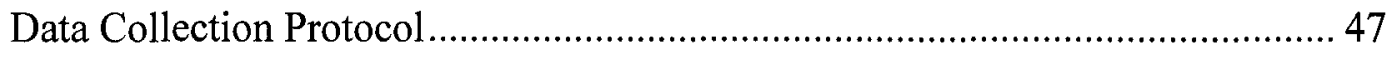

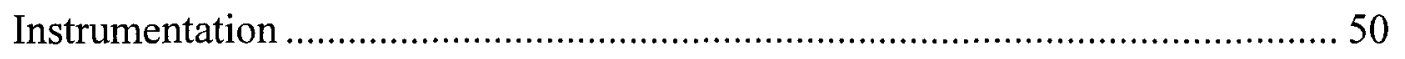

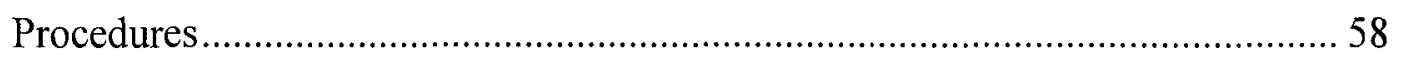

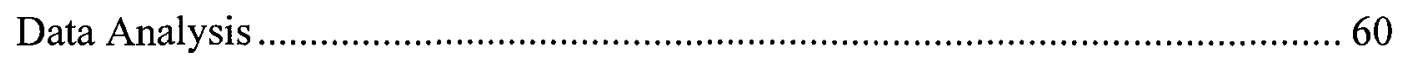

Limitations of the Research Design ..................................................................... 66

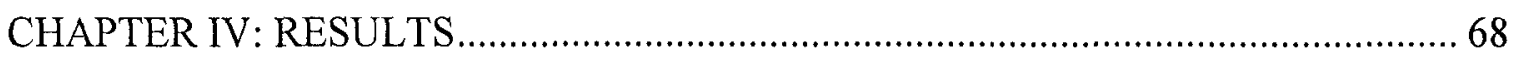

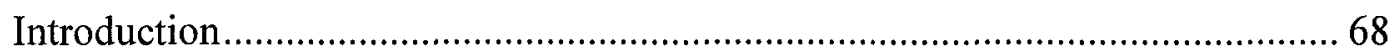

Description of the Study Population .................................................................... 70

Overall Effectiveness of the WebQuest as an Instructional Model ........................ 75

Comparing Two Cases: Overview of Significant Findings ................................. 77

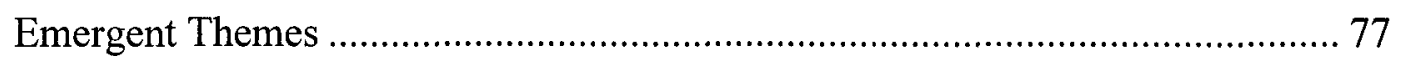

Results by Research Question........................................................................... 82

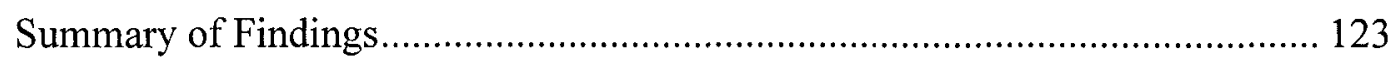

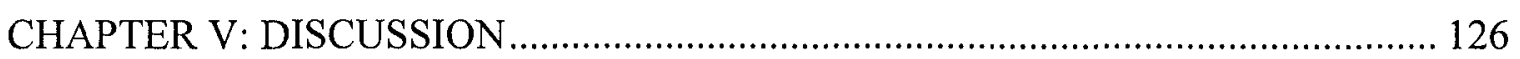

Overview of Major Findings....................................................................... 126

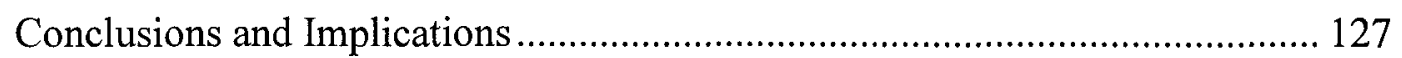

Strengths and Limitations of the Study ............................................................... 141

Suggestions for Future Research ................................................................... 144

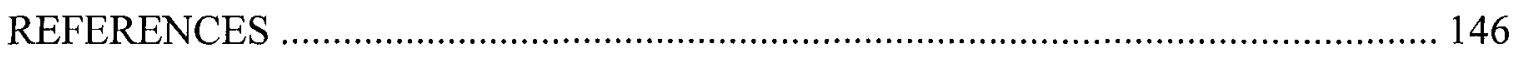

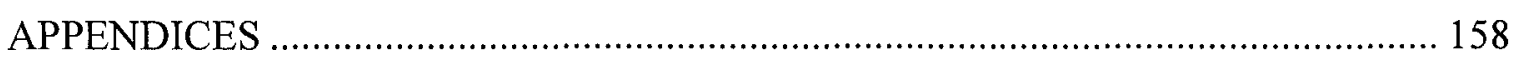




\section{LIST OF TABLES}

Table 3.1 Construct Definitions..... 49

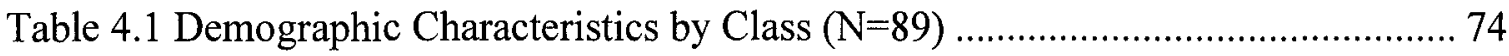

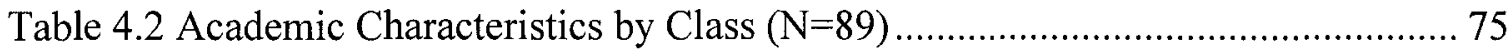

Table 4.3 Descriptive Statistics of Collaboration Rubric for Self by Class..................... 84

Table 4.4 Descriptive Statistics of Collaboration Rubric for Others by Class ................ 84

Table 4.5 Chi-Square for Self vs. Others by Class ..................................................... 85

Table 4.6 Weekly Time on Task by Class in Hours .............................................. 92

Table 4.7 ANCOVA for Week 3 Time on Task by Class Co-varying for Midterm Score

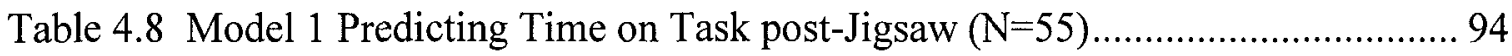

Table 4.9 Model 1 Coefficients of Variables Predicting Time on Task post-Jigsaw ....... 94

Table 4.10 Model 2 Predicting Time on Task post-Jigsaw .......................................... 95

Table 4.11 Model 2 Coefficients of Variables Predicting Time on Task post-Jigsaw ..... 95

Table 4.12 Group Work post-Jigsaw by Class....................................................... 100

Table 4.13 Groupwork Subscale Totals and Change Scores .................................... 101

Table 4.14 Current Group Experience versus Ideal Group Experience Post-Jigsaw by

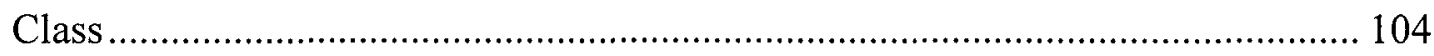

Table 4.15 WebQuest Satisfaction post-Jigsaw by Class ...................................... 108

Table 4.16 WebQuest Satisfaction Totals and Change Scores by Class ...................... 109

Table 4.17 Chi-Square for Interview Passages Coded as Strength and Weakness by Class

Table 4.18 Instructor Case Notes Regarding the WebQuest Experience (Week 2) ....... 117 
Table 4.19 Knowledge Outcomes by Class 119

Table 4.20 Knowledge Check Correlations with Demographic Variables..... 120

Table 4.21 Model Predicting Semantic Relationship Score 121

Table 4.22 Model Coefficients of Variables Predicting Semantic Relationship Score .. 121

Table 4.23 Performance Outcomes by Grade Status 122

Table 5.1 Midterm Score and WebQuest Cognitive Outcomes by Class $(\mathrm{N}=89)$ 140 


\section{LIST OF FIGURES}

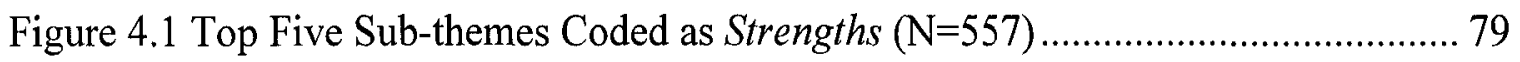

Figure 4.2 Top Five Sub-themes Coded as Strengths by Class ...................................... 80

Figure 4.3 Top Five Sub-themes Coded as Weaknesses $(\mathrm{N}=557) \ldots \ldots \ldots \ldots \ldots \ldots \ldots \ldots \ldots \ldots \ldots \ldots . . . .81$

Figure 4.4 Top Five Sub-themes Coded as Weaknesses by Class ................................... 82 


\section{CHAPTER ONE: INTRODUCTION}

Introduction of the Problem

The need for instructors to transform traditionally passive lectures and laboratories into more active learning environments is well documented (National Research Council [NRC], 2002). In fact, the call for curriculum reform in kindergarten through graduate school was made 20 years ago when the National Commission on Excellence in Education (NCEE) published "A Nation at Risk" (NCEE, 1983). This national report pointed out that student disengagement is pervasive and that many students are inattentive in school and unmotivated to learn.

While the most ambitious goals of education are to enhance students' critical thinking, promote deep learning that goes beyond superficial memorization and recitation of facts, build tolerance and appreciation for others, and improve interpersonal effectiveness and teamwork skills, these objectives are not often attained (Millis, 2002). Information technology holds promise for transforming the learning process and helping to realize these educational goals, but many of today's instructors are not adequately using technology inside or outside of the classroom. More importantly, they are not using teaching methods that leverage technology to facilitate more active and student-centered constructivist, problem-based, or cooperative approaches. The reason for this may be that teachers simply don't know how to take advantage of technology to promote more active learning experiences and as a result, student learning is not optimized. Without optimal learning opportunities that promote teamwork and critical thinking skills, students suffer economically, socially and politically (USDOL, 1992). Therefore, it is critical to develop 
and implement strategies for effective student-centered teaching and technology use, based on foundational theories of motivation.

Background of the Problem

\section{New Skills Necessary for Learning and Work}

We live in a knowledge-based world and, as Marchionini (1999) pointed out, "the proliferation of electronic information technologies for computation and communication has accelerated this transformation in the workplace and more deliberately in the school" (p. 17). Today's young citizens routinely accomplish concurrent cognitive processing of cell phone conversations, responding to email, instant messages, and making sense of large amounts of unfiltered information available on the Web. Some propose that those under 30 think in fundamentally different ways than their parents (Prensky, 2002).

Accomplishing work tasks in today's job environment also requires teamwork skills. In a national report published in 1992 by the U.S. Department of Labor (USDOL) and Education Secretary's Commission on Achieving Necessary Skills (SCANS), functioning well as a collaborative member of a team is listed as an "essential competency" for success in the workplace of today. Without teamwork skills students will not be well prepared to enter the professional arena. Simply put, students who do not attain teamwork skills will suffer because interpersonal competency has become so critical for individuals and organizations today. The serious consequences for today's students who do not have these skills require that effective teaching strategies be developed and implemented throughout education. Teachers need student-centered practices that they can use to take advantage of the Web and other technologies to enrich teaching and learning. Teachers also need to provide cooperative learning experiences 
that require teamwork skills and the use of information technology as a tool to prepare students to deal with the growing volume and complexity of rapid information flow.

\section{Instructional Strategies to Motivate Students and Foster New Skills}

Motivating students to learn is another challenge faced by teachers.

Unfortunately, there is no magic potion we can give students to make them want to learn or think critically (Ford, M., 1992). However, when students are working to solve a real problem, and when they believe that finding a solution has the potential to positively impact others, they are motivated to work hard (Solomon, 2003). As the NRC (2002) made clear, students in today's schools are motivated by engaging with real-life problems that challenge them to employ higher order thinking skills such as analysis, synthesis and evaluation (Bloom, 1956). Consequently, colleges of education are steering tomorrow's teachers toward educational practices that provide opportunities for learners' to solve the types of authentic, complex tasks that they will face in the world outside of the classroom.

\section{The WebQuest Model as an Instructional Strategy}

Using authentic tools and situations helps students learn how to gather and organize vast amounts of information to find reasonable solutions to everyday problems in a timely manner. As a result, teachers have many reasons for seeing the World Wide Web as an attractive tool for enhancing teaching and learning (Palloff \& Pratt, 1999). Given the exponential growth of the Internet, one problem with teaching with the Web is that students can waste a lot of time and effort in a search for information that may turn out to be overwhelming, inappropriate, or inaccurate. As more and more educational professionals turn to the Web as a tool for improving instruction, new ways of structuring 
student work are necessary (Benson, 2002). One strategy to address this growing problem while simultaneously building students' teamwork skills is the WebQuest. According to Dodge (1995), "a WebQuest is an inquiry-oriented activity in which most or all of the information used by learners is drawn from the Internet. WebQuests are designed to use learners' time well, to focus on using information rather than looking for it, and to support learners' thinking at the levels of analysis, synthesis and evaluation." In 1995, when the World Wide Web was still in its infancy, Bernie Dodge, a professor of educational technology at San Diego State University, began constructing the WebQuest model with Tom March as a tool to efficiently and elegantly integrate the Web into classroom instruction. WebQuests are designed to foster students' cooperative learning and higherorder thinking skills through engagement in authentic and personally meaningful decision-making and problem solving tasks (March, 2003). WebQuests focus on using relevant, appropriate and timely information rather than looking for it. Targeting student growth in the cognitive domain, they aim to support learners' thinking at the lofty levels of analysis and synthesis and creativity.

Referring to the critical attributes of WebQuests, Dodge (1995) explained that WebQuests are deliberately designed to make the best use of a learner's time because there is questionable educational benefit in having learners surfing the net without a clear task in mind. This is particularly true given the sheer volume of information available via the Internet and the limited time that most students have to access the Web for learning. For this reason, among others, educators from around the world are turning to the WebQuest model as a way to maximize the effectiveness of students' time in cyberspace (Steinbroner, 2000). 


\section{Using the WebQuest to Promote Higher-Order Thinking and Interdependence}

Corresponding with the higher levels of Bloom's (1956) Taxonomy of Educational Objectives (i.e., analysis, synthesis, evaluation), and Anderson and Krathwohl's (2001) revision of Bloom's Taxonomy (i.e., analysis, evaluation and creation), as well as Marzano's (2001) "New" Taxonomy of Educational Objectives (i.e., analysis, metacognition and self-system thinking), WebQuests use scaffolding to prompt learning groups to engage in problem solving and decision making tasks and this has been shown to facilitate more advanced or higher order thinking (Dodge, 1995; March, 1998). By chunking information (e.g., dividing Web sites into manageable groups) and asking students to engage in specific sub-tasks, a WebQuest can guide them through the type of thinking process that expert learners would typically use (March, 1998). Scaffolding can be thought of as temporary structures used to undergird students' academic performance, elevating them beyond their existing capabilities (March, 2003). WebQuests heighten interdependence by dividing learning resources so that the whole class examines some of the resources, while others are studied by subsets of learners who examine them through the lens of their specific role or particular perspective. Sometimes, a WebQuest involves the Jigsaw method. In a Jigsaw activity, an instructional problem is given to a small heterogeneous group and is divided into separate pieces (e.g., role-specific tasks) that are completed by different members of the group and then taught to their group members. Elliot Aronson, creator of the Jigsaw method (Aronson, Blaney, Stephan, Sikes, Snapp, 1978; Aronson \& Goode, 1980; Aronson \& Patnoe, 1997), conducted research indicating that the collaborative grouping method leads to improved mastery of course content, as well as increases in students' school 
attendance, more positive student self-efficacy beliefs, and deeper liking of teammates. Aronson and Patnoe also reported that the Jigsaw collaborative grouping technique resulted in higher levels of empathy for others, including people from different ethnicities and those from the opposite gender (1997).

Giving separate data sources to learners facilitates cooperation by providing the learners with an incentive to teach each other what they are learning (Dodge, 1997). In WebQuests, students work in small groups to tackle broad, ill-structured and often controversial problems. Because it's not realistic to expect each student to understand all aspects of a problem, students take on roles within their group which tends to promote their motivation to learn (March, 1998). While learners are encouraged to divide and conquer the sub-tasks (e.g., sorting, sifting and analyzing the information relevant to their particular roles), this is not to say that students don't gain larger understanding of the broad issue that they are studying. However, the model does suggest to students that it is simply impossible for everyone to know everything, and this is one of the great lessons that students learn from WebQuest interactions with experts whose works focus on what are essentially very small pieces of the knowledge puzzle (March, 1998).

\section{Statement of the Problem}

The WebQuest model is growing in popularity with teachers from around the world and many teacher-educators and experts in the field of educational technology espouse its potential to extend content knowledge and promote higher level thinking (e.g., Dodge, 2003; Jonassen, Howland, Moore, \& Marra, 2003; Kortecamp \& Bartoshesky, 2003; March, 2003; Monroe \& Orme, 2003; Solomon, 2003). However, there is very little in the way of empirical research on the elements that make a WebQuest 
effective. Furthermore, rich descriptions of how students interact during a well-developed WebQuest are largely absent from the literature. While the model is well received by teachers and students alike, most evidence of its effectiveness is anecdotal. In short, the WebQuest model suffers from a lack of scholarly research, which may hinder those practitioners interested in using this approach to design and deliver effective Webenhanced instruction. In addition, the existing evidence (e.g., Kortecamp \& Bartoshesky, 2003) emphasizes student engagement rather than learning outcomes, which can lead to the erroneous conclusion that a WebQuest has been effective even though it may not have led to greater student cognition.

Purpose of the Study

The purpose of this study was to advance knowledge about the effective use of the WebQuest model by conducting a comparative case study that employed qualitative and quantitative research methods. The study investigated the effectiveness of one particular option within the WebQuest model, the Jigsaw technique, by examining two variations of a lesson in order to provide a comparison of the effectiveness of the WebQuest model of instruction with, and without, the addition of the Jigsaw technique. This study sought to examine the effect of the Jigsaw cooperative grouping method on students' personal agency beliefs, engagement, and learning in a WebQuest problem-solving task.

\section{Research Questions}

The study focused on how 89 students enrolled in each of two sections of History of Sexuality (HIST 406), an undergraduate elective course taught at a large public university in the southwestern United States, responded to two versions of the WebQuest titled "Living with AIDS." One version was designed to provide greater opportunities for 
student interdependence and higher exposure to multiple perspectives by incorporating the Jigsaw method.

Three research questions were formulated to operationalize the study purposes and to structure the data analysis:

1. Will participation in a role-specific Jigsaw activity within a WebQuest produce a greater increase in students' personal agency beliefs than exposure to the same WebQuest without a role-specific Jigsaw activity?

a. Will participation in a role-specific Jigsaw activity within a WebQuest produce a significantly greater increase in students' academic self-efficacy beliefs than exposure to the same WebQuest without a role-specific Jigsaw activity?

b. Will participation in a role-specific Jigsaw activity within a WebQuest produce significantly more positive context beliefs than exposure to the same WebQuest without a role-specific Jigsaw activity?

2. How is the learning process different for students participating in a role-specific Jigsaw activity within a WebQuest as compared to students participating in the same WebQuest without a role-specific Jigsaw activity?

a. Do students participating in a role-specific Jigsaw activity within a WebQuest report more time on task (i.e., outside of class) than students participating in the same WebQuest without a role-specific Jigsaw activity? 
b. How is the quality of interaction with teammates, as reported in student journals, affected by participation in a role-specific Jigsaw activity within a WebQuest as compared to students participation in the same WebQuest without a role-specific Jigsaw activity?

c. How is students' satisfaction with the learning experience, as reported in their journals, affected by participation in a role-specific Jigsaw activity within a WebQuest as compared to students participation in the same WebQuest without a role-specific Jigsaw activity?

3. Does student performance on an HIV/AIDS Semantic Relationship Test and HIV/AIDS Relationship Judgment test, as well as writing in response to a final (essay) test question exhibit greater depth of understanding concerning "living with AIDS" for those students participation in a role-specific Jigsaw activity within a WebQuest than for students participation in the same WebQuest without a role-specific Jigsaw activity?

Rationale and Theoretical Framework for the Study Motivation is at the root of many of education's most far reaching and enduring problems, and previous research indicates that motivation plays a strong role in student engagement and academic achievement (Ford, 1992). Motivational Systems Theory (MST) synthesizes elements from many theories of motivation and provides an integrated way of blending the best of psychology, education and business theories of motivation (Ford, 1992). In his book "Motivating Humans: Goals, Emotions and Personal Agency Beliefs," Ford stated that learning "is governed primarily by motivational processes" (p. 22). MST will provide the theoretical foundation for this study and the researcher will 
focus specifically on the construct of Personal Agency Beliefs (i.e., people's capability or self-efficacy beliefs as well as their beliefs about the supportiveness of the context/environment).

Active learning environments that support more inquiry-oriented, problem-based, cooperative learning and the wise use of today's rich array of information technology resources may be the answer to problems in student motivation. This study was predicated on the premise that learning is a social process (Bandura, 1986; Bruner, 1960; Johnson \& Johnson, 1976; Piaget, 1971; Slavin, 1983), and that it is important for teachers to consider this social interdependence when developing educational approaches. As Johnson, Johnson and Smith (1998) suggested fostering collaboration can result in improved student effort to achieve, more positive relationships with others, and increased psychological health. Cooperative learning moves away from the old paradigm of education based on the presumption that the student mind is merely an empty vessel into which the instructor pours in their knowledge. Johnson, Johnson and Smith (1998) noted that:

As relationships within the class or college become more positive, absenteeism decreases and students' commitment to learning, feeling personally responsibility to complete assigned work, willingness to take on difficult tasks, motivation and persistence in working on tasks, satisfaction and morale, willingness to endure pain and frustration to succeed, willingness to defend the college against external criticism or attack, willingness to listen to and be influenced by peers, commitment to peer's success and [intellectual] growth, and productivity and achievement can be expected to increase (p. 43).

The concept of cooperative learning is nothing new. In the early $20^{\text {th }}$ century, the esteemed American educator John Dewey (1924) encouraged the use of cooperative learning as part of his ideal that schooling should embody the goals of a free and democratic society. 
Importantly, cooperative learning strategies can promote engagement in problemsolving tasks that an individual might not otherwise try, thus providing the individual with an opportunity to enhance their confidence (e.g., personal agency beliefs and collective efficacy beliefs). Personal Agency Beliefs (PABs) are an individual's beliefs about their own capabilities and their beliefs about whether or not the context / environment will support their goal-directed behavior. Collective efficacy is "shared beliefs about the capabilities of a group for effective action" (Ford, 1992, p. 193), and both of these beliefs can be powerfully enhanced when students are made responsible not only for their own learning, but also for helping their teammates learn (Aronson et al., 1978).

Today's complex job environment calls for new forms of teaching and learning. Students must be better prepared to acquire new skills for succeeding in school and at the workplace. For instance, education must expand students':

- ways of thinking about complex, often overlapping, dynamic structures;

- conceptual understanding of broad economic, technical and social contexts;

- cognitive abilities (e.g., problem solving given ill-structured tasks and activities);

- emotional maturity necessary for success in learning and business environments;

- social competencies needed for effectively co-operating and communicating with many different kinds of persons (Achtenhagen, 2000). 
If an instructor's goal is for students to learn more, like school better, get along with their fellow students better, and to recognize the importance of social skills and civic values, research evidence from Johnson, D. W., Johnson, R., and Smith (1998) made a clear and compelling case for education dominated by cooperative learning strategies. But instructors need help identifying educational approaches that successfully put theory into practice in the classroom. Two teaching methods that support the use of cooperative learning strategies are the Jigsaw (Aronson et al., 1978) and the WebQuest (Dodge, 1995). Both of these educational approaches provide practical guidelines that teachers can use to design instruction that promotes cooperative learning skills.

The WebQuest and Jigsaw strategies help instructors create problem-based learning (PBL) activities designed to deeply engage students in ways unheard of in traditional classrooms (Solomon, 2003). Conceptually, the portrait of a problem-based learning environment would include students:

- discussing broad perspectives;

- defending and supporting different positions;

- working toward compromise;

- creating products and presentations for audiences outside their classroom;

- using real world tools to help them develop socially-constructed knowledge;

- developing personally meaningful solutions to authentic, complex tasks and problems that they care about.

Engagement in PBL comes from empowering students with responsibility for their own learning. Solving real world problems that are tied to the curriculum is at the 
core of PBL units that are often interdisciplinary and make use of the synergy that emanates from students actively participating in collaborative groups that require interdependence in order to reach a common goal. Another key feature of PBL is the amount of choice given to the learner. The sense of control that comes from deciding their own course of action based on their data gathering and analysis, synthesis and evaluation of the information can be powerfully motivating for students. Typically, students demonstrate their newly acquired knowledge (i.e., solution to the problem) in a culminating presentation or demonstration. In some cases, the presentation is to a jury of their peers who will help the instructor measure what they learned and how well they are able to communicate it to others (NRC, 2002; Solomon, 2003).

\section{Need for Research on New Educational Approaches}

Experts from the National Research Council (2003) and the wider education community are calling for "a more rigorous, scientific approach to the development of new educational approaches" (p. 21,). The WebQuest is one such approach that deserves serious research attention. As of March 30, 2004 the non-profit WebQuest Website (http://webquest.sdsu.edu) launched in early 1998 had seen 5,648,402 visitors and was averaging over 5000 hits each weekday. Despite the thousands of teachers using the model, there is scant of research about its effectiveness (Dodge, 2003b). Another educational approach that is worthy of more scholarly research is the Jigsaw method of collaborative grouping (Aronson et al., 1978). This is especially true because as Steinbroner (2000) pointed out, Aronson and Patnoe's (1997) book, “The Jigsaw Classroom," lays out the advantages of using the method, but it fails to mention anything about how technology may be used within the context of "The Jigsaw Classroom." 
Instructors and school leaders need empirical evidence that these models can make a difference from the learner's perspective and more needs to be understood about the models' impact on student engagement and learning. Research data can help instructors determine how to best use technology to facilitate cooperative, problem-based learning. Importantly, in order for instructors to adopt these new approaches to teaching, they need support including professional development programs, technical support programs, equipment acquisition, library resources, and the construction of appropriate instructional facilities (ATPC, 2003). Therefore, this research provided timely information that teachers, administrators and staff affiliated with professional development centers can use to inform the design of pedagogically relevant educational technology training programs.

\section{Significance}

While it is clear that there has not been enough research on the WebQuest model, this study is especially important because it employed a research plan that avoids what Clark (1983) called the "media comparison trap" (i.e., comparing WebQuests with nonWebQuests). Simply, this study attempted to look at the specific elements that cause WebQuests to be effective. This was done by carefully examining two variations of the model used within the context of an undergraduate history course. The findings may help practitioners and researchers further understand how various WebQuest design elements impact students' personal agency beliefs, engagement with the educational process, and learning outcomes. The present study sought to provide a contribution to the theory and practice of active, constructivist pedagogy and clarify the rationale for cooperative and problem-based strategies that take advantage of emerging technologies for teaching. 


\section{Definition of Terms}

\section{Collective Efficacy}

Beliefs about a group's capabilities for effective action.

\section{Context Beliefs}

Beliefs about how supportive the environment is for goal-attainment efforts. In this study context beliefs are synonymous with collective efficacy beliefs.

\section{Constructivist Theory}

Pedagogical philosophy built on promoting learner-centered environments that acknowledge and capitalize on the social construction of knowledge.

\section{Cooperative Learning}

Educational strategy that capitalizes on the fact that learning is a social enterprise by fostering student interaction with the instructor and fellow classmates.

\section{Experimental Classroom}

A place on campus designed to support faculty who wish to experiment with cooperative teaching strategies involving the use of emerging educational technologies. It is also a location for conducting research aimed at measuring and documenting the use of technological tools to improve teaching and learning.

Jigsaw

Educational approach where the work of a group is divided into pieces (e.g., rolespecific tasks) and each member of the group learns their piece and then through the process of solving their piece of the puzzle teaches what they learned back to their fellow group members. 
Personal Agency Beliefs

Personal Agency Beliefs (PABs) influence what we do and how vigorously we do it. PABs are made up of expected or anticipated beliefs about whether or not the individual can reach a goal, as well as expectancies about whether or not the environment will be responsive to the individual's efforts aimed at achieving that particular goal.

\section{Problem-Based Learning}

In problem-based learning (PBL), real world problems are tied to the curriculum, and the instructional units are often interdisciplinary. The instructor's role in PBL is as a guide or facilitator. The instructor serves as a resource that may not have all the answers, only guiding questions and problem solving advice.

\section{Scaffolding}

Temporary structures used to support students' academic achievement by lifting them above their existing capacities.

Self-Efficacy

Self-efficacy is a person's assessment of personal competence in a particular domain.

Structural Knowledge

Knowledge of how concepts within a domain are interrelated. Structural knowledge (knowing why) serves to mediate the translation of declarative knowledge (knowing that) into more applied or procedural (knowing how) knowledge.

\section{WebQuest}

Designed to use learners' time well, to focus on using information rather than looking for it, and to support learners' higher-level thinking, it is an inquiry-oriented 
activity in which most or all of the information used by learners is drawn from the Internet.

\section{Summary}

One of the primary tasks of educators is to prepare students to be able to function as interdependent members of teams who can work collaboratively with others to solve ill-structured problems that require synergy and a focus on common interests rather than self-interests. Furthermore, as Streufert \& Streufert (1978), Bandura (1997), and other prominent scholars have suggested, social interaction creates more complex knowledge structures within individuals participating in interpersonal experiences. Unfortunately, students who do not attain teamwork skills often suffer socially and economically. The bleak consequences for these students necessitate that effective teaching strategies be developed and implemented at all levels of education. Accordingly, teaching strategies need to be examined in light of interconnected theories that focus on what it takes to motivate students to learn. Through an empirical analysis built on the foundation of Motivational Systems Theory and constructivist teaching approaches, this study sought to identify WebQuest design factors that can enhance student personal agency beliefs, engagement and learning outcomes. More specifically, the study investigated the impact of the Jigsaw cooperative grouping technique on student engagement and learning in a WebQuest problem-solving task. Ultimately, the present study set out to identify WebQuest design factors that can enhance student engagement and learning.

The following chapter describes a review of the relevant literature as it relates to some of what is already known about motivation and learning, the social construction of knowledge and cooperative learning strategies. 


\section{CHAPTER TWO: REVIEW OF THE LITERATURE}

\section{Introduction}

The purpose of this chapter is to review the theoretical foundations and the research relevant to the study of personal agency beliefs, student engagement and knowledge construction in a technology-rich cooperative learning environment. This review demonstrates how the current study of the WebQuest model and the Jigsaw method builds on the methodologies and findings, and addresses the gaps identified in related research in the field.

Since the present study is rooted in Motivational Systems Theory, the chapter begins with a review of the theory and, in particular, the construct of "personal agency beliefs." Next, the review describes the body of knowledge surrounding the measurement of student engagement. Theoretical foundations and definitions associated with the social construction of knowledge and its relationship to students' level of learning (i.e., structural knowledge) is then laid out. Lastly, the review provides an overview of existing literature on cooperative learning strategies, including a detailed description of the WebQuest model and Jigsaw method including research related to these approaches.

$$
\text { Motivation and Learning }
$$

\section{Motivation Systems Theory}

The structure for this study comes from Martin Ford's Motivational Systems Theory (1992). Motivational Systems Theory (MST) is a theoretical offspring of the Living System Framework, a comprehensive conceptualization of the "whole person-incontext" (D. Ford, 1987; M. Ford \& D. Ford, 1987). MST synthesizes common elements from many theories, blending the best of psychological, educational, and business 
theories of motivation. It builds on the "living systems framework", a larger, more "comprehensive theory of human functioning and development" (D. Ford, 1987, p. ix).

The practical utility of using MST to support this study is based on the understanding that "MST is designed to help people understand and deal with problems of learning, behavior change, and effective performance in themselves and others" (Ford, 1992, p. 15). A key assumption of MST is that motivation is the basis for learning (i.e., skill and knowledge development), and behavior change (i.e., enduring use of new schema in other contexts). Motivation determines how, where and to what ends a person will apply their capacity for behavioral self-construction (Ford, 1992). MST explains how motivational processes interact with other psychological, behavioral, and environmental factors that influence human behavior. MST provides "a set of principles for facilitating positive and productive motivational patterns" (Ford, 1992). MST describes what motivation is, how it works, and how it influences what people do and how well they do it.

MST is aimed at understanding motivation in relation to the "whole person" (in context). According to Ford (1992), "motivation is defined as the organized patterning of three psychological functions that serve to direct, energize, and regulate goal-directed activity: personal goals, emotional arousal processes, and personal agency beliefs" (p. 3). Goals

Personal goals represent anchors that provide organization and coherence to the experiences people have in different context-specific environments. Goals serve two main functions: First, they signify the consequences to be achieved (or avoided). Second, they direct and sustain the content and direction of people's action (Ford, 1992). 


\section{Emotions}

Emotions play a strong role in determining how much energy (e.g., attention) a person applies to a given situation. Citing the work of others, Ford (1992) indicated that emotions provide a very powerful mechanism for regulating people's behavior because affective experiences have an immediacy that is hard to ignore.

\section{Personal Agency Beliefs}

Personal Agency Beliefs (PABs) influence what we do and how vigorously we do it (Ford, 1992). PABs are made up of expected or anticipated beliefs about whether or not the individual can reach a goal (e.g., a learner's belief that they have the right skills, knowledge, and essential capabilities for academic achievement). PABs are also made up of expectancies about whether or not the environment will be responsive to the individual's efforts aimed at achieving a particular goal (e.g., a learner's belief that they have a supportive environment for learning). Bandura (2001) stated that "Personal agency operates within a broad network of sociostructural influences, and in these agentic transactions, people are producers as well as products of social systems" (Abstract section).

\section{Capability Beliefs (Self-Efficacy)}

First defined in Bandura's (1986) Social Cognitive theory, self-efficacy is a context-specific assessment of competence in a particular domain (Pajares, 2002). Selfefficacy can also be thought of as the belief in one's capabilities to organize and execute the action needed to successfully manage different situations (Bandura, 1986). Selfefficacy is a judgment of competence that influences the choices we make, the effort we put forth, and how tenacious we are when confronting obstacles (Bandura, 1986). Writing 
about an "agentic perspective" (Bandura, 2001) postulates that, "to be an agent is to intentionally make things happen by one's actions" (p. 2).

Context Beliefs

Context beliefs are beliefs that one has about whether there is a supportive or hostile environment that will enable or hinder performance (Ford, 1992). A critical component of PABs, context beliefs must be positive in order to "motivate" someone to action (Ford, 1992). In this study, the construct of context beliefs were defined as measures of collective-efficacy or students' beliefs about the capability of their group.

There is research that indicates that people with high personal agency beliefs are more successful academically (Pintrich \& De Groot, 1990), will this hold true with regard to the performance on the WebQuest model? What about when you merge the WebQuest and Jigsaw?

\section{Student Engagement}

Bandura (1997) has postulated that a person's behavior should be viewed as a function of their beliefs or expectations about their ability to engage in or achieve behavioral outcomes. A person's perceived self-efficacy influences all aspects of their behavior including the time that they spend on the acquisition of new knowledge (Baldwin, May, \& Burns, 1999). Self-efficacy also influences the choices people make, the amount of effort they will expend, and how much they persist in the face of barriers (Baldwin, et al., 1999; Pajares, 2003).

Specifically defining student engagement is difficult because it is context specific and relative to a given task (Brewster \& Fager, 2000). However, the National Survey of Student Engagement (NSSE, 2003) indicates that the most commonly accepted measure 
for student engagement is self-reported time on task. The NSSE (2003) clearly points out the pitfalls and potential threats to validity, reliability and credibility of self-report data (e.g., the halo effect, whereby students inflate certain aspects of their behavior). Despite the limitations, research such as the studies presented in The Seven Principles for Good Practice in Undergraduate Education (Chickering and Gamson, 1994) indicates that "time on task" is a sound measure of student engagement and that it is a critical factor for promoting student achievement. In fact, researchers have reported that engaged behavior (e.g., time on task) is positively correlated with achievement on standardized tests (Logan and Keefe, 1997). Notably, Pintrich and DeGroot (1990) reported a relationship between cognitive engagement and student achievement, but they also make an important observation that higher performance was a function of both the "will" and the "skill" of the students participating in their study.

The Social Construction of Knowledge

\section{Constructivist Theory}

While we cannot reduce artful teaching to a particular model, method, or form, understanding the underlying theory is essential for selecting the most appropriate teaching approach (Millis, 2002). Constructivist learning theorists posit that learning is the process of constructing knowledge and that learning is an active process that involves interaction, reflection, and dialogue with others (Bruner, 1986; Jonassen, 1999; Piaget, 1954; Vygotsky, 1978, 1986). It is a pedagogical philosophy (e.g., social constructivist theory, sociocultural theory of learning) based on promoting learner-centered environments that acknowledge and capitalize on the social construction of knowledge that occurs through social discourse and joint activity (Wang, 2001). 
Thomas (2001) defined constructivism as a "philosophical perspective derived from the work of Immanuel Kant which views reality as existing mainly in the mind, constructed or interpreted in terms of one's own perceptions" (p. 12), and he notes that a person's prior experiences, mental structure (schemata), and personal agency beliefs bear upon how experiences are interpreted and how knowledge and understanding is constructed. Constructivism is a relatively new term within educational philosophy (Thomas, 2001), and it has not yet been fully applied to studies of instructional technology (Steinbroner, 2000).

Unlike the more mechanistic theories from cognitive science that disconnect cognitive processes from interpersonal life, constructivism focuses on the inter-workings of socially situated factors in human development, adaptation, and change (Bandura, 2001). This theoretical framework sees human functioning as socially interdependent, richly context sensitive, and "conditionally orchestrated within the dynamics of various societal subsystems and their complex interplay" (Bandura, 2001, p. 5).

Tom March (1998) suggested that:

When students need to understand a more complex or sophisticated topic like those that comprise WebQuests, it doesn't help to serve them simplified truths, boiled down examples, or step-by-step formulas. What they need are many examples with lots of information and opinions on the topic through which they will sift until they have constructed an understanding that not only connects to their own individual prior knowledge, but also builds new schema that will be refined when students encounter the topic again in the future (Developing Thinking Skills section).

Used in relation to constructivist teaching strategies, the term "Weltanschauung" refers to world views or the fact that people interpret and process information and concepts differently from one another (Thomas, 2001). Describing the attributes of a WebQuest, Dodge (1995) wrote, "WebQuests are most likely to be group activities, 
although one could imagine solo quests that might be applicable in distance education or library settings." The researcher suspects that group activities may be more than "noncritical attributes" of learner-centered WebQuests, and that exposing students to a broad perspective by building WebQuests that have students working with other students (physically or virtually) can serve to build a tolerance for different, often opposing, world views.

Because the WebQuest focuses on fostering students ability to synthesize information, to express personal opinions, and to draw insights from valuing others' perspectives, it is part of a constructivist movement that aims to transform learners from passive knowledge consumers to active knowledge producers who grow socially and intellectually through the creation of new and personally relevant meanings (Dodge, 2003b).

\section{Structural Knowledge}

Learning with technology is said to increase the likelihood of "assimilation" of knowledge into the content structures of the brain (Monroe \& Orme, 2003). To investigate this assimilation (i.e., learning) within the context of the Living with AIDS WebQuest, the researcher investigated students" "structural knowledge," a form of knowledge representation laid out in detail by Jonassen and his colleagues in 1993.

The concept of structural knowledge must be understood in terms of its relationship to declarative and procedural knowledge. Declarative knowledge or "knowing that" is the basis for procedural knowledge, or "knowing how" (Jonassen, Beisner, \& Yacci, 1993). In essence, declarative knowledge is the cognizance of an object, event or idea that allows one to describe or define it. Although, it does not 
necessarily mean that the individual understands the object, event or idea. Declarative knowledge can be thought of as schemas or constructs about objects, events or ideas that are defined by attributes from other schemas. Procedural knowledge on the other hand is how learners apply or use declarative knowledge (i.e., "knowing how" to solve problems, make plans, or formulate arguments that require accessing and interrelating relevant schemata, and applying the appropriate attributes to the particular situation). According to Jonassen et al. (1993) structural knowledge "mediates the translation of declarative knowledge into procedural knowledge and facilitates application of procedural knowledge" (p. 4).

Structural knowledge is an understanding of how concepts within a particular domain are interrelated (Diekhoff, 1983). Structural knowledge is "knowing why" and it provides the conceptual basis for how ideas, events or objects are interconnected within a person's cognitive structure (Jonassen et al., 1993). Because it goes beyond the rote memorization needed to regurgitate facts, structural knowledge is the basis for useful knowledge application. Shavelson (1972) refers to structural knowledge as a person's "cognitive structure" (i.e., how people organize and represent constructs within long-term memory). Understanding these patterns of relationships between concepts (structural knowledge) is important for educators to focus on because it allows learners to form the connections they need to apply knowledge outside of the classroom environment.

How does one measure a learner's structural knowledge? Representing and assessing structural knowledge can be done using simple verbal questions that can be analyzed descriptively (Jonassen et al., 1993). Two methods described by Jonassen and 
his colleagues include the Semantic Relationship Test and the Relationship Judgment Test (1993).

\section{Semantic Relationship Test}

One method for evaluating a learner's comprehension of the nature of relationships between concepts within a particular content domain is to ask the learner to classify or describe the conceptual nature of the relationships between significant concepts presented, explained or discussed during instruction (Jonassen et al., 1993). To assess the learner's knowledge of these relationships, one would simply ask the student to classify the nature of the relationship between pairs of selected concepts that he or she had been exposed to through the instructional process. For instance, while there are many possible relationships between concepts, Jonassen and his colleagues explain that most concepts can be linked in one of the following ways (1993, p. 90):

- has part/is part of;

- has kind/is kind of;

- causes/is caused by;

- precedes/comes after;

- describes (defines)/is description (definition) of;

- $\quad$ assists/is assisted by;

- has example/is example of, etc.

As you can see, this partial list of categories describes asymmetric relationships, or relationships in both directions. However, the relationships between concepts may or may not be directional in nature. Typically, semantic relationship tests consist of multiple 
choice questions which ask learners to select the best relationship between the concepts presented. Scoring consists of counting the number of correct classifications.

\section{Relationship Judgment Test}

Relationship judgment tests can be thought of as similarity ratings that ask the learner to assess the strength of relatedness between two concepts (Jonassen et al., 1993). While these tests evaluate declarative (e.g., definitional) knowledge, they are also helpful for assessing structural knowledge. Like semantic relationship tests, relationship judgment tests present learners with a pair of concepts from the content domain. However, in the case of relationship judgment tests, the learner is asked to indicate the strength of the relationship between the two concepts, as opposed to the conceptual nature or type of relationship between the concepts.

Both the semantic relationship test and the relationship judgment test compare the learner's ratings directly with those of experts from within the given content domain. While these techniques have not been widely investigated by empirical research, their validity and reliability is supported by Jonassen and Wang (1993). Nevertheless, the researcher used a variety of other techniques to measure knowledge acquisition in the present study.

\section{Cooperative Learning Strategies}

The term "cooperative learning" refers to a teaching strategy in which small heterogeneous groups of students use a variety of learning activities, such as the Jigsaw method, to improve their acquisition of knowledge about the subject matter (Aronson et al., 1978; Aronson \& Patnoe, 1997; Johnson \& Johnson, 1981; Slavin, Sharan, Kagan, Lazarowitz, Webb, \& Schmuck, 1985; Steinbroner, 2000). Cooperative learning is not 
something new, having origins that predate the United States by thousands of years. For example, in the late $19^{\text {th }}$ and early $20^{\text {th }}$ century, notable American educators Colonel Francis Parker and John Dewey espoused the potential for cooperative learning to foster the process of active citizenship and the civic goals of a free and democratic society (Dewey, 1924; Johnson \& Johnson, 1994). Yet, by the middle of the $20^{\text {th }}$ century, the emphasis was shifting to more competitive educational practices in American schools (Slavin et al., 1985; Johnson, Johnson \& Holubec, 1992; Steinbroner, 2000).

More recently, drawing on a robust and compelling research base, several scholars have developed specific instructional strategies for engaging students in cooperative learning activities (Aronson, Blaney, Stephan, Sikes, \& Snapp, 1978; Aronson \& Patnoe, 1997; Dodge, 1995; Johnson and Johnson, 1976; Johnson, Johnson and Smith; 1998; Slavin, 1983). Though not entirely a new concept, a common element found in all of these cooperative learning strategies is the notion of "interdependence" whereby each member of a team is not only responsible for individually learning the content, but also for helping their fellow teammates learn the material. Encouraging this atmosphere of cooperation in the classroom has been shown to promote student achievement and greater use of higher-level cognitive and critical thinking skills than do more traditional (i.e., competitive or individualistic) learning strategies (Johnson \& Johnson, 1994).

Cooperative learning environments provide many advantages, and consistent results from studies conducted by Aronson and his colleagues (Aronson, Blaney et al., 1978; Aronson \& Patnoe, 1997) have established that students in cooperative learning classrooms: 
- grew to like their fellow teammates even more than they liked others in their classroom;

- declined in absenteeism and liked school better than their counterparts in more individualistic and competitive classrooms;

- exhibited greater self-esteem than their counterparts in more individualistic and competitive classrooms;

- outperformed their counterparts in more individualistic and competitive classrooms in terms of mastery of the course material;

- learned to empathize with one another to a greater extent than their counterparts in more individualistic and competitive classrooms.

Researchers have conducted literally hundreds of studies investigating the impact of cooperative learning, and the studies can be roughly divided into two main sections (1) those with a focus on academic achievement, and (2) those with a focus on socialemotional gains.

A meta-analysis of cooperative learning studies conducted by Johnson, Maruyama, Johnso, Nelson, and Skon (1981) revealed increases in both academic achievement and productivity. The analysis investigated 122 studies of cooperative learning spanning from 1924-1981. Because some of the studies were better designed than others, the researchers followed up the initial meta-analysis with a more focused look at the stronger studies. They concluded that there was a convincing link between cooperative methods and academic achievement. Building on the analysis conducted by Johnson, Maruyama et al. (1981), Slavin (1983) conducted his own meta-analysis targeting only 46 "well designed" studies that used individual achievement as the 
outcome. By eliminating the productivity variable, Slavin's (1983) research addressed the question: What conditions of cooperative learning have a positive influence on student achievement? Overall, Slavin's (1983) analysis found that nearly 90 percent of the cooperative learning techniques that embedded both individual accountability and group rewards resulted in academic gains.

Another area of research on cooperative learning strategies related to academic achievement is time on task. For instance, in a review of over thirty studies on cooperative learning that measured time on task, Johnson and Johnson (1989) found that learners engaged in cooperative learning methods spent more time on task than learners in more or individualistic environments. The evidence from this meta-analysis indicated that students in cooperative learning settings appear to spend considerably more time on task than do students working in more traditional (i.e., competitive or individuallyoriented) learning environments, and this alone may account for at least some of the aforementioned academic achievement gains.

However, Aronson \& Patnoe (1997) posit that spending more time on task or “...simply interacting with an individualistic reward structure or being a member of a group is not enough for success. The key requirement is positive interdependence...students must interact with and depend on one another for cooperative learning to be successful" (p. 23). This quote speaks to the important social-emotional aspects associated with beneficial cooperative learning methods.

Along similar lines, David and Roger Johnson conducted a meta-analysis in 1989 that investigated the social benefit of cooperative learning methods. Data from their review of almost 200 studies focusing on interpersonal attraction, 100 studies looking at 
social support, and about 80 studies measuring self-esteem revealed strong support for the social-emotional benefits of cooperative learning. Furthermore, a 1987 cooperative learning research study conducted by Wulff, Nyquist and Abbott, with over 800 college students, indicated that students see the benefits of cooperative learning, especially with regard to learning in their large classes. Specifically, their survey results found that the second most frequently cited factor contributing to the students' learning in large classes was "other students."

In order for cooperative learning methods to promote positive student achievement and social-emotional gains, several essential elements must be in place (Aronson \& Patnoe, 1997; Johnson \& Johnson, 1989):

- individual accountability;

- group goals;

- positive, goal-directed face-to-face interaction;

- instruction directed at increasing interpersonal skills;

- instruction directed at increasing group process skills.

Making each individual in a small group responsible for a specific task or specialty area is important for establishing an environment of cooperation whereby each team member has a unique contribution to make to the overall group product. By design, certain cooperative learning methods (e.g., Jigsaw) attempt to ensure that the group cannot do well unless each member of the team contributes to the process, and this can foster both group goals and individual accountability. Furthermore, for cooperative learning to reap social-emotional benefits, it is essential to provide students with training in the principles associated with positive (i.e., efficient and effective) interpersonal and 
small group process skills (Cohen, 1994). This is particularly true given that most students receive little scaffolding or coaching in small group dynamics (Millis, 2002), nor do they have a great deal of prior experience working as active members of interdependent teams that inherently rely on mutual support (Cohen, 1994). But, in a world that increasingly depends on sharing knowledge and positive relationships, it is more important than ever before that students learn "cooperative" skills.

Cohen (1994) suggested that teachers interested in promoting positive interpersonal experiences for their students should establish norms for equal participation. Summarizing cooperative "skill-building" principles laid out by Bandura (1969) and others, Cohen (1994) listed the following norms for cooperative problem solving behavior:

- $\quad$ say your own ideas

- listen to others; give everyone a chance to talk

- ask others for their ideas

- give reasons for your ideas and discuss many different ideas

To encourage teambuilding, and to avoid dominance by one or more members of the group, Cohen (1994) recommended that teachers list and continually ask the following questions:

- is everyone talking;

- are you listening to each other;

- $\quad$ are you asking questions;

- are you giving reasons for ideas and getting out different ideas? 
Like Aronson et al. (1978), Cohen (1994) laid out the strong need to mix groups by gender, race, ethnicity, and academic ability. Both authors explained the need to provide a heterogeneous mixture of students in order to expose students to a broad perspective. Cohen (1994) also pointed out the importance of providing detailed written instructions that spell out the tasks that groups will be responsible for, the resources that they should draw on to accomplish the task, and the role that each student will play in order to help them reach the curricular academic goal.

Johnson, Johnson and Smith (1998) referred to the past century's high volume of research on cooperative learning strategies as "staggering," explaining that not only does the research base indicate a clear positive effect on student achievement, as importantly they also found it affects interpersonal relationships:

As relationships within the class or college become more positive, absenteeism decreases and students' commitment to learning, feeling of personal responsibility to complete assigned work, willingness to take on difficult tasks, satisfaction and morale, willingness to endure pain and frustration to succeed, willingness to defend the [class or] college against external criticism or attack, willingness to listen and be influenced by peers, commitment to peer's success and growth, and productivity and achievement can be expected to increase (p. 43).

\section{The Jigsaw Method}

The case of Brown versus the Board of Education of Topeka, Kansas (1954) led to the desegregation of public schools and with this landmark ruling came a tumultuous experience for many students who, for the first time in their lives, found themselves in the same classroom as students from various racial and ethnic groups. As Aronson et al. 
(1978) pointed out, there was a great deal of tension, which occasionally erupted into physical violence. As the father of four children in public schools, Elliot Aronson, a social psychologist teaching at the University of Texas in the early 1970's, took more than a passing interest in the volatile situation facing the youngsters attending Austin, Texas public schools. As an experienced researcher whose focus was on interpersonal relations and crisis management, he was well-qualified to suggest possible intervention strategies, and when Austin's Superintendent of Schools asked for his advice he was more than willing to help. Aronson's solution for addressing the growing interethnic conflict and aggression was to develop a process for encouraging students to learn to like and trust each other, "not as an extracurricular activity but in the course of learning their reading, writing, and arithmetic" (1997, p. 6). Simply, he and his colleagues saw the problem as a learning problem, and they believed that students (especially the students who were in high schools at the time) had become indoctrinated into an academically competitive process that only served to fuel the seeds of distrust for people from different racial and ethnic groups.

Needless to say, integration issues are incredibly complex and there was and is no silver bullet to cure all the ills associated with the Supreme Court's (Brown v. Board of Educ., 1954) forward-thinking policy of "inclusion." However, in his attempt to change the teaching and learning process in the Austin public schools, Aronson was able to draw on his vast experience with small group dynamics and social interaction. Essentially, he and his colleagues were able to change the basic pedagogical structure of teaching (beginning with one teacher and 30 students) by placing the students into small, interdependent groups and modifying the role of the teacher to more of a guide or 
facilitator of learning rather than the sole source for all the answers (Aronson et al., 1978). The new process made it imperative that students treat each other as resources and share the responsibility for learning the curricular information.

As Aronson and his colleagues (1978) spelled out: "The problem with far too many educational innovations is that there is little or no systematic evaluation to see if they are really as effective as the enthusiastic supporters say they are" (p. 101). Indeed, if the initial impressions and experiences of teachers and students look promising, it is often the case that you will hear of the innovation being touted publicly with loud cries for widespread adoption. However, Aronson and his colleagues were not going to fall into this trap. Instead, they began a full-scale research effort to investigate the impact of the Jigsaw cooperative learning strategy.

Aronson and his colleagues (1978) used a scientific approach insofar as they formulated their research questions beforehand, and then they used questionnaires and other instruments to compare data from persons (i.e., teachers and students) experiencing the Jigsaw method with data collected from persons not experiencing the Jigsaw method. The control group was made up of traditional, competitive classrooms where the teachers did the teaching and where the students were not divided into Jigsaw groups. Teachers from both the control classes and the Jigsaw classes were selected carefully in order to ensure that both groups of teachers were viewed as highly competent and highly committed. The teachers were from the same schools and taught the same grade levels. To test their hypothesis that students in the Jigsaw classes would like school more than students in the control classes, the researchers developed a 22-item questionnaire to measure students' attitudes toward school and toward themselves. A second measure 
investigated students' liking for their classmates. The two instruments were used as pre and post-Jigsaw measures for both the Jigsaw and control classes, and the researchers utilized a standardized script to make sure that the questionnaires were administered in the same way for both classes.

Because the researchers did not want the students in the Jigsaw classes to sense that the survey instruments were related in any way to the fact that they were working in groups and therefore potentially distort the way that they might have answered the questions, students in both groups were told that the were part of a study about the entire school system and that other students from other schools in the system were also being asked to participate (Aronson et al., 1978). Methodologically, the researchers were also careful not to share the results from the surveys with the participating teachers and this assurance of student anonymity was seen as an important way to help ensure honest answers. As important was the fact that the researchers made a concerted effort to make sure that the Jigsaw classes were "student-centered" and that the control classes were "teacher-centered." To accomplish this goal they asked the teachers from the control classes to refrain from breaking their students into small (cooperative) groups during the course of the research study. Another concern of the researchers was that the Jigsaw method was being used consistently in all Jigsaw classes, and this was addressed by conducting a series of pre-research workshops that were identical for all the Jigsaw teachers. In an attempt to make sure that the findings from their research would apply to all students (e.g., not just boys or Mexican-Americans), the Jigsaw teachers were asked to distribute differences in race, ethnicity, academic ability and sex as evenly as possible among the groups. Of course, this was also done as a matter of routine because the Jigsaw 
method seeks to expose students to a wide-range of perspectives and viewpoints on the topic of study. Finally, the researchers saw the benefit of teambuilding exercises, because, as Aronson and his colleagues explain, “....simply putting students in the same small group was no guarantee that they would be able to work together..." (1978, p. 107). For example, to demonstrate the importance of listening to one another, Aronson and his colleagues designed an exercise in which students in each small group were asked to introduce themselves by name - all at the same time! This quick and easy exercise demonstrated the importance of listening and taking turns while talking. The last thing that Aronson and his colleagues did to reinforce good teamwork skills was to set aside five minutes at the end of each group period for students to process what had happened on that day. For instance, students used this time to fill out a checklist that indicated whether or not their group listened to each other, whether they had asked each other questions, whether they looked at each other, took turns talking, etc.

Aronson et al. (1978) provide a brief overview of a "typical" Jigsaw session:

Each group member was responsible for learning all the curriculum material, but each student had direct access to only his part of the material - the part he was to teach to others. Since he had to depend on his groupmates to teach him the rest of the material, each student learned that it was essential for all his groupmates to do a good job of teaching their parts of the material. Along with that, students had to do a good job of listening. And, if material being taught was not clear, groupmates had to learn to ask the student teacher to clarify the material. Moreover, it was functional to learn to ask in ways that would help the student do a better job of teaching rather than to be destructive or intimidating. In essence, the students in each group were putting their knowledge together a piece at a time, each student contributing to his piece of the Jigsaw puzzle (p. 109).

The results of the Jigsaw research conducted by Aronson and his colleagues

(1978) provided substantial evidence that the students in the Jigsaw classrooms: 
- increased their liking for their groupmates without decreasing their liking for the other students in their classroom;

- liked school to a greater extent than students in non-Jigsaw classrooms;

- increased in self-esteem;

- decreased in competitiveness;

- viewed their classmates as learning resources more than students in nonJigsaw classrooms;

- showed a greater ability to empathize with others - both inside and outside of the school environment.

Noteworthy, based on objective test results, Black and Mexican-American students in Jigsaw classrooms learned the content material significantly better than Black and Mexican-American students in non-Jigsaw classrooms, and Anglos performed just as well in the Jigsaw as no-Jigsaw classrooms (Aronson et al., 1978). In addition, the essential aspects of this research have been replicated in different parts of the country (e.g., Aronson \& Patnoe, 1997; Geffner, 1978).

The Jigsaw method addressed the factors that are necessary for student motivation to learn, such as goals, emotions and personal agency beliefs. Because it increased student interdependence and hence student engagement, an indicator of motivation to learn, the Jigsaw is one of the most effective cooperative learning strategies (Abrami, Chambers, Poulsen, DeSimone, d'Apollonia, \& Howden, 1995).

Since the original Jigsaw method was introduced over 25 years ago, new variations and extensions of have been developed. One relatively new method that in 
many cases builds on the Jigsaw method and taps the rich and timely information available via the Internet is the WebQuest model.

\section{The WebQuest Model}

The WebQuest is an inquiry-oriented activity that uses the Internet to engage students in active, constructive, intentional, authentic and cooperative learning (Dodge, 1995; March, 1998; Jonassen, 2003). It is a teaching strategy with the potential to connect students to other students, experts and researchers not only in the United States, but also across the entire planet. The building blocks of a WebQuest provide teachers with an efficient, student-centered and easy-to-follow design that incorporates both cooperative and problem-based learning strategies. According to Dodge (2001), the building blocks or critical attributes of the model include the following:

- Introduction that sets the stage by grabbing attention and providing context and background information that arouses learner interest.

- Task where the learning outcome (brief description of what the learner will have done at the end of the lesson) is clear, authentic, complex, interesting, and doable.

- Process or clearly defined steps that the learners will go through to complete the task. The process needs to be concise but may include strategies for dividing the task into sub-tasks, or descriptions of roles to be played or perspectives to taken by each learner. Links to instructor-identified Web sites and references to off-line resources are embedded here.

- Resources / information needed to finish the task

- Most, but not necessarily all, of the resources are woven into the fabric of the WebQuest page itself as anchors linking to latest 
information on the Internet. "Information sources might include web documents, experts available via e-mail or realtime conferencing, searchable databases on the net, and books and other documents physically available in the learner's setting. Because pointers to resources are included, the learner is not left to wander through webspace completely adrift" (Dodge, 1995).

- Evaluation and explicit guidance on the organization and presentation of information acquired in relation to assessment criteria or scoring rubrics.

- Conclusion that brings closure to the quest, activates students knowledge about what they've learned, and encourages them to extend the experience into other areas of interest.

Building a WebQuest is not much different from building any kind of lesson because it requires that the teacher orient the learners, give them an interesting yet doable task, provide them with the resources and guidance they will need to solve the problem, tell them how they will be assessed, and then summarize and extend the lesson into other domains (Dodge, 1997).

The thinking skills that a WebQuest requires are in-line with Marzano's (1992) "Dimensions of Learning" and include such skills as comparing, classifying, inducing, deducing, analyzing errors, constructing support, abstraction, and analyzing multiple perspectives (Dodge, 1995).

Not merely a Web-based scavenger hunt, whereby students are sent off on the Internet to randomly gather information, a WebQuest requires students to work together in small groups with other students (either in their physical classroom or with other 
students from across town or around the world) to seek out, analyze, evaluate and apply what they find (Dodge, 2003b). It is a process that encourages and scaffolds the transformation of information into usable knowledge (Peterson, Caverly, \& McDonald, 2003).

A key component of the WebQuest model is "scaffolding," a temporary structure that provides aid to students at specific points in the learning process (Dodge, 2003b), and it is important because it allows learners to accomplish a task that they may not be able to do without help. Specifying the task, the roles and perspectives, the links and offline resources, the guidelines and templates, all serve to provide the essential structure or scaffolding that students' need to move beyond simply locating answers and restating facts to deeper, more lasting and transformational learning (Dodge, 2003b). However, Dodge (2003b) has suggested slowly removing the scaffolding over time. Building on this, Molebash described fading the WebQuest support in an attempt to move from "structured inquiry" to more guided or open inquiry (i.e., placing more responsibility on the learner by gradually allowing more flexibility with the task and deliverables, providing fewer Web-based resources or more unfiltered primary sources of information that come from databases that are only available on the "deep web") with the ultimate educational goal being the growth of self-directed learners (personal communication, September 3, 2003).

The development of the WebQuest model was heavily influenced by several theories of motivation (Dodge, 2003b), and rightfully so since there is ample evidence that motivation and affect play central roles in learning processes (Hayes, 1996), and that motivational concepts play a major role in most serious efforts to analyze and explain 
human behavior (Vroom, 1964). To clarify terms, the researcher turned to Dictionary.com (Lexico, 2004) which cites the following definitions for motivation: "The act or process of motivating" (American Heritage Dictionaries, 1996), and "The psychological feature that arouses an organism to action; the reason for the action" (WordNet, 1997). A more holistic definition includes a systems perspective insofar as motivation has many aspects and that it must be defined in a comprehensive fashion. Keller's (1983) ARCS Model of Motivational Design is one such perspective and this is one of the key theories that Dodge (2003b) cites as a major influence on his development of the WebQuest model. He also looked to Malone and Lepper's (1987) Fun Taxonomy and their research on educational simulations and games as he was developing the model. Other important theories that strongly influenced Dodge's development of the WebQuest were Martin Ford's (1992) Motivational Systems Theory, Csikszentmihalyi's (1990) Flow Theory, and Wlodkowski's (1993) Time Continuum Model of Motivation. As Wlodkowski (1993) puts it, "for the learner, motivation is an initial determining factor that colors all that follows in a learning event. Motivation should be considered throughout the design and development process, not just as an embellishment." Jonassen, Howland, Moore, and Marra (2003) suggest that the WebQuest is a good model for teachers interested in using the Internet as a constructivist learning tool "because they provide a clearly defined structure and their design and use is well supported" (p. 45). And, in a special "Problem-based Learning" edition of the Technology and Learning journal (Solomon, 2003), Michael Simkins, director of the Challenge 2000 Multimedia Project, a U.S. Department of Education Challenge Grant funded to encourage problem-based learning, offered these suggestions for teachers 
interested in creating a problem-based learning project: "Plan activities by reviewing other projects. For example, take a look at WebQuests...for insights, guidelines and templates."

Dodge (2003b) provides a classification of WebQuest tasks and lists 12 different task categories that a teacher might find useful when designing their own WebQuest: retelling; compilation; mystery; journalistic; design; creative product; consensus building; persuasion; self-knowledge; judgment; scientific; and analytical. However, a teacher could just as easily choose from one of the many existing WebQuests available via the Internet. Dodge's WebQuest portal (2003a) and SBC's Knowledge Network Explorer (2004) offer links to literally hundreds of WebQuests. Yet, as Jonassen and his colleagues (2003) caution, while there is an abundance of WebQuests available to teachers via the Web, they vary dramatically in terms of quality and teachers need to be critical consumers when shopping for pre-made WebQuests. Unfortunately, not all WebQuests are created equal (March, 2003), and often "so-called WebQuests may bear [only] a superficial resemblance to real WebQuests in that students use Internet resources to produce a technology-enhanced product" (p. 42). In fact, among a plethora of other rich resources, The WebQuest Page (Dodge, 1998, Training Materials section) provides a rubric for evaluating WebQuests.

Since the first WebQuest was developed, despite a lack of empirical research to support its use, both practitioners and students alike have embraced the model in increasing numbers. Such massive interest in the WebQuest model is evidenced by over 5 million hits to the WebQuest page since it was first released, the expanding collection of WebQuest lessons submitted by teachers from around the world, and the dozens of 
sessions devoted to the model in recent conferences hosted by today's leading educational technology professional organizations, including the International Society for Technology in Education's (ISTE) National Educational Computing Conference (2003), the Society for Information Technology and Teacher Education (AACE, 2003), and the Association for Educational Communications and Technology (AECT, 2003). Growing international popularity is further evidenced by recently invited talks and keynote presentations on the topic of the WebQuest model in countries such as Romania, China and New Zealand (Geraghty, 2004).

\section{Summary}

Chapter two began with a review of the theoretical foundation for the present study, Motivational Systems Theory, and, in particular, the construct of "personal agency beliefs." Next, the review described the body of knowledge surrounding the assessment of student engagement. Theoretical foundations and definitions associated with the social construction of knowledge and its relationship to students' level of learning (i.e., structural knowledge) were then laid out. Lastly, the review provided an overview of existing literature on cooperative learning strategies, including a detailed description of the Jigsaw method and WebQuest model including research related to these approaches. 


\section{CHAPTER THREE: METHODS}

Chapter III begins with a discussion of the study's research methodology. Next, a description and rationale for the study's design, sample, population, and procedures is presented. After that, data collection, instrumentation, and data analysis is laid out. Lastly, potential biases and limitations of the research design are discussed.

\section{Design}

A comparative case study methodology (Yin, 2003) was selected based on the nature of the study's research questions. Framed as a two-case case study, with two undergraduate university classes as the units of analysis and the individual students enrolled within the two classes as the embedded units of analysis, the two particular cases were selected mainly to facilitate understanding about the design elements that cause WebQuests (with a teamwork component) to be effective at raising students' personal agency beliefs, engagement and learning.

This two-case research design follows replication logic insofar as the researcher attempted to duplicate the exact conditions associated with the use of a new curricula while altering one condition in one of the two classes under investigation (see Appendix A).The two classes illustrated contrasting strategies for designing and implementing a new educational technology innovation known as the WebQuest. The researcher was interested in how this one instructional intervention (WebQuest) - implemented in two ways (with Jigsaw or without Jigsaw) with undergraduate students enrolled in a specific History (elective) course affected student performance, student ability to collaborate/team, and student self and collective efficacy beliefs. 
The case study embraced the paradigm of a context-sensitive research design, utilizing inductive, inquiry-oriented data analysis, and was consistent with case study design in general (e.g., Creswell, 1998; Denzin \& Lincoln, 2000; Guba \& Lincoln, 1988; Stake, 1995, 2000; Yin, 2003). Specifically, the case study was bounded by time, multiple cases, and utilized multiple sources of student information to paint a rich, descriptive picture of the learning process. In an attempt to verify the trustworthiness of the description, the researcher was careful to take interpretations of the case back to the course instructor in order to gather feedback that was then woven back into the fabric of the final discussion of the study (Merriam, 1988). The mixed-modal research methodology for this study was refined on the basis of a pilot study that was conducted with the same instructor in the spring of 2003. The pilot data provided considerable insight into the design of the study and information obtained from the pilot study was combined with information from the ongoing review of relevant literature to inform the final research design.

\section{Sample and Population}

The population for this study consisted of two class sections of History of Sexuality (HIST 406), an undergraduate elective taught at a large public university in the southwestern United States during the fall 2003 semester. The two classes spent the same amount of time (three, two-hour and 40-minute class sessions spread over three weeks) with the same instructor collaborating in the same sized (four-person) groups at the same time of day (late afternoon) one day a week (Monday or Wednesday). It is noteworthy that both classes attempted to solve the identical WebQuest task (i.e., to help support a 
friend or loved-one who is "HIV-positive" and "Living with AIDS") within the same technology-rich college classroom environment.

Subjects

The study explored the experiences of 89 students from two classes who participated in the "Living with AIDS" WebQuest. By random assignment based on a coin toss, one class was exposed to the WebQuest with a Jigsaw element, and the other class was exposed to the WebQuest with No Jigsaw element. The Jigsaw class was broken into 12 WebQuest groups, and the No Jigsaw class was broken into 11 WebQuest groups. Each group consisted of approximately four students, which was determined because this size is large enough to contain students who bring a variety of diverse opinions, experiences and learning styles to the mix, while it also allows for the group to continue to function well if a group member is absent (Millis, 2002). The four-person teams were assembled by the researcher to construct heterogeneous groups (e.g., by gender and academic ability/midterm score) because the cooperative learning research supports such a structure (Aronson et al., 1978).

\section{Data Collection Protocol}

The data collection protocol details the specific procedures that the researcher laid out for answering each of the three research questions prior to the study getting underway (see Appendix L). The protocol was designed to enhance the reliability of the study's design and was used by the researcher to ensure that the data collection proceeded with sufficient care against potentially biased procedures. It served as a plan regarding the information that needed to be collected and why it was important for answering each respective research question. 
The researcher used both quantitative and qualitative research methods to analyze student reactions to the two versions of the WebQuest (one with, and one without, the Jigsaw collaborative grouping method employed). The study investigated the idea that students participating in a WebQuest designed with a Jigsaw component might outperform students participating in the same WebQuest without a Jigsaw component (e.g., in terms of researcher's ratings on the capstone essay). Performance was measured in terms of student self-reports of academic self-efficacy, engagement (e.g., time-ontask,), and researcher scores on the learning outcome measures. The study also investigated the idea that students participating in a WebQuest designed with a Jigsaw component might report higher quality of interaction with teammates, and greater satisfaction with the learning process. Table 3.1 defines the constructs used within the study, and lays out the type of measurement (e.g., self-report), as well as the research question that each construct is related to. 
Table 3.1 Construct Definitions

\begin{tabular}{|c|c|c|c|c|}
\hline Construct & Definition & Measurement & Instrument & $\begin{array}{l}\text { Research } \\
\text { Question }\end{array}$ \\
\hline $\begin{array}{l}\text { Personal } \\
\text { Agency - } \\
\text { Academic } \\
\text { Self-efficacy } \\
\text { Beliefs }\end{array}$ & $\begin{array}{l}\text { Individual perception of } \\
\text { academic competence }\end{array}$ & $\begin{array}{l}\text { Student self- } \\
\text { report }\end{array}$ & $\begin{array}{ll}\text { - } & \text { Collaboration rubric (self) } \\
\text { - } & \text { Semi-structured Interviews } \\
\text { - } & \text { Qualitative journal items }\end{array}$ & $\# 1(\mathrm{a})$ \\
\hline $\begin{array}{l}\text { Personal } \\
\text { Agency } \\
\text { - Context } \\
\text { Beliefs }\end{array}$ & $\begin{array}{l}\text { Individual perception of } \\
\text { group effort (i.e., beliefs } \\
\text { about how supportive the } \\
\text { environment is for } \\
\text { achieving their goals) }\end{array}$ & $\begin{array}{l}\text { Student self- } \\
\text { report }\end{array}$ & $\begin{array}{ll} & \text { Collaboration rubric } \\
\text { - } & \text { Semi-structured Interviews } \\
\text { - } & \text { Qualitative journal items } \\
\text { - Group work journal items }\end{array}$ & $\# 1(b)$ \\
\hline $\begin{array}{l}\text { Engagement } \\
\text { - Time on } \\
\text { task } \\
\end{array}$ & $\begin{array}{l}\text { Time spent working on the } \\
\text { WebQuest outside of class }\end{array}$ & $\begin{array}{l}\text { Student self- } \\
\text { report }\end{array}$ & $\begin{array}{ll} & \text { Time record } \\
\text { - } & \text { Semi-structured Interviews } \\
\text { - } & \text { Qualitative journal items } \\
\end{array}$ & \#2(a) \\
\hline $\begin{array}{l}\text { Engagement } \\
\text { - Quality of } \\
\text { interaction }\end{array}$ & $\begin{array}{l}\text { Experience working as a } \\
\text { member of a team }\end{array}$ & $\begin{array}{l}\text { Student self- } \\
\text { report }\end{array}$ & $\begin{array}{ll}\text { - } & \text { Group work journal items } \\
\text { - } & \text { Collaboration rubric } \\
\text { (others) } \\
\text { - Semi-structured Interviews } \\
\text { - } \quad \text { Qualitative journal items } \\
\end{array}$ & $\# 2(\mathrm{~b})$ \\
\hline $\begin{array}{l}\text { Engagement } \\
\text {-Satisfaction }\end{array}$ & $\begin{array}{l}\text { Affective state during task } \\
\text { and resulting satisfaction } \\
\text { with WebQuest experience }\end{array}$ & $\begin{array}{l}\text { Student self- } \\
\text { report }\end{array}$ & $\begin{array}{ll}\text { - } & \text { WebQuest journal items } \\
\text { - } & \text { Semi-structured Interviews } \\
\text { - } & \text { Qualitative journal items } \\
\end{array}$ & $\# 2(\mathrm{c})$ \\
\hline $\begin{array}{l}\text { Learning - } \\
\text { Structural } \\
\text { Knowledge }\end{array}$ & $\begin{array}{l}\text { Complex levels of } \\
\text { thinking (i.e., evidence of } \\
\text { deeper level of } \\
\text { understanding about } \\
\text { HIV/AIDS) as assessed by } \\
\text { examining the learner's } \\
\text { comprehension of the } \\
\text { nature of relationships } \\
\text { within the content domain. }\end{array}$ & $\begin{array}{l}\text { Researcher } \\
\text { rating }\end{array}$ & $\begin{array}{ll} & \text { Performance on "Living } \\
\text { With AIDS" final essay } \\
\text { - } & \text { Performance on HIV/AIDS } \\
\text { Semantic Relationship Test } \\
\text { - } & \text { Performance on HIV/AIDS } \\
\text { Relationship Judgment Test }\end{array}$ & $\# 3$ \\
\hline
\end{tabular}

\section{Case Study Database}

Multiple sources of evidence were used to increase the construct validity of the study, and to facilitate cross-case analysis. In order to keep the evidentiary base of raw data in one central repository, the following records were entered into the researcher's case study database:

- Demographic data for each subject (e.g., major, units, midterm score, group, role, etc.) $\mathrm{N}=92$

- Weekly Journals ( $\sim 3$ per student) $\mathrm{N}=255$ 
- Weekly *Timesheets ( 2 per student) $\mathrm{N}=1151$

- "Knowledge Check" Scores aka Semantic Relationship / Relationship Judgment Test results ( 1 per student) $\mathrm{N}=86$

- Team Presentation Scores (11 teams from No Jigsaw / 12 teams from Jigsaw) N=23

- Collaboration Rubrics ( 4 per student) $\mathrm{N}=321$

- Essays Test results ( 1 per student) $\mathrm{N}=92$

- Interview transcriptions (ten students per No Jigsaw and Jigsaw class were interviewed, and one student was randomly selected from each student group) $\mathrm{N}=20$

- Weekly researcher case notes

- Weekly instructor case notes

The researcher strongly believed that having a case study database available for independent inspection by other interested researchers would markedly increase the reliability study (Yin, 2003).

\section{Instrumentation}

The following instruments sought to illuminate how the two WebQuest designs (one utilizing the Jigsaw approach) influenced students' personal agency beliefs, and their engagement with the course/content, as well as their mastering of the course content.

\section{Collaboration Rubric}

As a measure of personal agency beliefs, the Collaboration Rubric was used to gather information on students' academic self-efficacy beliefs and collective efficacy beliefs. The Collaboration Rubric asked students to rate themselves and their teammates

1 *Timesheet data part of weekly journal for both classes in week 1 
regarding the quality of group collaboration. The Rubric included three subscales with a total of ten items. Students rated each item on a four-part scale that included ' 1 ' (beginning), '2' (developing), '3' (accomplished), and '4' (exemplary). Subscales were calculated to measure Contribution (three items), Take Responsibility (four items), Value Others' Viewpoints (three items), and the sum of these three subscales was calculated as the Collaboration Rubric Total score. In addition, one item asked students to rate the Knowledge of the material on a ten-point scale from "F" (1) to "A+" (10). Knowledge was not included as part of the Collaboration Rubric Total.

The data was collected after the WebQuest, and students completed one Collaboration Rubric for each individual in their group (Others), and one for themselves (Self). For example, one student might complete one rubric for self, and one rubric for each of their three teammates for a total of four rubrics completed. Scores on the Collaboration Rubric for Others were used as a measure of context beliefs, and more specifically, collective efficacy. As a measure of students' academic self-efficacy, scores on the Collaboration Rubric for Self were used, as well as a comparison of ratings of Self relative to Others. This data was used to answer research question number one.

\section{Semi-structured Interviews}

Student ratings of engagement were recorded by the researcher through semistructured interviews that illuminated students' perceptions of the WebQuest activity and its impact on their learning process. This data was used to answer research question number two. 


\section{Weekly Journal}

As a measure of student engagement, weekly journal entries provided data on students' perception of the quality of interaction with their peers and satisfaction with the learning process. This data was also used to answer research question number two.

\section{Weekly Time Record}

The weekly time records provided data on students' time-on-task working on the WebQuest outside of class, and this data was also used to answer research question number two. Specifically, students were asked to record the amount of time spent on the WebQuest project outside of class, rounded to the nearest quarter hour and broken down by categories that included hours spent reading web pages, reading print material, talking with people in project group, and talking with people outside project group.

\section{Knowledge Check and Final Essay}

Student learning was examined by the researcher's rating of students' level of structural knowledge (Jonassen, Beissner, \& Yacci, 1993) on two tests designed by the researcher to assess students' gains in structural knowledge (see Appendix M), as well as on the culminating independent writing assignment (see Appendix N). The Knowledge Check was a 25-item multiple-choice questionnaire with three demographic items, plus two sub-scales: the Semantic Relationship sub-score and the Relationship Judgment subscore. Students were told that their scores on this instrument would not be graded, but would be used to inform the instructor about gaps in their understanding so that he could tailor his review for the final. This data was used to answer research question number three. 
A comparison of the knowledge construction process for each class was done by examining the students' deliverables (individual essays, semantic relationship tests, and relationship judgment tests) in order to determine the level of structural knowledge within the outcomes. For instance, closely examining the ideas presented within the essays was used to reveal the structural knowledge of the students responsible for creating them and whether or not this is influenced by the degree of interaction and collaboration within the respective approach (WebQuest with Jigsaw versus WebQuest without Jigsaw).

\section{Student Essay \& Scoring Criteria}

Examples of student cognitive skills put forth by Thomas (2001) included reading comprehension, memory of academic texts, and essay writing. Thomas (2001) also pointed out that strong student essays (i.e., that demonstrate "cognitive skills") included the recognition of prepositional relationships within the material being studied. Because part of the focus of this study's third research question is on the depth of understanding exhibited in students' writing, a quantifiable metric was developed to score the individual students' final essays (see Appendix K).

Further, for the final essay, the researcher worked with the course instructor and three experts from the field to develop a list of possible assertions that the students might make in response to the final essay question based in part on their respective role (e.g., historian, doctor, psychologist, or economist within the WebQuest). The content experts were instructors who had taught an undergraduate general education course titled "Confronting AIDS" at a large public university in the southwestern U.S. during the fall 2003 semester. 
The students were given and asked to prepare for three possible AIDS-related questions that they might see on the final and were told at the beginning of the WebQuest that on the day of the exam they would only be asked one of the three possible essay questions. The actual question that they faced on the final essay is listed below: Essay Question

"How would you choose to spend money to fight the spread of AIDS if money was not an object? When explaining your solution system, consider the following:

- What would be your main emphasis and/or target population, and why?

- What else might you do?

- What is your rationale for how you would prioritize spending the money" HIV/AIDS Semantic Relationship Test

A semantic relationship test was developed by the researcher (with input and feedback from the course instructor and three content experts) to assess gains in a student's structural knowledge related to major HIV/AIDS concepts after doing individual research based on their respective role, working with their WebQuest group, hearing other students' small group presentations, and listening to the instructor's lectures on living with AIDS. Below are the directions given to the students for the Semantic Relationship Test portion of the knowledge check, as well as two sample items. Directions to students: Please classify the nature of the relationships between the following important HIV/AIDS concepts.

HIV+...AIDS
a. is caused by
b. causes 
c. is the same as

d. precedes

Symian virus...HIV
a. is characteristic of
b. comes after
c. is caused by
d. causes

HIV/AIDS Relationship Judgment Test

A relationship judgment test (Diekhoff, 1983; Jonassen et al., 1993) was

developed by the researcher (with feedback from instructor and content experts) to elicit students' structural knowledge related to major HIV/AIDS concepts after doing individual research based on their respective role, working with their WebQuest group, hearing other students' small group presentations, and listening to the instructor's lectures on living with AIDS. Below are the directions given to the students for the Relationship Judgement Test portion of the knowledge check, as well as two sample items.

Directions to students: Please judge the strength of the relationships between the following important HIV/AIDS concepts by answering TRUE or FALSE for each of the following relationship statements

HIV is not related to AIDS

Definition of homosexuality is highly related to the definition of AIDS 


\section{Purpose of the Relationship Tests}

The objective of the tests was to gather information on students' structural knowledge about HIV/AIDS. Additionally, the tests were developed to contrast the structural knowledge between students in the Jigsaw and no-Jigsaw classes. The researcher compared counts with the jigsaw and control classes. In addition, each student was asked to identify their previous experience with the content (GS 340), previous experience with the WebQuest, and number of units taken during the same semester as the study. This information enabled the researcher to make additional comparisons between the Jigsaw class and the no-Jigsaw class.

\section{Expert Interviewing}

The researcher conducted three separate face-to-face interviews with experts on HIV/AIDS in October 2003 to evaluate how the proposed Semantic Relationship Test and Relationship Judgment Test were written (i.e., how they felt undergraduate college students would comprehend and assign meaning to the different test items). Respondents were recruited because they were teaching a "Confronting AIDS" (undergraduate, general education elective) course at a large public university in the southwestern United States in the fall of 2003.

The interview began with the researcher describing the purpose of the study and the context of the classroom environment. After a brief explanation of the WebQuest model, the experts were asked to complete the tests using a "think aloud" methodology. The interviews were used to refine questions and clarify language. In addition, the interviews enabled the researcher to eliminate problematic items based on probing about 
items that appeared to be confusing. Input from the experts in the area of HIV/AIDS helped improve the wording and flow of the test items.

\section{Interviews}

To further investigate the research questions and to address the reliability and validity of the survey instruments, the researcher obtained a subset of participants' perspectives on the WebQuest process through semi-structured interviews that utilized a pre-prepared interview protocol (see Appendix O). Over a five-day period, the researcher and one other interviewer conducted in-person interviews with 20 students, approximately one from every group, with 10 participating from each class. At the time of the interviews, students had received feedback and grades on their group presentations, but not for their final essay exam. Interviewers followed a script, took notes during the interviews, and tape-recorded all interviews for future analysis. Throughout the interview process, the researcher and other interviewer continually reviewed and discussed their notes and interview tape recordings. During that review process and after five interviews were completed, the researcher identified a theme related to students' academic selfefficacy beliefs. As a result of the emergence of this theme, the researcher added a question to the script asking about confidence going into the final essay. Consequently, the first five students out of twenty interviewed did not receive that additional question.

Transcripts of interviews were used to compare and triangulate with data gathered from the students' journal entries, time records, and the researcher's and instructor's case notes. The aim of the interviews was to reduce error and to either validate or disconfirm the researcher's interpretations of the other data collected. The ultimate purpose of the interviews was to help the researcher converge on a well-corroborated descriptive picture 
of the context in order to gain a rich understanding of the natural setting. Below are a few sample items from the interview protocol.

Sample interview questions

1. How does this class compare to other classes you've taken at SDSU?

2. Describe your experience with the "Living With AIDS" WebQuest.

3. Tell me about how much time it took for you? For your group?

Procedures

At the beginning of the study, the instructor introduced the researcher to the class. The researcher then described the research effort to the students via a brief oral discussion that emphasized the voluntary nature of their participation, the benefits of their involvement, and assurances of confidentiality (see Appendix B). Students were advised of the specific procedures they were to follow, provided with contact information for the principal investigator and the University's Institutional Review Board, and were encouraged to ask questions of the researcher, the institution, or the teacher. Each student was asked to sign a standard informed consent form indicating his or her willingness to participate in the study. Every student in both classes agreed to sign the form and all the forms were collected by the researcher on the first day of the study.

The course syllabus included information about the WebQuest assignment and research effort. During class in week one of the WebQuest assignment, the researcher gave a brief tour of the WebQuest website, and the group communication tools to be used on the university's Web-based course management system, and gave students more detailed information about the WebQuest. The details associated with the WebQuest, including an excerpt from the course syllabus, the in-depth description given to the 
students at the start of the unit describing both the individual and group deliverables, as well as informational small group collaboration guides, grading criteria and a three-week time line can be found in the Appendices (see Appendices C through F). Students were also given a copy of the research script/protocol with information on how to contact the researcher or the institution about the study. Finally, students received three copies of the weekly journal and time sheet that they were to fill out and hand-in at the start of each class (see Appendices $\mathrm{G}$ and $\mathrm{H}$ ), as well as the rubrics used to score their small group presentations, and a rubric to fill out for themselves and each of their teammates at the conclusion of the WebQuest (see Appendices I and J). A rubric was developed to score students' final essay questions a priori, but was modified and the students did not see it prior to completing their culminating independent writing assignment (see Appendix K).

During the week one class, the instructor also assigned groups and explained that this was part of the research effort. Students were asked to relocate to tables with their new group members for the remainder of the semester. Next, the researcher conducted a quick group process exercise to demonstrate the value of each person's contribution with everyone participating equally, and to point out the negative effects of one person dominating the group. During the last half of class, students began working on the WebQuest assignment with their teams, while the instructor and researcher were available to answer questions. There were very few questions, and students worked primarily independently.

During week two, students in the Jigsaw class met with their expert groups for one half of the class, then worked in their WebQuest groups for the second half of class. Students in the No Jigsaw class spent the whole time in their WebQuest groups. The 
instructor was not in the class that day, and the researcher was there to facilitate and answer questions as necessary. There were few questions from students in both classes, and when there were, the researcher directed students to the WebQuest Website to find the answers.

During the week three class, students presented their group PowerPoint presentations to the class. The instructor acted as the master of ceremonies, and the researcher acted as the time keeper to keep students to the seven-minute time limit. The instructor and researcher used a rubric to score the presentations, and these grades were not used as part of the research. The next week, students completed the final essay exam.

Data Analysis

Quantitative and qualitative analysis techniques were used to explore the data in light of the research questions. Quantitative analyses included simple descriptive statistics, correlations, analyses of variance, analyses of covariance, chi-square, and linear regression. Qualitative analyses utilized "categorical aggregation" (Creswell, 1998; Stake, 1995) insofar as the researcher sought to assemble a collection of instances from the breadth of available data to illuminate patterns so that issue-relevant meaning could emerge.

Responses from the student interviews and open-ended journal items were broken down into meaningful passages and coded according to major themes and sub-themes, using blind review so that the researcher was unaware of whether the passage was from a student in the Jigsaw or No Jigsaw class. Major themes corresponded with the three driving research questions and included Personal Agency Beliefs, Context Beliefs, and Student Engagement. Within each of these major themes, specific sub-themes emerged 
and were coded through a process of constant comparative analysis (Creswell, 1998). Each passage was also coded as a strength or weakness.

\section{Examination of Variables}

Within the context of this bounded system, the case study examined one manipulated variable (Jigsaw or No-Jigsaw), and its impact on the following three dependent variables:

- student self-report of personal agency beliefs, including academic and collective efficacy;

- student self-report of engagement;

- student learning outcomes (analysis of structural knowledge as rated by researchers).

To investigate the influence of existing independent variables, the researcher investigated students' demographic information such as:

- academic ability (score on HIST 406 midterm exam);

- prior experience within content domain (whether or not students had taken GS 340 , a general studies elective course offered at the same university titled “Confronting AIDS");

- prior experience with the WebQuest model;

- number of units taken during the semester of the study;

- major of study at the university;

- gender. 


\section{Personal agency beliefs}

To examine academic self-efficacy and collective efficacy, the researcher used the Collaboration Rubric data for Self and Others and computed analyses of variance with Class as the independent variable and dependent variables including Collaboration Rubric total, its four subscales. Linear regression was computed with independent fixed factors including Class, Midterm score, the interaction of Class and Midterm score, and the interaction of Class and Grade Status and the Collaboration Rubric total and all four subscales for Self and Others. In order to investigate academic self-efficacy beliefs from another perspective, the researcher examined how individuals rated themselves relative to how they rated their teammates using a Chi-square analysis. For each rubric in which an individual student rated their Other teammates, a code was given indicating whether the student's rating of Self was either lower than (0), or equal to or higher than (1) the rating of the teammate. The researcher examined how individuals rated their current group experience versus their ideal group experience post-jigsaw by Class using a Chi-square analysis. Qualitative analyses were used to examine open-ended journal responses and interview data.

\section{Time on task}

As a measure of student engagement, this study used students' self-report of time on task, and more precisely, the amount of time students spent outside of class working on the WebQuest. The three weekly totals were calculated by summing all items including hours spent reading web pages, reading print material, talking with people in project group, and talking with people outside project group. Analysis of covariance were run and linear regression was computed with independent fixed factors including 
Class, Grade Status, Midterm Score, GS340, WebQuest Prior, Units, and time on task post-Jigsaw. Qualitative analyses were used to examine open-ended journal responses and interview data.

\section{Group work satisfaction}

As a measure of student engagement, this study used the Group Work subscale of the weekly journals to examine students' context beliefs, and more specifically, their beliefs about the collective efficacy of their group. The Group Work subscale, including a subset of nine items from the weekly student journals, asked students to specifically think about their group experiences over the previous seven days as they related to the WebQuest. Change scores were calculated for the Group Work subscale to examine whether context beliefs had increased from before to after the Jigsaw. Because there were two weeks of journal data that were pre-Jigsaw, two change scores were calculated. The first change score was calculated by subtracting the week one from week three Group Work subscale total score. The second change score was calculated by subtracting the week two from week three Group Work subscale total score. The researcher computed analyses of variance for the totals of the Group Work subscale for weeks one and two (pre-Jigsaw) and week three (post-Jigsaw), and for change scores from week one to three and from week two to three by Class. Qualitative analyses were used to examine openended journal responses and interview data.

\section{WebQuest satisfaction}

As a measure of student engagement, this study used the WebQuest Satisfaction subscale of the weekly journals to examine students' context beliefs, and more specifically, their beliefs about the learning environment. The WebQuest Satisfaction 
subscale, including a subset of five items from the weekly student journals, asked students to specifically think about their experiences with the WebQuest over the previous seven days. Change scores were calculated for the WebQuest Satisfaction subscale to examine whether satisfaction had increased from before to after the Jigsaw. Because there were two weeks of journal data that were pre-Jigsaw, two change scores were calculated. The first change score was calculated by subtracting the week one from week three WebQuest Satisfaction subscale total score. The second change score was calculated by subtracting the week two from week three WebQuest Satisfaction subscale total score. The researcher computed analyses of variance for the totals of the WebQuest Satisfaction subscale for weeks one and two (pre-Jigsaw) and week three (post-Jigsaw), and for change scores from week one to three and from week two to three by Class. Qualitative analyses were used to examine open-ended journal responses and interview data.

\section{Depth of understanding}

In order to assess students' depth of understanding concerning the topic "living with AIDS," students in both classes completed the Knowledge Check instrument in week three, post-Jigsaw, and a timed written essay as part of the final exam. Totals were calculated for the Essay score, the Knowledge Check total and its two sub-scales: the Semantic Relationship sub-score and the Relationship Judgment sub-score. Analyses of variance were computed for the Knowledge Check total score, the Semantic Relationship and Relationship Judgment sub-scores, and the final essay total score by Class.

Correlations and linear associations were computed between Class, Grade Status, WebQuest Prior, Midterm Score, and the Semantic Relationship sub-score. Qualitative 
analyses were used to examine open-ended journal responses, interview data, and instructor case notes.

\section{Interrater Reliability}

The essays were scored by the instructor in order to determine students' grade for the purposes of the class, worth $10 \%$ of the students' total course grade. However, for the purposes of this study, the researcher and another rater scored the essays using a ten-point rubric that addressed five quality dimensions (see Appendix K).

Six essays (7\%), three from each class, were randomly selected for scoring by the researcher and another rater in order to determine inter-rater reliability before proceeding with scoring the other essays. Correlations calculated for the essay total scores resulted in a high inter-rater reliability $(\mathrm{r}=.961)$. This result was considered to be a strong correlation, and therefore, the 87 essays from both classes were randomly distributed so that the researcher and another rater each scored approximately half of the essays. It is important to note that at the time of the interviews, students did not yet know their grades on the final WebQuest essay.

\section{Protection of Human Subjects}

Students' rights were safeguarded by complying with protocols established by the Committee for the Protection of Human Subjects (CPHS) at San Diego State University. Protocol approval (\#03-09-322) was obtained from the SDSU Institutional Review Board in September, 2003. The Committee for the Protection of Human Subjects at the University of San Diego also reviewed the study's research design and methodology and joint approval to proceed was received on October 10, 2003 (see Appendix P). 
This study only used the last four digits of the students' identification number as subject identifiers and all other student information (e.g., name, social security number, email address) was eliminated prior to inclusion in the case study database and subsequent data analyses.

\section{Limitations of the Research Design}

Potentially, biases can result from participant-observation, such as bias due to the researcher's manipulation of events. Among the possible biases anticipated, the most threatening are described below as well as the steps taken by the researcher to try and ameliorate them.

The limitations of the research design are those commonly associated with utilizing a case study methodology. And, as Yin made clear, one possible weakness of this approach is reflexivity (1994). For instance, the researcher's presence might have caused a change that otherwise would not be there, or, in the case of the semi-structured interviews, the interviewee may have expressed what they believed the interviewer wanted to hear. As such, another doctoral student that was not involved in any way with the WebQuest conducted two-thirds of the student interviews, and the principal researcher conducted one-third. It is worth noting that the principal researcher was not planning on conducting any of the interviews, but the other doctoral student was ill and could not make it to one-third of the scheduled interviews.

Another potential pitfall of the study's approach included the possibility of "selectivity" whereby the researcher might have missed facts and only "tuned-in" to the data that he was most interested in finding (Yin, 1994). For example, the closed, fixed response survey items may have forced the respondents to fit their experiences and 
feelings into the schema that the researcher used, and the students' may have perceived this as limiting, impersonal or even mechanistic (Fraenkel \& Wallen, 1996). Therefore, the researcher sought broad coverage of the available data by also including interviews, qualitative journal data, and researcher and instructor case notes.

A further weakness with the case study methodology in general, and this research design in particular, was the time-consuming nature of collecting and analyzing multiple sources of information in order to provide an in-depth description of the context and setting (Creswell, 1998). And as with any study, there is always the potential for subjectivity or reporting bias, a huge threat to internal validity. As such, the researcher took initial findings back to the course instructor to help deal with problems of validity and reliability.

To control for what might be the greatest limitation to this design, the researcher worked with another graduate student to rate the students essays for structural knowledge using a scoring rubric developed with the course instructor and all student essays were scored using a blind review process.

Finally, using information from a variety of data (e.g., survey instruments, interviews, and student essays) to triangulate findings was done to address some of the aforementioned limitations and might have also served to increase the external validity of the study. 


\section{CHAPTER IV: RESULTS}

\section{Introduction}

This study investigated the use of the WebQuest model in an undergraduate college course, and the impact of the Jigsaw method on students' personal agency beliefs, student engagement, and learning. Using a comparative two-case case study design (Yin, 2003), this study sought to facilitate understanding about the design elements that cause WebQuests (with a teamwork component) to be effective at raising students' personal agency beliefs, engagement and learning.

This chapter describes the demographic and academic characteristics of the study population, and provides both qualitative and quantitative data analysis results. Specific findings related to each research question are presented, and the following research questions are addressed:

1. Will participation in a role-specific Jigsaw activity within a WebQuest produce a significantly greater increase in students' personal agency beliefs than exposure to the same WebQuest without a role-specific Jigsaw activity?

a. Will participation in a role-specific Jigsaw activity within a WebQuest produce a significantly greater increase in students' academic self-efficacy beliefs than participation in the same WebQuest without a role-specific Jigsaw activity?

b. Will participation in a role-specific Jigsaw activity within a WebQuest produce significantly more positive context beliefs than participation in the same WebQuest without a role-specific Jigsaw activity? 
2. How is the learning process different for students participating in a role-specific Jigsaw activity within a WebQuest as compared to students participating in the same WebQuest without a role-specific Jigsaw activity?

a. Do students participating in a role-specific Jigsaw activity within a WebQuest report more time on task (i.e., in-class and outside of class in terms of individual time and group time) than students participating in the same WebQuest without a role-specific Jigsaw activity?

b. How is the quality of interaction with teammates, as reported in student journals, affected by participation in a role-specific Jigsaw activity within a WebQuest as compared to students doing the same WebQuest without a rolespecific Jigsaw activity?

c. How is students' satisfaction with the experience, as reported in their journals, affected by a role-specific Jigsaw activity within a WebQuest as compared to students doing the same WebQuest without a role-specific Jigsaw activity?

3. Will student performance on an HIV/AIDS Semantic Relationship Test and HIV/AIDS Relationship Judgment test, as well as writing in response to a final (essay) test question exhibit greater depth of understanding concerning "living with AIDS" for those students participating in a role-specific Jigsaw activity within a WebQuest than for students participating in the same WebQuest without a rolespecific Jigsaw activity?

This chapter is divided into four sections: a detailed description of the study population, an examination of the overall effectiveness of the WebQuest model, a brief 
overview of significant findings, and a summary of the quantitative and qualitative analyses.

\section{Description of the Study Population}

A total of 89 undergraduate students participated in the study. The Jigsaw class included 45 students in 12 groups, and the No Jigsaw class included 44 students in 11 groups. This section presents the demographic and academic characteristics of the study population. Tables 4.1 and 4.2 show the demographic and academic characteristics of the study population by class.

Gender. Approximately thirty percent of participants were male, and seventy percent were female. Both classes were made up of a similar ratio of males to females. A Chi-square analysis was performed and no significant differences were found between classes for gender.

Grade Status. This variable was dichotomized into "credit" (taking the course for credit only) or "letter" (taking the course for a letter grade). Approximately twenty percent of students were taking the course for credit only, and eighty percent of students were taking it for a letter grade. A Chi-square analysis was performed and no significant differences were found between classes for grade status.

Prior Experience with the Course Content. This variable was dichotomized into yes and no categories. The course GS340 titled "Confronting AIDS" was considered to cover similar content as the course examined in this study, "History of Sexuality," as well as the WebQuest assignment, "Living with AIDS." Therefore, if students had previously taken GS340, they were considered to have prior experience with the course content. The majority of students ( $88 \%$ ) had not taken the course GS340 prior to this 
study, whereas $12 \%$ had taken GS340. A Chi-square analysis was performed and no significant differences were found between classes for prior experience with similar course content (GS340).

Prior Experience with the WebQuest Model. This variable was dichotomized into yes and no categories. Students were asked whether or not they had prior experience with the WebQuest model. Almost all of the students (98\%) in this study had no prior experience with the WebQuest model. A Chi-square analysis was performed and no significant differences were found between classes for prior experience with the WebQuest model.

Major College. Study participants were from 29 different majors of study, and seven different colleges of study. Most students were from the College of Professional Studies and Fine Arts (39\%) including majors in art, child development, foods and nutrition, journalism, music, kinesiology, public administration, criminal justice administration, and communication studies. One-fifth $(20 \%)$ of students were from the College of Arts and Letters including majors in economics, English, French, history, political science, social science, sociology, and women's studies. Fourteen percent (14\%) of students were from the College of Business Administration, which was also their major area of study. Ten percent (10\%) of students were from the College of Sciences including majors in biology, computer science, geological sciences, and psychology. Eight percent (8\%) of students were from the College of Health and Human Services including majors in communicative disorders, nursing, and social work. Seven percent (7\%) of students were from the College of Engineering including majors in computer, and electrical engineering. One student $(1 \%)$ was from the College of Interdisciplinary 
Studies. A Chi-square analysis was performed and no significant differences were found between classes for Major College.

Midterm Score. The midterm exam was given to students in both classes midway through the semester and prior to participation in the WebQuest assignment. Scores on the midterm exam ranged from 54 to 99 for participants, with a mean score of 85.1 . There was a greater range of scores in the Jigsaw class (range $=54$ to 99), with a lower minimum score and a higher maximum score as compared to the No Jigsaw class (range $=69$ to 97 ). Furthermore, the Jigsaw class had a lower mean and approximately twice the variance as compared to the No Jigsaw class. These differences in midterm scores were significant $[F(1,85)=5.89, \mathrm{p}=.017]$, with students in the No Jigsaw class exhibiting a significantly higher level of understanding of the course material going into the WebQuest than students in the Jigsaw class. Therefore, the researcher controlled for midterm in the statistical analyses described later in this chapter.

Number of Units. Including the three-unit class under study, the number of units taken during the Fall 2003 semester ranged from 6-21, with a mean of 13.6. The Jigsaw and No Jigsaw classes were very similar in terms of their mean scores, variance, and range. There was no statistically significant difference in the number of units taken by class.

In summary, the descriptive analyses show that the Jigsaw and No Jigsaw classes were comparable, with no statistically significant differences by gender, credit, prior experience with the course content, prior experience with the WebQuest model, major college, or number of units. The study population was mostly female, taking the course for a letter grade, and had no prior experience with the content or the WebQuest model. 
The number of units taken by students ranged from 6-21, with a mean of 13.6. Scores on the midterm ranged from 54-99, with a mean of 85.1 , and there was a statistically significant difference in midterm score by class, with the Jigsaw class having a lower mean, greater range, and approximately twice the variance as compared to the No Jigsaw class. Therefore, the researcher controlled for midterm score in subsequent analyses when comparing the Jigsaw and No Jigsaw classes. 
Table 4.1 Demographic Characteristics by Class ( $\mathrm{N}=89)$

\section{Class}

$$
\text { Jigsaw ( } \mathrm{N}=45) \quad \text { No Jigsaw }(\mathrm{N}=44) \quad \text { Chi-Square }
$$

\begin{tabular}{|c|c|c|c|}
\hline Gender & & & $\begin{array}{c}\chi^{2}=.026 \\
p=.872\end{array}$ \\
\hline Male & $31 \%$ & $29 \%$ & \\
\hline Female & $69 \%$ & $71 \%$ & \\
\hline Grade Status & & & $\begin{array}{c}\chi^{2}=.376 \\
p=.540\end{array}$ \\
\hline Credit & $22 \%$ & $17 \%$ & \\
\hline Letter & $78 \%$ & $83 \%$ & \\
\hline $\begin{array}{l}\text { Prior Experience with the } \\
\text { Course Content }\end{array}$ & & & $\begin{array}{c}\chi^{2}=.002 \\
p=.968\end{array}$ \\
\hline Has taken GS340 & $12 \%$ & $12 \%$ & \\
\hline Has not taken GS340 & $88 \%$ & $88 \%$ & \\
\hline $\begin{array}{l}\text { Prior Experience with the } \\
\text { WebQuest Model }\end{array}$ & & & $\begin{array}{c}\chi^{2}=.000 \\
p=.987\end{array}$ \\
\hline Has experience & $2 \%$ & $2 \%$ & \\
\hline Does not have experience & $98 \%$ & $98 \%$ & \\
\hline Major College & & & $\begin{aligned} \chi^{2} & =1.516 \\
p & =.958\end{aligned}$ \\
\hline Arts and Letters & $18 \%$ & $23 \%$ & \\
\hline Business Administration & $15 \%$ & $14 \%$ & \\
\hline Engineering & $8 \%$ & $7 \%$ & \\
\hline Health and Human Services & $8 \%$ & $9 \%$ & \\
\hline $\begin{array}{l}\text { Professional Studies } \\
\text { and Fine Arts }\end{array}$ & $40 \%$ & $39 \%$ & \\
\hline Sciences & $10 \%$ & $9 \%$ & \\
\hline Interdisciplinary Studies & $3 \%$ & $0 \%$ & \\
\hline
\end{tabular}


Table 4.2 Academic Characteristics by Class ( $\mathrm{N}=89)$

Class

\begin{tabular}{lcccccc}
\cline { 2 - 6 } & \multicolumn{2}{c}{$\begin{array}{c}\text { Jigsaw } \\
(\mathrm{N}=45)\end{array}$} & $\begin{array}{c}\text { No Jigsaw } \\
(\mathrm{N}=44)\end{array}$ & & \\
\cline { 2 - 7 } & Mean & SD & Mean & SD & F & $\mathrm{p}$ \\
\hline Midterm Score & 83.0 & 10.2 & 87.2 & 5.1 & 5.89 & .017 \\
Number of Units & 13.7 & 3.2 & 13.5 & 3.0 & .11 & .737 \\
\hline
\end{tabular}

Overall Effectiveness of the WebQuest as an Instructional Model

Personal Agency Beliefs

Data from the Collaboration Rubric and interviews indicated that students were confident about their knowledge of the WebQuest topic (i.e., AIDS), and were well prepared approaching the final WebQuest essay. In addition to knowledge of the topic, students discussed improvements in academic skills such as presentation skills and the use of technologies (e.g., computers, the Internet, PowerPoint). Students also reported other areas in which they felt their academic skills had been positively influenced through participation in the WebQuest project, such as being more critical of information on the Web, enhancing their research and presentation skills, and being an effective team member. Students in both classes also expressed confidence in their group members' effort and abilities.

\section{Engagement}

Using time on task outside of class as a measure of student engagement, the data from weekly time records showed that over the three weeks that students could have worked on the WebQuest assignment, on average, students spent a total of approximately 19 hours outside of class on the WebQuest, as shown in Table 4.6. Furthermore, students 
reported an increase in time on task from week one through week three. During the interviews, few students voiced concern that the WebQuest assignment required more time than expected, as shown in Figure 4.3.

Students in both classes reported high satisfaction with the WebQuest experience, with the WebQuest structure standing out as a top strength in the interviews. The WebQuest seemed to provide a solid structure for students to follow, allowing students to work more independently and requiring minimal facilitation from the instructor or researcher. Students also reported an increase in satisfaction with the WebQuest over time, from week one through week three.

Students in both classes also reported high satisfaction with the group experience, with increasing satisfaction over time. Students in both classes rated their teammates quite positively regarding their contributions to the group effort. Students were also likely to agree with the statement, "I rarely put forth more effort than others," indicating satisfaction regarding teammates' contributions to the group effort. In the weekly journals, when students were asked to use one word to describe their opinion of their current group experience, many more students used a positive word rather than a negative or neutral word to describe their experience. Furthermore, interview data suggested that students had positive experiences working in groups, with three of the top ten strengths related to quality of interaction with teammates, including group collaboration / communication. Finally, in his case notes, the instructor reported, "students were so engaged that $90 \%$ didn't take their break (unheard of!)." 


\section{Learning Outcomes}

Based on interviews and journal data, students in both classes reported that they had "learned a lot" through participating in the WebQuest. Students reported positive changes in beliefs and attitudes regarding the content. For example, comments indicated more of a global perspective on the HIV/AIDS problem, more compassion towards victims, and that students' attitudes had "changed for the better." The instructor's comments echoed those of students, with the instructor indicating that students exhibited a great deal of empathy towards people living with HIV/AIDS.

\section{Comparing Two Cases: Overview of Significant Findings}

The two classes were found to be comparable on all important variables except their score on the midterm which was given just before the WebQuest segment of the course. Significant differences were found by class in the following important areas of the study. Students in the No Jigsaw class were more likely to use a negative word to describe the quality of interaction with teammates in the final week of the WebQuest assignment. Students in the Jigsaw class reported more perceived strengths and fewer weaknesses with the WebQuest experience than the No Jigsaw class, and shared more positive and fewer negative remarks regarding satisfaction with the experience overall. Finally, students in the Jigsaw class spent significantly less time on task in the final week of the WebQuest assignment when controlling for midterm score and prior experience with the content domain.

\section{Emergent Themes}

Responses from the student interviews were broken down into meaningful passages and coded according to major themes and sub-themes. Major themes 
corresponded with the three driving research questions and included Personal Agency Beliefs, Context Beliefs, and Student Engagement. Within each of these major themes, specific sub-themes emerged and were coded using constant comparative analysis (Creswell, 1998). Each passage was also coded as a strength or weakness. Figures 4.1 through 4.4 present the descriptive statistics for the interview passages coded into subthemes and sorted according to frequency in descending order. Figures 4.1 and 4.2 are sorted according to strengths and strengths by class, and Figures 4.3 and 4.4 are sorted according to weaknesses and weaknesses by class. No sub-themes stood out as either an overwhelming strength or weakness. Furthermore, several sub-themes were mentioned by different interviewees as both a strength and a weakness, for instance "group collaboration / communication" (1212), "WebQuest structure" (1221), and "learning challenge / difficulty" (1246). 
Figure 4.1 Top Five Sub-themes Coded as Strengths ( $\mathrm{N}=557)$

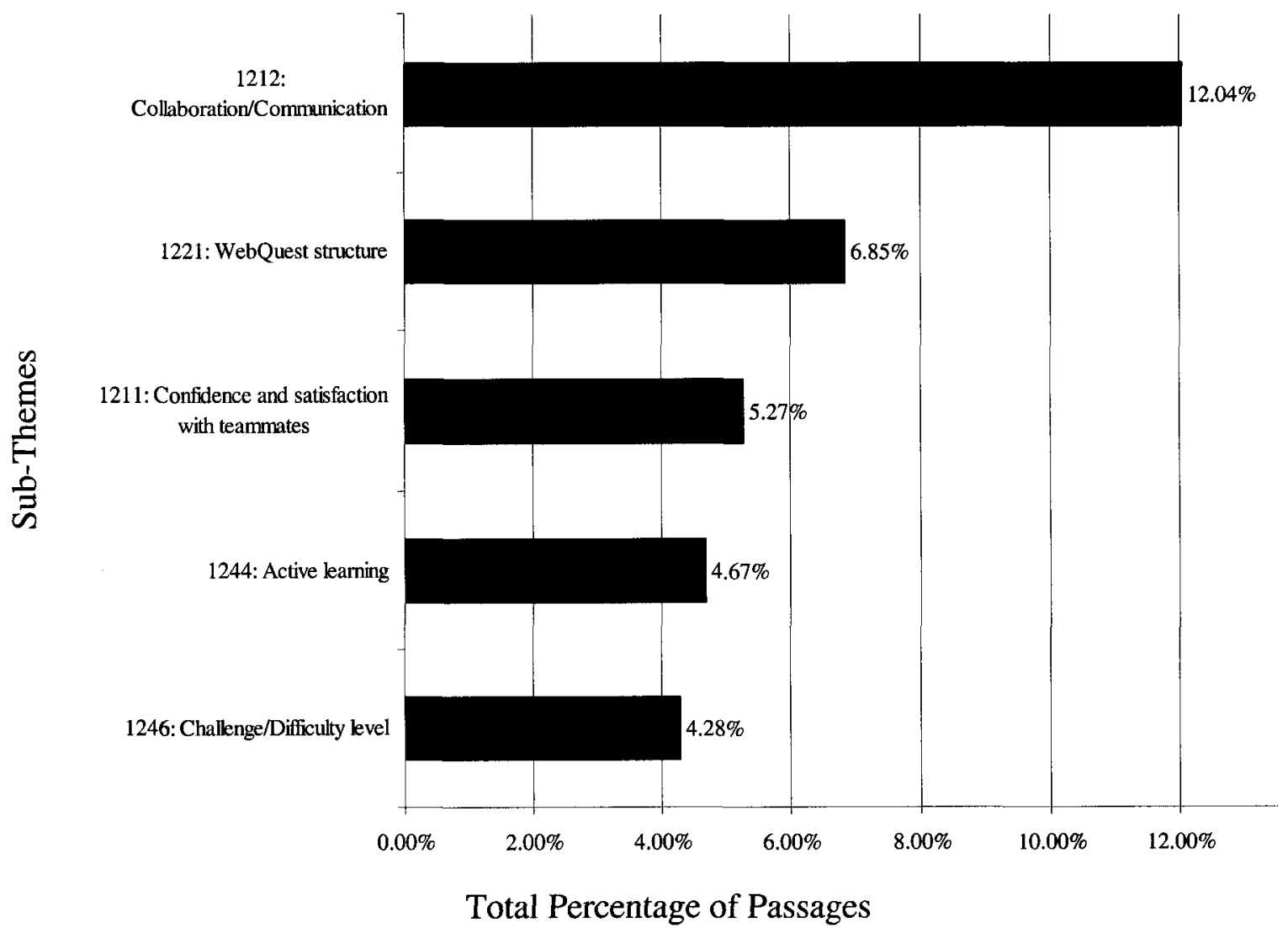


Figure 4.2 Top Five Sub-themes Coded as Strengths by Class

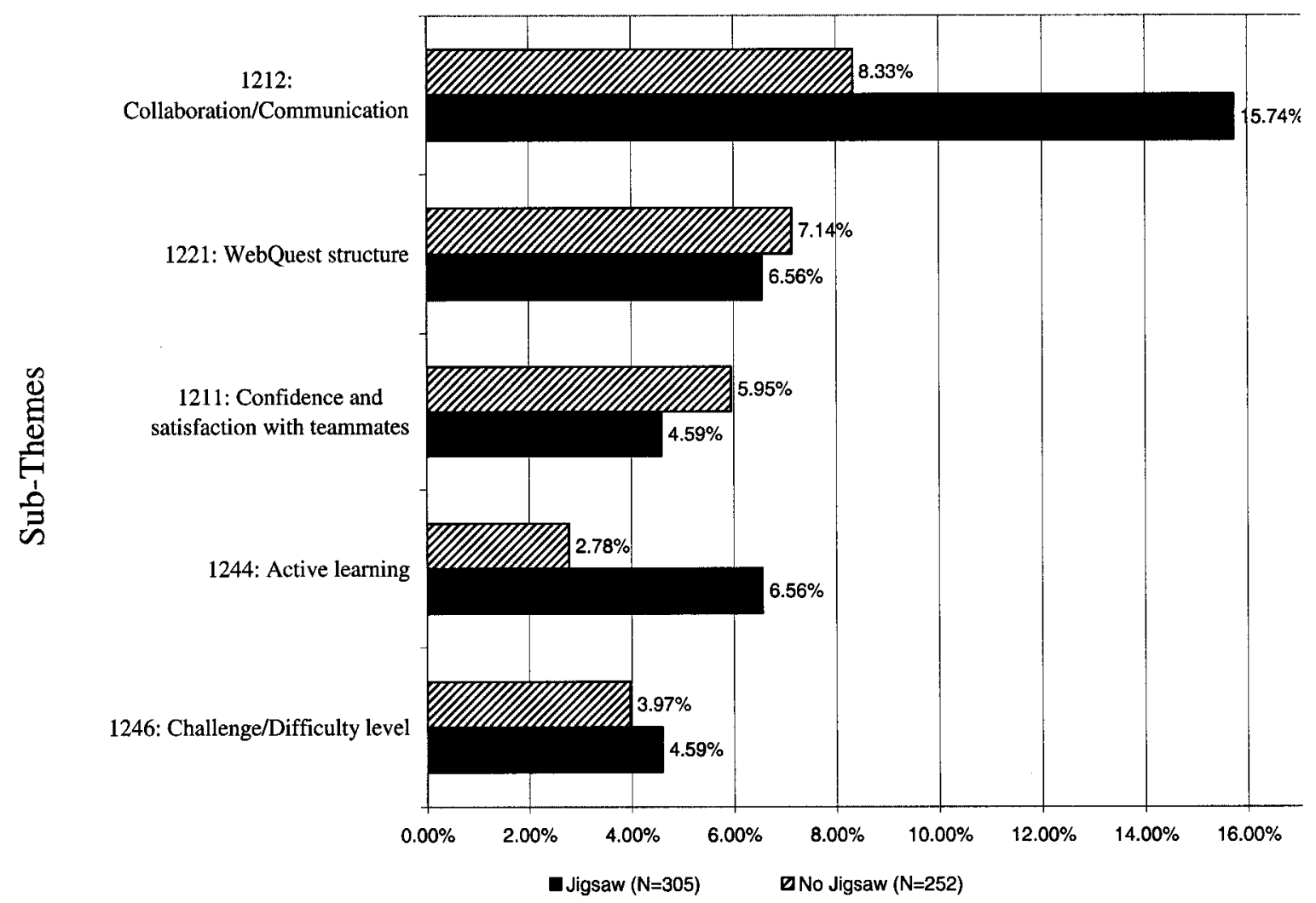

Total Percentage of Passages 
Figure 4.3 Top Five Sub-themes Coded as Weaknesses $(\mathrm{N}=557)$

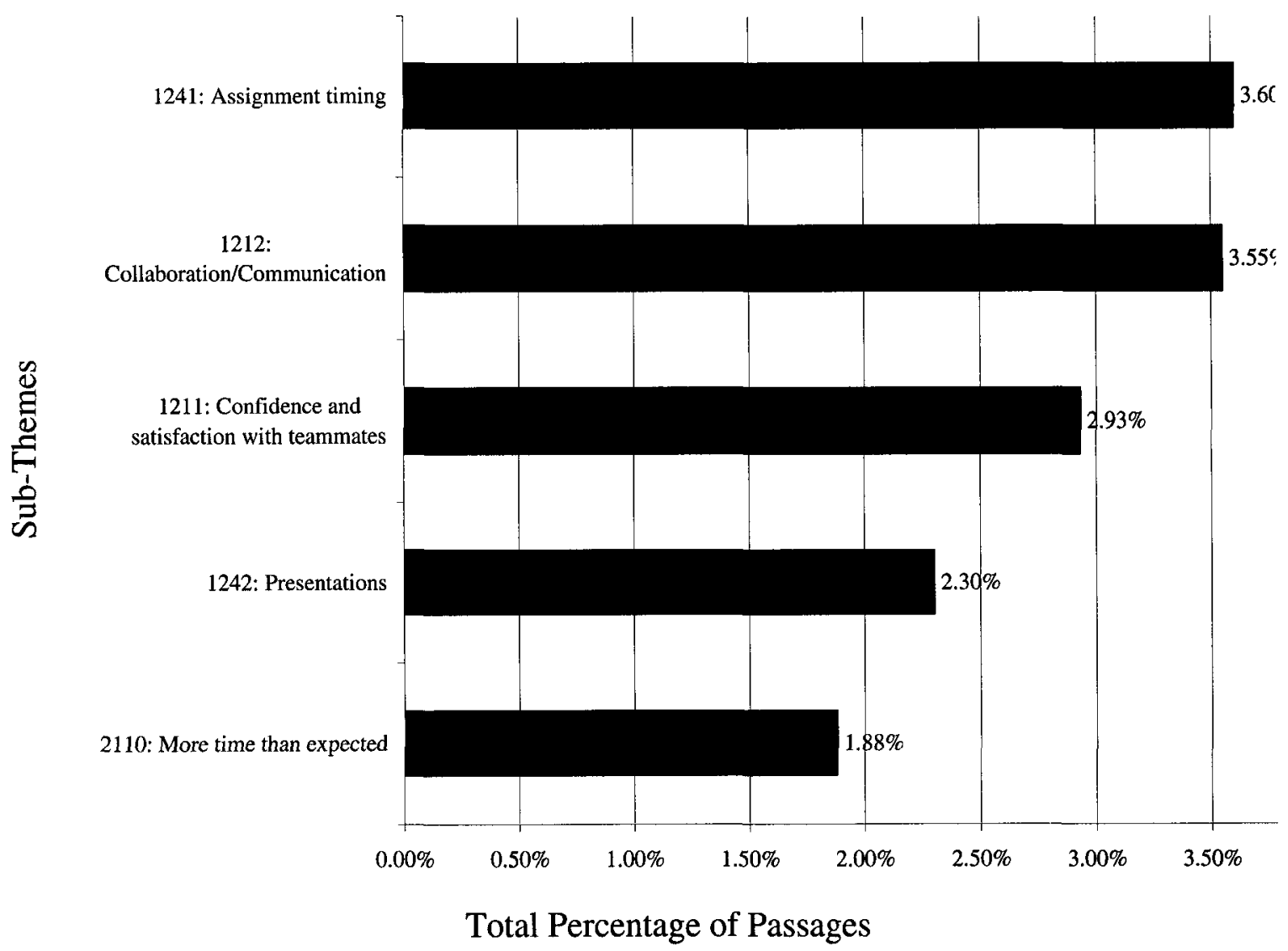


Figure 4.4 Top Five Sub-themes Coded as Weaknesses by Class

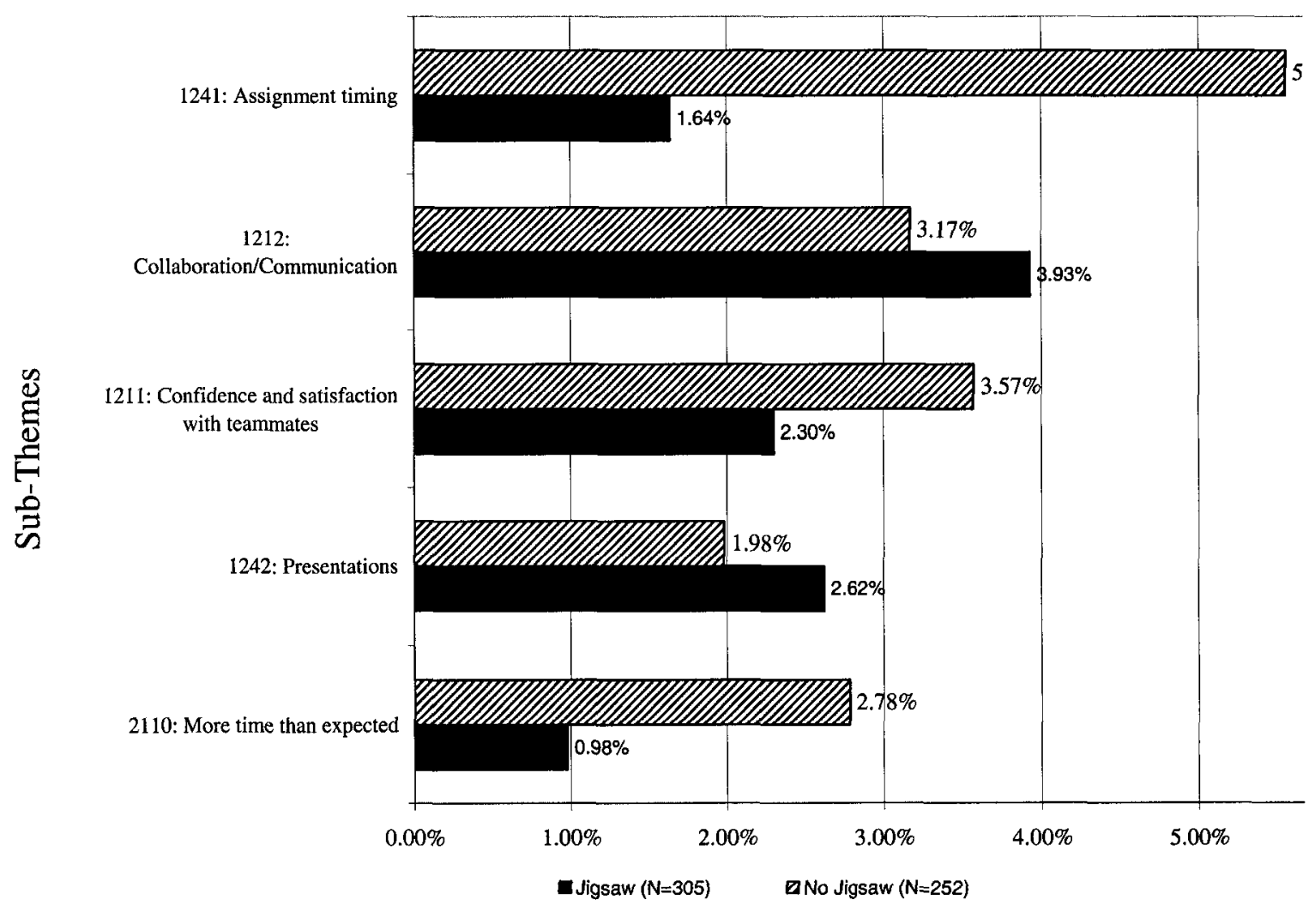

Total Percentage of Passages

Results by Research Question

Research Question \#1A: Will exposure to a role-specific Jigsaw activity within a

WebQuest produce a significantly greater increase in students' academic self-efficacy beliefs than exposure to the same WebQuest without a role-specific Jigsaw activity?

In order to examine whether the Jigsaw method significantly increased students' academic self-efficacy beliefs, the researcher used both quantitative and qualitative data from the Collaboration Rubric, student journals, and interview data. 
Quantitative Data

Tables 4.3 and 4.4 present the descriptive statistics and the analyses of variance for the total, three subscales, and the Knowledge score from the Collaboration Rubric for Self and Others. Table 4.5 presents the findings from a Chi-Square analysis comparing student's ratings of self relative to others. Each table is preceded by a brief description of the results.

Tables 4.3 and 4.4 show that the means and standard deviations for ratings of Self and Others for No Jigsaw and Jigsaw classes are similar, with students in both classes rating themselves and their teammates quite positively. On average, students in both groups consistently rated themselves higher than they rated their teammates. No statistically significant differences were found by Class. Linear regression techniques found that Class, Midterm score, the interaction of Class and Midterm score, and the interaction of Class and Grade Status were not good predictors of Collaboration Rubric outcomes for Self. 
Table 4.3 Descriptive Statistics of Collaboration Rubric for Self by Class

$$
\text { Class }
$$

Jigsaw No Jigsaw $(\mathrm{N}=44)$

$(\mathrm{N}=45)$

\begin{tabular}{|c|c|c|c|c|c|c|}
\hline & Mean & $\mathrm{SD}$ & Mean & $\mathrm{SD}$ & $F$ & $p$ \\
\hline $\begin{array}{l}\text { Contribution Total } \\
\text { (possible score 3-12) }\end{array}$ & 11.18 & 1.03 & 11.35 & 1.10 & .52 & .473 \\
\hline $\begin{array}{l}\text { Take Responsibility Total } \\
\text { (possible score } 4-16 \text { ) }\end{array}$ & 15.52 & 0.79 & 15.50 & 0.99 & .02 & .897 \\
\hline $\begin{array}{l}\text { Value Others' Viewpoint } \\
\text { Total (possible score 3-12) }\end{array}$ & 11.72 & 0.61 & 11.66 & 0.68 & .09 & .765 \\
\hline $\begin{array}{l}\text { Knowledge } \\
\text { (possible score 1-10) }\end{array}$ & 9.61 & 0.68 & 9.81 & 0.46 & .05 & .828 \\
\hline $\begin{array}{l}\text { Collaboration Rubric Total } \\
\text { (Sum of Contribution, Take } \\
\text { Responsibility, Value } \\
\text { Others' Viewpoint) } \\
\text { (possible score } 10-40 \text { ) }\end{array}$ & 38.42 & 1.97 & 38.52 & 2.21 & 2.54 & .115 \\
\hline
\end{tabular}

Table 4.4 Descriptive Statistics of Collaboration Rubric for Others by Class

Class

\begin{tabular}{|c|c|c|c|c|c|c|}
\hline & \multicolumn{2}{|c|}{$\begin{array}{l}\text { Jigsaw } \\
(\mathrm{N}=115)\end{array}$} & \multicolumn{2}{|c|}{$\begin{array}{l}\text { No Jigsaw } \\
(\mathrm{N}=126)\end{array}$} & \multirow[b]{2}{*}{$F$} & \multirow[b]{2}{*}{$\mathrm{p}$} \\
\hline & Mean & $\mathrm{SD}$ & Mean & $\mathrm{SD}$ & & \\
\hline $\begin{array}{l}\text { Contribution Total } \\
\text { (possible score 3-12) }\end{array}$ & 11.16 & 1.63 & 10.96 & 2.00 & .75 & .389 \\
\hline $\begin{array}{l}\text { Take Responsibility Total } \\
\text { (possible score 4-16) }\end{array}$ & 15.00 & 2.26 & 14.73 & 2.80 & .63 & .428 \\
\hline $\begin{array}{l}\text { Value Others' Viewpoint } \\
\text { Total (possible score 3-12) }\end{array}$ & 11.47 & 1.61 & 11.13 & 2.05 & 2.05 & .154 \\
\hline $\begin{array}{l}\text { Knowledge } \\
\text { (possible score 1-10) }\end{array}$ & 9.22 & 1.79 & 9.21 & 2.04 & 1.13 & .289 \\
\hline $\begin{array}{l}\text { Collaboration Rubric Total } \\
\text { (Sum of Contribution, Take } \\
\text { Responsibility, Value } \\
\text { Others' Viewpoint) } \\
\text { (possible score 10-40) }\end{array}$ & 37.64 & 5.10 & 36.83 & $6 . \dot{56}$ & .00 & .964 \\
\hline
\end{tabular}


As shown above Tables 4.3 and 4.4 , students across both classes consistently rated themselves higher than they rated their teammates. However, this was not the case when looking specifically at students in the Jigsaw class. Table 4.5 shows that students in the Jigsaw class were more likely to rate Self lower than Others as compared to the No Jigsaw class, though this difference was not significant.

Table 4.5 Chi-Square for Self vs. Others by Class

\section{Class}

\begin{tabular}{lcc} 
& No Jigsaw & Jigsaw \\
\hline Rated Self Lower than Others & 29 & 35 \\
Rated Self Equal or Higher than Others & 97 & 73 \\
\hline$\chi 2=2.581, \mathrm{p}=.108$ &
\end{tabular}

\section{Qualitative Data}

To investigate the Jigsaw's impact on academic self-efficacy, the researcher examined those responses that were coded according the main theme of personal agency beliefs, and sub-themes including knowledge of the topic, and academic skills. Three of the top ten sub-themes reported as strengths were related to the major theme of personal agency beliefs, including sub-themes knowledge of topic and confidence.

\section{Knowledge of the Topic}

Upon examining interview passages, the sub-theme coded sixth most frequently as a strength (4.24\%) was confidence (1110), including $6.89 \%$ of Jigsaw passages and $1.59 \%$ of No Jigsaw passages with this code. The sub-theme coded eighth most frequently as a strength (4.05\%) was knowledge of the topic (1120), including $4.92 \%$ of Jigsaw passages and 3.17\% of No Jigsaw passages with this code (see Appendix Q). 
Students in the Jigsaw class frequently expressed confidence about their knowledge of the WebQuest topic (i.e., AIDS), with comments that related to how much they learned, how well prepared they were for the final essay (which counted as $10 \%$ of their final course grade), and that the WebQuest experience was "educational." Several students in the No Jigsaw class also expressed confidence about their preparedness for the final essay. However, students in the Jigsaw class expressed statements about their own learning and positive academic self-efficacy beliefs more often and with more enthusiasm than those in the No Jigsaw class. The following are illustrative quotations from students:

Student \#21646: [...Regarding] the essay, I wasn't quite sure what to expect. I was pretty confident that after sitting through 12 presentations, and just from doing it in my group, I was really well prepared and I felt pretty confident that no matter what the question was, I would be able to pretty much summarize from the role, especially just utilizing what my team did [with] all that research that we all...read through as well. (1110)

Student \#24752: I'm not super worried about it...I probably shouldn't say this [but] I honestly haven't really looked at all the other people's [PowerPoint presentations that were made available via the Web], but I learned a lot just from our own group stuff ... I'm not too worried about it. (1120)

During the interview process, a theme emerged from student responses that specifically related to their confidence about going into the final essay exam. Therefore, after five interviews were completed, the researcher added a question to the interview protocol asking, "How confident were you going into the final essay?" Most of the students interviewed from the Jigsaw class, and many, though fewer, of the students interviewed from the No Jigsaw class, expressed confidence about how well prepared they felt approaching the final WebQuest essay. 
Most students in both classes said that they approached the final WebQuest essay with the belief that the essay prompt was open-ended and an "opinion" question as opposed to being more fact-based, and that there "was not one right answer." As one student from the Jigsaw class shared:

Student \#21646: The [essay] question... was surprising because it was a little bit more... abstract to where it allowed you to be creative on how you would do something as opposed to a regimented [question], taking the four roles like the doctor [and others], and [asking], 'how would you help this person?' But [the essay] allowed us to apply...the knowledge of what we had learned to be creative...instead of being regimented to where sometimes you get overwhelmed by trying to recall facts and information and you know, 'oh I didn't do enough, I did too much,' but... I was pretty confident going into it. (1110)

\section{Academic Skills}

Separate from knowledge of the topic, students discussed improvements in academic skills such as presentation skills and the use of technologies (e.g., computers, the Internet, PowerPoint). The task for the WebQuest was to deliver a five to seven minute culminating presentation back to the class. Though not required, all groups chose to use PowerPoint. When asked how this class compared to other classes taken at this university, several students reported that they gained confidence related to using this electronic presentation tool (i.e., PowerPoint) through the WebQuest assignment. The following are illustrative quotations from students:

Student \#24857: I've never used PowerPoint for [a] presentation at [this university]. This is the first time PowerPoint was used...So that was pretty good, learning about that. (1130)

Student \#18493: I've never done a PowerPoint presentation. I've only given oral presentations, so I was really new to ... PowerPoint and kind of intimidated at first. But then once I found other people ... in my group who had [used PowerPoint] before and knew what was going on [I felt more confident]. (1130) 
Students reported other areas in which they felt their academic skills had been positively influenced through participation in the WebQuest project, such as being more critical of information on the Web, and enhancing their research and presentation skills, and being an effective team member. For instance, when asked, "What would you tell another student in terms of the whole group part of the WebQuest experience," one student shared that the WebQuest had bolstered her confidence in her own ability to be a "responsible" group member, noting:

Student \#29140: I would say it was a good thing. It was positive because...it gives you a chance to collaborate with your group, and you have to meet up with them on your own time and it gives you some responsibility too, when you work as a group it is a team effort, and I think it teaches a lot about that too. (1120)

Positive Experiences in the Expert Group

By design, students in the Jigsaw class participated in a WebQuest group as well as the Jigsaw group made up of "expert" students who had the same role assignments. When describing their WebQuest experience, many students made comments indicating positive academic self-efficacy beliefs that related to participating in the expert group. The following are illustrative quotes from students in the Jigsaw class:

Student \#21646: When we met in ... our expert groups, it was really cool to be able to say, 'well I'm on this page, I found this article,' and then someone would say, 'great ...could you email it to me?' And so we were able to just swap information back and forth. So, I think ...it added a lot of conversation that sometimes you don't know how to fuel, or you don't know how to become an expert in certain things...I liked working in [the] expert group because I found that a lot of people had found a lot of other websites and other links and other information [so that] we were able to start swapping the information back and forth and really adding to the knowledge that we were getting... but then bring it all back to the group and talk about it. (1213)

Student \#20878: When we got together as the specific doctor groups, I had a lot of information. I felt like I had more than I needed, which is really 
interesting, [because] that is not always me...So I was overly prepared, but that was really nice. (1110)

Interview data revealed that some students in the No Jigsaw benefited from what could be considered ad hoc expert groups with students outside their WebQuest group, some of whom had the same role or city, in order to discuss the deliverables and share Web sites and resources. As one student explained:

Student \#18493: I talked to [other students with my same role and asked], did you see anything that had to do with, did you notice anything, and that's when I got a couple clues from them. And then I just started checking out [the resources they gave me], and so as we worked better or more as a group, I think, it was better for me personally because it gave me feedback and [gave me] the information from them, and I could bounce stuff off of them and they were really supportive and helpful. They weren't real stingy with their work. (1213)

Research Question \#1B: Will exposure to a role-specific Jigsaw activity within a WebQuest produce significantly more positive context beliefs than exposure to the same WebQuest without a role-specific Jigsaw activity?

In order to examine whether the Jigsaw method significantly increased students' context beliefs, the researcher used both quantitative and qualitative data from the Collaboration Rubric, student journals, and interview data.

\section{Quantitative Data}

As described earlier, scores on the Collaboration Rubric for Others were used as a measure of students' context beliefs, and more specifically, their beliefs about the collective efficacy of their group. Table 4.4, presents the descriptive statistics and the analyses of variance for the total, three subscales, and the Knowledge score from the Collaboration Rubric for Self and Others. As you can see in Table 4.4, the means and standard deviations for ratings of Others for No Jigsaw and Jigsaw classes are similar, 
with students in both classes rating themselves and their teammates quite positively. While mean scores for students in the Jigsaw class were consistently higher than those for the No Jigsaw class on every subscale, no significant differences were found by Class. Linear regression techniques found that Class, Midterm score, the interaction of Class and Midterm score, and the interaction of Class and Grade Status were not good predictors of Collaboration Rubric outcomes for Others.

\section{Qualitative Data}

To investigate the Jigsaw's impact on collective-efficacy, the open-ended questions from the weekly journals were used to examine the quality of group interaction, and to compare students' perceptions of their actual versus ideal group experiences, for which a significant difference was found by Class. Next, the researcher referred to those responses from the interviews that were coded according the main theme of context beliefs and sub-theme confidence with group work (1212).

\section{Group Collaboration and Communication}

Upon examining interview passages, three of the top five codes that were used most frequently to identify students' positive experiences were related to the quality of interaction with their teammates for both classes, as shown in Figure 4.1. The sub-theme coded most frequently as a strength $(12.04 \%)$ was "group collaboration / communication," (1212) including $15.74 \%$ of Jigsaw passages and $8.33 \%$ of No Jigsaw passages with this code. The following are illustrative quotations from students:

Student \#29410: I would say [the group experience] was a good thing. It was positive because...it was random assignments so we met other people...It gives you a chance to collaborate with your group, and you have to meet up with them on your own time and [it] gives you some responsibility too, when you work as a group which is a team effort and I think it teaches a lot about that too. (1212) 
Student \#24411: By meeting in group, like I said before, sharing information, you kind of tend to learn much faster from a peer than, this is my perspective, than from the professor because the professor sometimes you know, goes off, tries to answer other questions, kind of goes off the subject. (1212)

Conversely, this same sub-theme, (group collaboration / communication), was coded also second most frequently as a weakness $(3.55 \%)$ including $3.93 \%$ of Jigsaw passages and $3.17 \%$ of No Jigsaw passages with this code.

Student \# 19026: [We should have] met more often, kept in better contact with each other. The only time we really talked about it, [was in] the class period, and then the day before it was due...We really didn't keep the lines of communication open. We kind of just expected everyone to do what they were supposed to do. (1212)

The students from the Jigsaw class appeared much more confident about their group, with almost double the number of passages coded as a strength, and with three out of the ten people interviewed mentioning that the WebQuest was the "best group experience ever." In fact, one student interviewed from the Jigsaw class said, "as far as the group projects... I liked this one better than any one I've ever done." There were no superlative comments resembling these during the interviews with the No Jigsaw class. Whereas students from the No Jigsaw class were also generally happy with their group experience, none of them described it as the "best ever."

Research Question \#2A: Do students exposed to a role-specific Jigsaw activity within a WebQuest report more time on task (i.e., in-class and outside of class in terms of individual time and group time) than students exposed to the same WebQuest without a role-specific Jigsaw activity? 
In order to identify whether the Jigsaw made a difference in students' self-report of time spent working on the WebQuest task outside of class, the researcher used both quantitative and qualitative data from three weekly time sheets, student journals, and interview data.

\section{Quantitative Data}

Table 4.6 presents the descriptive statistics and the analyses of variance for each weekly time sheet. Tables 4.8 and 4.9 present the linear association between Class, Grade Status, Midterm Score, GS340, WebQuest Prior, Units, and time on task outcomes.

Tables 4.10 and 4.11 present the linear association between Class, Midterm Score, GS340 and time on task outcomes. Each table is preceded by a brief description of the results.

Table 4.6 shows that weekly measures of time on task are similar for the No Jigsaw and Jigsaw classes, with no significant differences by Class. Students in both classes reported an increase in time on task from week one through week three. Over the three weeks that students could have worked on the WebQuest assignment, on average, students in the No Jigsaw class spent a total of 19.28 hours outside of class on the WebQuest, and students in the Jigsaw class spent 19.09 hours.

Table 4.6 Weekly Time on Task by Class in Hours

$$
\text { Class }
$$

\begin{tabular}{lcccccc} 
& \multicolumn{2}{c}{$\begin{array}{c}\text { Jigsaw } \\
(\mathrm{N}=115)\end{array}$} & $\begin{array}{c}\text { No Jigsaw } \\
(\mathrm{N}=126)\end{array}$ & & \\
\cline { 2 - 5 } & Mean & SD & Mean & SD & F & p \\
\hline $\begin{array}{l}\text { Week 1 } \\
\text { (pre-Jigsaw) }\end{array}$ & 3.65 & 2.64 & 4.14 & 2.50 & .72 & .399 \\
$\begin{array}{l}\text { Week 2 } \\
\text { (pre-Jigsaw) }\end{array}$ & 5.25 & 4.27 & 4.92 & 4.04 & .12 & .728 \\
$\begin{array}{l}\text { Week 3 } \\
\text { (post-Jigsaw) }\end{array}$ & 10.19 & 6.04 & 10.22 & 6.17 & .00 & .986
\end{tabular}


Because there was a significant difference in Midterm score by Class, the researcher performed an analysis of covariance for each of the weekly time on task dependent measures using class as the independent variable and Midterm score as the covariate. A significant difference was found by Class for time on task in week three, as shown in Table 4.7.

Table 4.7 ANCOVA for Week 3 Time on Task by Class Co-varying for Midterm Score

\begin{tabular}{lccccc} 
& Sum of Squares & df & $\begin{array}{c}\text { Mean } \\
\text { Square }\end{array}$ & F & p \\
\hline Corrected & 239.73 & 2 & 119.87 & 4.68 & .013 \\
Model & 460.85 & 1 & 460.85 & 17.98 & .000 \\
Intercept & 182.69 & 1 & 182.69 & 7.13 & .010 \\
Midterm score & 122.82 & 1 & 122.82 & 4.79 & .033 \\
Class &
\end{tabular}

a. R Squared $=.141$ (Adjusted R Squared $=.111$ )

The researcher used linear regression techniques on post-Jigsaw time on task data to examine the effect of other independent variables including: Grade Status; prior experience with the content (GS340); prior experience with the WebQuest; and total number of Units, (see Table 4.8). The researcher found that Class, Grade Status, Midterm Score, WebQuest Prior, GS340, and Units were not good predictors of time on task post-Jigsaw $(\mathrm{F}=2.183, \mathrm{p}=.061)$. However, as can be seen in Table 4.9, a statistically significant association was found between Class and post-Jigsaw time on task $(t=-2.252$, $\mathrm{p}=.029)$ and Midterm Score and post-Jigsaw time on task $(\mathrm{t}=-2.511, \mathrm{p}=.015)$. 
Table 4.8 Model 1 Predicting Time on Task post-Jigsaw (N=55)

\begin{tabular}{|l|l|l|l|}
\hline $\mathrm{R}$ & R Square & $\mathrm{F}$ & $\mathrm{p}$ \\
\hline $.463(\mathrm{a})$ & .214 & 2.183 & $.061(\mathrm{a})$ \\
\hline
\end{tabular}

(a) Predictors: (Constant), \# Units, Class, WebQuest Prior, Grade Status, GS340, Midterm Score

Table 4.9 Model 1 Coefficients of Variables Predicting Time on Task post-Jigsaw

\begin{tabular}{lccc} 
& \multicolumn{2}{c}{$\begin{array}{c}\text { Standardized } \\
\text { Coefficients }\end{array}$} & \\
\cline { 2 - 3 } & Beta & $\mathrm{t}$ & $\mathrm{p}$ \\
\hline (Constant) & & 3.823 & .000 \\
Class & -.306 & -2.252 & .029 \\
Grade Status & .035 & .267 & .790 \\
Midterm Score & -.339 & -2.511 & .015 \\
GS340 & -.200 & -1.505 & .139 \\
WebQuest Prior & -.034 & -.252 & .802 \\
\# Units & -.002 & -.018 & .986 \\
\hline
\end{tabular}

Next, a restricted model was calculated to predict post-Jigsaw time on task using Class and Midterm as fixed independent factors. In addition, though not significant in the first model, GS340 (prior experience with similar content) was included in the restricted model because the $t$ value was less than $-1(t=-1.505, p=.139)$, and therefore contributed to increase the goodness of fit of the model. The results of the restricted model are presented in Table 4.10 and 4.14.

Model 2 indicated that Class, Midterm Score, and GS340 were significant predictors of time on task post-Jigsaw $(\mathrm{F}=4.917, \mathrm{p}=.004)$. The best fitting model produced an R-square of .208. That is, the goodness of fit of this model indicates that $21 \%$ percent of total variation in time on task post-Jigsaw can be explained by Class $(\mathrm{p}=.031)$, Midterm score $(\mathrm{p}=.005)$, and GS340 $(\mathrm{p}=.033)$. 
Table 4.10 Model 2 Predicting Time on Task post-Jigsaw

\begin{tabular}{|l|l|l|l|}
\hline R & R Square & F & p \\
\hline $.457(\mathrm{a})$ & .208 & 4.917 & .004 \\
\hline
\end{tabular}

(a) Predictors: (Constant), Class, GS340, Midterm Score

Table 4.11 Model 2 Coefficients of Variables Predicting Time on Task post-Jigsaw

\begin{tabular}{lccc} 
& \multicolumn{2}{c}{$\begin{array}{c}\text { Standardized } \\
\text { Coefficients }\end{array}$} & \\
\cline { 2 - 2 } & Beta & $\mathrm{t}$ & $\mathrm{p}$ \\
\hline (Constant) & & 4.703 & .000 \\
Class & -.275 & -2.219 & .031 \\
Midterm Score & -.367 & -2.946 & .005 \\
GS340 & -.261 & -2.186 & .033 \\
\hline
\end{tabular}

As described earlier, when calculating the analyses of variance for time on task for weeks one, two, and three, there was no significant difference by Class. However, when controlling for Midterm Score and whether or not the student had prior experience with the content (GS340), Class was significant in post-Jigsaw time on task, as shown in the restricted model below using unstandardized coefficients:

Time on task post-Jigsaw (week 3$)=30.672-2.930$ CLASS $($ Jigsaw=1 $)-$

\section{.216MIDTERM - 3.895GS340(YES=1)}

The final model may be interpreted as follows:

- students in the Jigsaw class spent 2.93 fewer hours in week three than students in the No Jigsaw class, holding midterm score and prior experience (GS340) constant;

- for every extra point on the midterm, students spent .216 fewer hours in week three, holding class and prior experience (GS340) constant; 
- students who had prior experience with the content (taken course GS340) spent 3.895 fewer hours in week three than students who had no prior experience, holding class and midterm score constant.

For example, using this model to predict time on task in week three, a student who was in the Jigsaw class, and had taken GS340, and received a 90 on the midterm likely spent 4.41 hours outside of class on the WebQuest. Whereas a student who was in the No Jigsaw class and had not taken GS340, and received a score of 90 on the midterm likely spent 11.23 hours outside of class on the WebQuest.

Based on the restricted model, when controlling for midterm score and whether or not the student had taken another course focusing on same the content domain (i.e., completed the course GS340 "Confronting AIDS"), this model indicates that the Jigsaw decreased the amount of time students spent working on the WebQuest outside of class by several hours. The effect of the Jigsaw on time spent was stronger than the effect of having taken GS340, as shown by the standardized coefficients in Table 4.11.

\section{Qualitative Data}

To further explore the amount of time that students reported working on the WebQuest outside of class, and to determine the extent to which the Jigsaw had affected time on task, the researcher examined the interview and journal data. In the journal, students responded to two open-ended items that asked students what they would tell a new student about their experiences with the WebQuest, and whether they had any other comments about their WebQuest experience over the previous seven days. One question from the interview protocol asked students how much time they spent working on the WebQuest. These items, along with the rest of the interview questions, were analyzed 
and coded. To examine time on task, the researcher referred to those responses that were coded according the main theme of student engagement, and sub-themes including time on task, more time than expected and less time than expected.

More Time than Expected

Upon examining interview passages, the sub-theme coded fifth most frequently as a weakness (1.68\%) was more time than expected (2110) including $0.98 \%$ of Jigsaw passages and $2.78 \%$ of No Jigsaw passages with this code, as shown in Figure 4.2. As this data indicates, few students from either class voiced concern that the WebQuest assignment required more time than expected, and there was no clear difference by Class. When asked about the likelihood of choosing another class with a WebQuest, a couple of students remarked:

Student \#18493: I would be skeptical at first of choosing the Web Quest because...I would see it as extra work on top of the whole class.

Student \#15589: If I was going to be overloaded with courses, I would pick the one without the Web Quest. But, if I knew that the Web Quest was replacing a test, or like an essay or something, I would take it.

Upon further examination of the interview passages, there seemed to be a trend that indicated that students from both classes who were assigned a city outside the United States, such as Cairo or St. Petersburg, found it more "time consuming" to conduct research and found it more difficult or "painful" to find the information they needed to complete the WebQuest task as compared to those students who were assigned a city within the United States. Below is a passage from a student assigned to the city Cairo, which illustrates this point.

Student \#10098: The only thing that I thought was kind of difficult was the certain cities that were chosen. Like the one I had, where there were only a couple links to get information from, so... I know that a lot of the other cities had many links, like San Diego or San Francisco, and there 
were only one or two for our city... It was kind of a pain to have to go and search for different [web-based resources]. (1224)

\section{Less Time than Expected}

One person from each class made comments during the interviews that were coded under the sub-theme indicating that the WebQuest took less time than expected (2120). Some students assigned to cities within the United States reported having ample time for research and that finding information was "easy." For instance, one student from the Jigsaw class, assigned the city of San Diego, was asked to talk about how much time she spent working on the WebQuest. Her response follows:

Student \#26783: It was easy because [the fictitious person in the WebQuest assignment scenario] was [from] San Diego, so... there is a lot of resources, where as I don't know about [places such as] Cairo or other places that might have been harder to find. But I found a lot of information through the Internet and... I didn't think it was hard at all... to find what I was looking for... So it didn't take me that long to really establish my part of the group. (2120)

A student from the No Jigsaw class who was assigned the city of San Diego responded to the same question by saying, "I pretty much did all my work on the Internet... It really didn't take me that long to get the information I needed." It is clear that both of these students were able to readily obtain the Web-based information they needed to complete their portion of the WebQuest task.

Another observation made by the researcher based on the interview data was that time on task, or difficulty of the time spent on task, may have also been related to the relationship between a student's WebQuest assigned role (e.g., doctor, historian) and their declared major of study. For example, one student assigned the role of psychologist who happened to be a psychology major said: "Being a psychology major, I had access to 
a lot of books and a lot of websites and stuff like that, so I think on my part, it was a little bit easier just because of that."

In summary, the qualitative data did not reveal any major differences in time on task as a result of the Jigsaw. However, the quantitative data showed that time on task could be predicted by instructional method (i.e. No Jigsaw or Jigsaw class), with students who were exposed to the Jigsaw spending less time on task when holding midterm score and prior experience with the content constant.

Research Question \#2B: How is the quality of interaction with teammates, as reported in student journals, affected by exposure to a role-specific Jigsaw activity within a WebQuest as compared to students exposed to the same WebQuest without a rolespecific Jigsaw activity?

In order to identify whether the Jigsaw made a difference in students' perceptions about the quality of interaction with their teammates, the researcher used both quantitative and qualitative data from the Collaboration Rubric, student journals, and interview data.

\section{Quantitative Data}

Table 4.12 presents the descriptive statistics and the analyses of variance for each of nine items of the Group Work subscale for week three (post-Jigsaw). Table 4.13 presents the descriptive statistics and the analyses of variance for the totals of the Group Work subscale for weeks one and two (pre-Jigsaw) and week three (post-Jigsaw), and for change scores from week one to three and from week two to three. Each table is preceded by a brief description of the results. 
The means and standard deviations for the No Jigsaw and Jigsaw classes are similar, with students in both classes rating their group work experience positively postJigsaw. It is noteworthy that when rating their teammates' effort relative to their own, students in both classes reported that they rarely put forth more effort than others in their groups. No statistically significant differences were found for Group Work satisfaction post-Jigsaw by Class.

Table 4.12 Group Work post-Jigsaw by Class

$$
\text { Class }
$$

\begin{tabular}{|c|c|c|c|c|c|c|}
\hline & \multicolumn{2}{|c|}{$\begin{array}{l}\text { Jigsaw } \\
(\mathrm{N}=45)\end{array}$} & \multicolumn{2}{|c|}{$\begin{array}{l}\text { No Jigsaw } \\
(\mathrm{N}=44)\end{array}$} & \multirow[b]{2}{*}{$\mathrm{F}$} & \multirow[b]{2}{*}{$\mathrm{p}$} \\
\hline & Mean & $\mathrm{SD}$ & Mean & SD & & \\
\hline $\begin{array}{l}\text { Group raised interesting ideas } \\
\text { (possible score } 1-5 \text { ) }\end{array}$ & 3.50 & 1.11 & 3.29 & 0.98 & .81 & .370 \\
\hline $\begin{array}{l}\text { Challenging questions were raised in group } \\
\text { discussions } \\
\text { (possible score 1-5) }\end{array}$ & 3.17 & 0.96 & 3.05 & 0.92 & .33 & .570 \\
\hline $\begin{array}{l}\text { Group stimulated me to discuss new ideas. } \\
\text { (possible score 1-5) }\end{array}$ & 3.60 & 0.98 & 3.39 & 0.94 & .93 & .338 \\
\hline $\begin{array}{l}\text { I put forth more effort than others in my group. } \\
\text { (possible score 1-5) }\end{array}$ & 2.59 & 1.04 & 2.93 & 1.19 & 1.90 & .172 \\
\hline $\begin{array}{l}\text { Everyone in the group participates. } \\
\text { (possible score 1-5) }\end{array}$ & 4.21 & 1.02 & 3.80 & 1.28 & 2.57 & .113 \\
\hline $\begin{array}{l}\text { We try to make each other feel good. } \\
\text { (possible score } 1-5 \text { ) }\end{array}$ & 3.86 & 1.04 & 3.71 & 1.12 & .39 & .532 \\
\hline $\begin{array}{l}\text { We are able to talk and say what we think. } \\
\text { (possible score } 1-5 \text { ) }\end{array}$ & 4.36 & 1.00 & 4.03 & 1.25 & 1.76 & .188 \\
\hline $\begin{array}{l}\text { We try to listen and pay attention to each other. } \\
\text { (possible score } 1-5 \text { ) }\end{array}$ & 4.24 & 0.85 & 4.10 & 0.87 & .53 & .470 \\
\hline $\begin{array}{l}\text { It doesn't seem like one person is talking most } \\
\text { of the time. } \\
\text { (possible score } 1-5 \text { ) }\end{array}$ & 3.79 & 1.02 & 3.97 & 0.77 & .86 & .356 \\
\hline
\end{tabular}

Over time, students in both classes reported greater satisfaction with their group work experience, as indicated by the increase in mean scores from week to week. For the week one to week three change scores, there was a similar yet modest increase in group 
work satisfaction for both classes. For the week two to week three change scores, both classes showed a positive change in group work satisfaction. Despite only modest increases post-Jigsaw, the change score for the Jigsaw class was three times more positive than that of the No Jigsaw class. No statistically significant differences were found for Group Work satisfaction totals or change scores by Class.

Table 4.13 Groupwork Subscale Totals and Change Scores

\section{Class}

$\begin{array}{cc}\text { Jigsaw } & \text { No Jigsaw } \\ (\mathrm{N}=45) & (\mathrm{N}=44)\end{array}$

\begin{tabular}{lcccccc} 
& Mean & SD & Mean & SD & F & p \\
\hline $\begin{array}{l}\text { Group Work subscale total, Week 1 } \\
\text { (possible score 9-45) }\end{array}$ & 32.53 & 4.83 & 30.45 & 7.71 & 2.05 & .156 \\
$\begin{array}{l}\text { Group Work subscale total, Week 2 } \\
\text { (possible score 9-45) }\end{array}$ & 32.67 & 4.12 & 31.91 & 3.69 & .64 & .426 \\
$\begin{array}{l}\text { Group Work subscale total, Week 3 } \\
\text { (possible score 9-45) }\end{array}$ & 33.27 & 4.13 & 32.26 & 4.33 & 1.14 & .289 \\
$\begin{array}{l}\text { Group Work subscale total, Week 3 minus } \\
\text { Week 1 }\end{array}$ & 0.97 & 5.29 & 1.08 & 6.57 & .01 & .937 \\
$\begin{array}{l}\text { Group Work subscale total, Week 3 minus } \\
\text { Teek 2 }\end{array}$ & 1.17 & 3.01 & 0.39 & 4.68 & .59 & .446
\end{tabular}

Week 2

\section{Qualitative Data}

When the interview data was examined, three of the top ten sub-themes reported as strengths were related to the major theme of group experience for both classes. Another group sub-theme in the top-ten related to students' perception that their group experience seemed more of an individual effort than a group effort. Finally, the subtheme related to expert groups was examined. 


\section{Confidence and Satisfaction with Group Members}

The sub-theme coded third most frequently (5.27\%) was "confidence and satisfaction with group members," (1211) including $4.59 \%$ of Jigsaw passages and $5.95 \%$ of No Jigsaw passages with this code. The following are illustrative quotations from students:

Student \#10098: I knew that each of [my teammates] would do the work they needed to do because when we first met they were...pretty active in looking through the different websites and interested in finding statistics and different things. But it was also kind of a break from what we would normally do in that class. Our group was into it. They thought it was fun. (1211)

Student \#19360: I was fortunate enough to be in a group where everybody did their share... we worked well together... we were able to all participate. (1211)

This same sub-theme, confidence and satisfaction with group members, was also coded third most frequently (2.93\%) as a weakness, including $2.30 \%$ of Jigsaw passages and $3.57 \%$ of No Jigsaw passages with this code. One area of dissatisfaction was due to having a group member who did not contribute equally to the team effort. For example, when asked, "What advice would you give another student if they were going to be doing a WebQuest," one student responded, "just be careful that you get a good group." Other students said:

Student \#19026: Because of the group dynamics it was frustrating. I had one group mate who totally dropped the ball and didn't do anything, so I ended up being a doctor and then half of the historian.

Student \#15882: There's always the danger of having somebody who is not going to perform their tasks, not only up to a level that you might expect for yourself, but also sometimes not at all." 
In some of those cases, students' dissatisfaction was mitigated by having the opportunity to rate their teammates' effort using the Collaboration Rubric. As one student stated:

Student \#15581: I liked [having the opportunity to rate my teammates], because I scored [one teammate] low in some things because she bossed us around but she never did any of her work on time. And I liked that because it gave me a little bit of power over the whole situation, [since] I'm not a person who's going to go tattle to the teacher about something like that. It's good to at least empower you with [the opportunity to use the Collaboration Rubric], and I know for a fact that other people in my group did the same thing. (1244)

Both classes felt confident in their team members, but the Jigsaw class was more likely to speak favorably about their teammates. For instance, ten out of ten of the interviewees from the Jigsaw class made positive comments about their group members' effort, whereas only eight out of ten of the interviewees from the No Jigsaw class made positive comments about their group members' effort.

\section{Current Group Experience versus Ideal Group Experience}

In the weekly journals, students responded to the questions, "What one word would you use to describe your group experience over the last seven days," and "What one word would you use to describe how you would like your group experience to be?" The researcher looked at the difference between students' opinion of their current group experience versus their opinion of how they wish their group experience would be for week three journal data by Class. One-word responses for both items were coded as neutral, negative, or positive. The difference between the two was then coded as negative to positive, or positive to positive for the Chi-Square analysis in Table 4.14. Neutral 
scores and the single instance of a positive to negative change were ignored for this analysis.

This Chi-Square analysis revealed a significant difference $(\mathrm{p}=.037)$ by Class. The No Jigsaw class was significantly more likely to use a negative word to describe their group experience during week three, including the following: hell, frustrating, nervewracking, hectic, useless, non-existent, inconvenient, hard work, long, and time consuming. However, students from the No Jigsaw class also used positive words such as good, great, influential, educational, working together, fun, fantastic, team, cooperative, and interesting.

Table 4.14 Current Group Experience versus Ideal Group Experience Post-Jigsaw by $\underline{\text { Class }}$

\section{Class}

\begin{tabular}{lcc} 
& No Jigsaw & Jigsaw \\
\hline Negative / Positive & 20 & 9 \\
Positive / Positive & 16 & 21 \\
Negative/ Negative & 2 & 2 \\
\hline
\end{tabular}

$\chi^{2}=4.338, \mathrm{p}=.037$

\section{Individual Aspect and Effort}

Another group sub-theme in the top ten $(3.10 \%)$ related to students' perception that their group experience seemed more of an individual effort than a group effort (1249), including $2.62 \%$ of Jigsaw passages and $3.57 \%$ of No Jigsaw passages with this code. One student commented:

Student \#10098: I think that our group worked pretty well. We did most of the work aside from the time we spent in class, most of the work was done individually...And then we just put our information together at the end, so we didn't really work as a group a whole lot outside of class. It was mostly just individual research. (1249) 
While some students saw this as a strength, others saw this as a weakness, as the

following quotation illustrates:

Student \#19360: The Web Quest limited you because it was individual work. You were looking for the information [yourself], versus a standard class [in which]...you learn about the material from the course material that the teacher gives you [including] the notes or the book or whatever, and then you discuss it and the teacher lectures on what they think is important to note or what...they know the facts are versus doing the work yourself on the Internet, not knowing if it's right, not knowing if that's exactly what they're looking for. So [the WebQuest] is very independent versus a growing experience where the teacher is bringing up points that you didn't think about before. (1249)

\section{Satisfaction with Expert Groups}

The sub-theme coded tenth most frequently (2.96\%) was "expert group," (1213)

including $3.93 \%$ of Jigsaw passages and $1.98 \%$ of No Jigsaw passages with this code.

Student \#25172: It was a good experience because it was almost like there were five people doing your work for you. So it was like everyone was giving a little piece of what they had found. (1213)

Student \#29140: Well, I thought it was very interesting, informative too because not only did I get my viewpoint at a psychologist, but I also got my other [expert group members'] viewpoint... I thought it was a lot better [than an individual assignment because] I think with the groups you got more interaction. [The groups] were helpful too, because I had a few questions on how I was going to approach something, and they answered it for me and it was the same [affirming my approach]. So I think it was a good idea that we did groups. And I thought it was also good that [other groups in the class were studying] different people from different countries and different [backgrounds and circumstances]. So I think that was interesting. (1213)

Two students were not pleased with their expert group experiences. One student felt that none of the people in her expert group were prepared for their meeting, and added that she herself had procrastinated and was not prepared either. The other student felt that there was a lack of collaboration in the expert group, or that she was not included in the information exchange that was taking place. She shared the following comment: 
Student \#28866: [The expert group] wasn't productive at all. A lot of [the experts] were [interacting] amongst each other, [saying], 'oh, check this out.' [The expert group] wasn't helpful at all. I just spent time looking at stuff myself...nobody was trading any information. I'd ask a question, [and] it would be kind of hard to get something out of anybody...It kind of was a waste of time.... They just kind of looked up something themselves or they would talk to their friend [saying]. 'oh, I found this, write this down, and look at this.' [There] wasn't really as much interaction as I thought [there] would be. (1213)

Research Question \#2C: How is students' satisfaction with the experience affected by exposure to a role-specific Jigsaw activity within a WebQuest as compared to students exposed to the same WebQuest without a role-specific Jigsaw activity?

As another measure of student engagement, and in order to examine how the Jigsaw affected students' overall satisfaction with the WebQuest learning experience, the researcher used both quantitative and qualitative data from the three weekly journals, interview data, instructor case notes and researcher case notes.

\section{Quantitative Data}

Table 4.15 presents the descriptive statistics and the analyses of variance for each of five items of the WebQuest Satisfaction subscale for week three (post-Jigsaw). Table 4.16 presents the descriptive statistics and the analyses of variance for the totals of the WebQuest Satisfaction subscale for weeks one and two (pre-Jigsaw) and week three (post-Jigsaw), and for change scores from week one to three and from week two to three. Each table is preceded by a brief description of the results.

Post-Jigsaw, the means and standard deviations for the No Jigsaw and Jigsaw classes are similar, with students in both classes rating their satisfaction with the WebQuest experience mostly positively (Table 4.15). Mean scores were slightly negative on the items that asked whether the WebQuest was "too time-consuming," and 
whether it felt like "busy work." There were no significant differences for the WebQuest satisfaction total score and most of the items. However, the No Jigsaw class reported significantly more satisfaction with their access to the necessary technology $[F(1,81)=4.65, p=.034]$. Though not statistically significant, there was a trend in which the No Jigsaw class reported more frustration with the WebQuest ( $\mathrm{p}=.097)$. Because there was a significant difference in technology access, the researcher controlled for technology access by using linear regression techniques, and found no significant difference in post-Jigsaw WebQuest satisfaction by Class.

This Chi-Square analysis revealed a significant difference $(\mathrm{p}=.037)$ by Class. The No Jigsaw class was significantly more likely to use a negative word to describe their group experience during week three, including the following: hell, frustrating, nervewracking, hectic, useless, non-existent, inconvenient, hard work, long, and time consuming. However, students from the No Jigsaw class also used positive words such as good, great, influential, educational, working together, fun, fantastic, team, cooperative, and interesting. 
Table 4.15 WebQuest Satisfaction post-Jigsaw by Class

\section{Class}

\begin{tabular}{|c|c|c|c|c|c|c|}
\hline & \multicolumn{2}{|c|}{$\begin{array}{l}\text { Jigsaw } \\
(\mathrm{N}=45)\end{array}$} & \multicolumn{2}{|c|}{$\begin{array}{c}\text { No Jigsaw } \\
(\mathrm{N}=44)\end{array}$} & \multirow[b]{2}{*}{$\mathrm{F}$} & \multirow[b]{2}{*}{$p$} \\
\hline & Mean & SD & Mean & $\mathrm{SD}$ & & \\
\hline $\begin{array}{l}\text { The WebQuest was interesting. } \\
\text { (possible score } 1-5 \text { ) }\end{array}$ & 3.76 & .726 & 3.61 & .919 & .70 & .404 \\
\hline $\begin{array}{l}\text { The WebQuest was not frustrating. } \\
\text { (possible score } 1-5 \text { ) }\end{array}$ & 3.52 & .804 & 3.17 & 1.09 & 2.82 & .097 \\
\hline $\begin{array}{l}\text { I had easy access to equipment and technology } \\
\text { I needed. } \\
\text { (possible score } 1-5 \text { ) }\end{array}$ & 4.07 & .808 & 4.44 & .743 & 4.65 & .034 \\
\hline $\begin{array}{l}\text { The WebQuest was not too time-consuming. } \\
\text { (possible score } 1-5 \text { ) }\end{array}$ & 2.90 & .958 & 2.85 & 1.12 & .06 & .812 \\
\hline $\begin{array}{l}\text { The WebQuest did not feel like busy work. } \\
\text { (possible score } 1-5 \text { ) }\end{array}$ & 2.74 & .990 & 2.78 & 1.09 & .03 & .873 \\
\hline
\end{tabular}

Students in the Jigsaw class reported higher satisfaction in all three weeks as compared to students in the No Jigsaw class, as presented in Table 4.16. When looking at the scores over time, there was a decrease in satisfaction from week one to week two, and an increase from week two to week three for both classes. For the week one to week three change scores, there was a modest decrease in WebQuest satisfaction for both classes, with the change score for the Jigsaw class eight times more negative than that of the No Jigsaw class. For the week two to week three change scores, both classes showed a small positive change in WebQuest satisfaction. Despite only modest increases post-Jigsaw from week two to week three, the change score for the Jigsaw class was ten times more positive than that of the No Jigsaw class. There were no statistically significant differences for weekly WebQuest Satisfaction scores or change scores by Class. 
Table 4.16 WebQuest Satisfaction Totals and Change Scores by Class

\section{Class}

\begin{tabular}{|c|c|c|c|c|c|c|}
\hline & \multicolumn{2}{|c|}{$\begin{array}{l}\text { Jigsaw } \\
(N=45)\end{array}$} & \multicolumn{2}{|c|}{$\begin{array}{c}\text { No Jigsaw } \\
(\mathrm{N}=44)\end{array}$} & \multirow[b]{2}{*}{$\mathrm{F}$} & \multirow[b]{2}{*}{$\mathrm{p}$} \\
\hline & Mean & SD & Mean & SD & & \\
\hline $\begin{array}{l}\text { WebQuest Satisfaction } \\
\text { subscale total, Week } 1 \\
\text { (possible score } 5 \text { - 25) }\end{array}$ & 17.63 & 2.79 & 16.95 & 4.03 & .76 & .387 \\
\hline $\begin{array}{l}\text { WebQuest Satisfaction } \\
\text { subscale total, Week } 2 \\
\text { (possible score } 5 \text { - 25) }\end{array}$ & 16.77 & 2.98 & 16.49 & 3.35 & .16 & .687 \\
\hline $\begin{array}{l}\text { WebQuest Satisfaction } \\
\text { subscale total, Week } 3 \\
\text { (possible score } 5 \text { - 25) }\end{array}$ & 17.00 & 2.43 & 16.85 & 3.37 & .05 & .817 \\
\hline $\begin{array}{l}\text { WebQuest Satisfaction } \\
\text { subscale total, Week } 3 \\
\text { minus Week } 1\end{array}$ & -.89 & 2.70 & -.11 & 3.91 & 1.03 & .313 \\
\hline $\begin{array}{l}\text { WebQuest Satisfaction } \\
\text { subscale total, Week } 3 \\
\text { minus Week } 2\end{array}$ & .56 & 2.75 & .05 & 2.42 & .75 & .389 \\
\hline
\end{tabular}

Qualitative Data

Figure 4.1, presented earlier, was sorted by top strengths, which can be considered to contribute to student satisfaction with the WebQuest experience. Figure 4.3 is sorted by top weaknesses, which can be considered to contribute to student dissatisfaction with the WebQuest experience. No sub-themes stood out as either an overwhelming strength or weakness. Furthermore, several sub-themes were mentioned by interviewees as both a strength and a weakness, for instance "group collaboration / communication" (1212), "WebQuest structure" (1221), and "learning challenge / difficulty" (1246). Table 4.17 presents the findings from a Chi-Square analysis comparing passages coded as either strengths or weaknesses by Class. The Chi-Square analysis revealed a significant difference $(\mathrm{p}<.025)$ by Class. The Jigsaw class had a 
significantly larger percentage of passages coded as strength and fewer passages coded as weaknesses as compared to the No Jigsaw class.

Table 4.17 Chi-Square for Interview Passages Coded as Strength and Weakness by Class

\section{Class}

\begin{tabular}{lcc} 
& $\begin{array}{c}\text { No Jigsaw } \\
(\mathrm{N}=252)\end{array}$ & $\begin{array}{c}\text { Jigsaw } \\
(\mathrm{N}=305)\end{array}$ \\
\hline Strengths & $67.06 \%$ & $81.31 \%$ \\
Weaknesses & $32.94 \%$ & $18.69 \%$ \\
\hline
\end{tabular}

$\chi^{2}=5.30, \mathrm{p}<.025$

WebQuest Structure

Upon examining interview passages, the sub-theme coded second most frequently as a strength (6.84\%) was "WebQuest structure" (1221), including 6.56\% of Jigsaw passages and $7.14 \%$ of No Jigsaw passages with this code, as shown in Figure 4.2. The following are illustrative quotations from students:

Student \#15589: I think [the WebQuest] would be a good thing to do in other classes because it gives you a very concentrated subject to think about, and when everybody's doing kind of the same subject you get a lot of different viewpoints and you get a broad range of information. (1221)

Student \#19026: I thought it was more structured [as compared to other classes]. [The WebQuest] provides you with a lot of information [about what is expected]. [The WebQuest] is kind of feeding you the information that you need in order to accomplish the task, versus most other classes wouldn't say, 'this is what you need to do, now go do it.' [Other classes] just kind of set you off and you're on your own. So [the WebQuest is] really structured and supportive. (1221)

One student commented that the WebQuest alleviated a lot of wasted time by providing quick access to useful information. She found the assignment easy because of the structure and links provided. The following quote is from a student in the Jigsaw class, but her sentiment echoes those of the majority of students interviewed from both classes. 
Student \#21646: I thought [the WebQuest] was really helpful and interesting because I've never really studied [this topic], ... so I think it provided a lot of good avenues to quickly connect as opposed to having to do a search in general and look for places to find information. It gave... the prompts. [For instance], 'if you're looking for information on this, go [to this resource].' So I thought from that aspect it alleviated a lot of wasted time. And it helped, especially ... for somebody who may not be computer knowledgeable too...So you weren't wasting time trying to figure out [where to find resources], and it's structured to where you can specifically get the answers that you were looking for. (1221)

This same sub-theme, "WebQuest structure," was also the sixth most frequently coded weakness $(1.68 \%$ ), including $0.98 \%$ of Jigsaw passages and $2.38 \%$ of No Jigsaw passages with this code. The following are illustrative quotations from students:

Student \#18671: I thought...the Web Quest itself...was good, but in a way I think it needed to be a little bit more structured on making people do some work throughout the time because...I'm a procrastinator, and I didn't really do any work the first couple of weeks... Maybe instead of just telling us to go home and work, and then meet with groups, and then go home and work, and then maybe meet with groups... [I think it would be better] having to set a specific goal, like deadlines for certain parts of it. And then [we would be required to] turn in a paragraph [detailing] what I looked up instead of just turning in a little piece of paper that has a couple notches on it [about time spent on task]. [That way], it's a little bit more work, but I think it actually would make people focus. (1221)

One of the aspects of the WebQuest structure that was frequently reported as a weakness was the format of the culminating group presentations. Several students complained that the allotted amount of time, five to seven minutes, was not enough to successfully present all of their material and adequately represent all of the research they had done. Another frequently reported source of dissatisfaction was the repetitiveness of the group presentations, with students having to sit through at least ten very similar presentations from other groups. The following is an illustrative quotation from one student: 
Student \#19360: I thought that [the WebQuest requirements] were very realistic except for the fact of the presentations... You were encouraged to find as much information as possible. However, when you went to do the presentation, you only had a minute and a half [per team member] to talk. And I think that the time issue really takes away from what you've learned...I understand you don't want people rambling on forever about their topic, but at the same time you can get so much more in-depth information and you can get certain feelings across to students when you're not sitting there talking a mile a minute just so you can get all your information in. (1242)

\section{Active Learning}

The sub-theme coded fourth most frequently as a strength (4.67\%) was "active learning" (1244), including $6.56 \%$ of Jigsaw passages and $2.78 \%$ of No Jigsaw passages with this code.

When asked to "describe the group aspect of the project," one student from the Jigsaw class described how the WebQuest was more active than his other general education classes, and how it helped him to develop his social skills through activities that forced meetings to take place with other students. The following are illustrative quotations from students:

Student \#12708: I liked working in a group. Usually we go [to class] and we listen to a lecture so we don't really get to interact. [With the WebQuest], being in a group, we got to meet each other and work with each other, and I thought it was a fun activity. (1244)

Student \#25172: This was a more interactive class as far as communicating with students. Usually in General Education classes you weren't expected to collaborate...you just kind of sit in class, take your notes, [and] take a test... This Web Quest project came about and you ended up collaborating with someone, which always makes it...more enjoyable... The WebQuest is a little more interactive. And not just that you gain personal skills [or] social skills, but I think it also helped my group [because] it gave us the opportunity to collaborate. (1244)

While several students enjoyed the active learning aspect, there were a few students who were not satisfied with the fact that the WebQuest required more active 
learning. When asked, "What would you tell a new student about your experience with the WebQuest over the last 7 days," one student from the No Jigsaw class responded by saying that "it was okay, but if I had a choice I would not choose to participate. I enjoy the traditional classroom environment better." This statement indicated that this student clearly preferred the traditional lecture method to more active approaches to instruction. Other students from the No Jigsaw and Jigsaw classes expressed similar feelings, but a review of the Week 3 Journal data indicated that it was more the exception for the Jigsaw class.

\section{Perceived Level of Difficulty of the WebQuest}

Passages with the sub-theme "learning challenge / difficulty" (1246) were more often considered a strength $(4.28 \%)$ rather than a weakness $(1.16 \%)$ by interviewees. Students from both classes described the WebQuest as "easy." For example, when asked, "What advice would you give another student if they were going to be doing a WebQuest," one student from the No Jigsaw class replied, "I'd tell them that it was pretty easy because all the information is kind of presented to you, you just have to sort through it." One student from the Jigsaw class responding to the same question was even more adamant about how easy he thought the WebQuest was. He said:

Student \#24411: The way it was formatted for this class it was not hard at all. It was really easy. It was really user friendly. Pretty much in my personal experience [with the WebQuest], there were no setbacks, nothing hard. It was easy, to tell you the truth, because it was specific to the point....It was working efficiently. (1246)

Another student from the Jigsaw class went so far as to say, "The WebQuest questions did a good job of explaining everything. You [would] have to be pretty stupid not to get a good grade." 
When asked, "As it relates to the WebQuest assignment, how does this class compare to other classes you've taken at SDSU," one student from the Jigsaw class responded by saying that she felt that the WebQuest was not very challenging and that this was because individual roles made it easier through the straightforward division of labor. Another student from the Jigsaw class responded to the same question by saying that it was, "Easier, compared to my other General Education classes. I would say it was definitely a better experience as far as communication with other students."

A few students perceived the WebQuest as difficult or challenging. For instance, one student felt that the WebQuest was frustrating, time-consuming, and he didn't like that it was different from his typical college class assignments, noting:

Student \# 19360: It totally changed the dynamics of the classroom because usually...you do reading and you have a class discussion about the material and what's going on in the material. [However, with the WebQuest] you are kind of left on your own to find out your own information. And the Internet is... informative, it has a lot of different [resources, but] some of them are verifiable and some of them aren't. So you don't really know what is and what isn't [credible] unless you do some more research and it can be very frustrating and time consuming if you can't find what you're looking for. (1246)

\section{WebQuest New and Different}

Another sub-theme in the top ten (4.12\%) related to students' perception that the WebQuest experience was new and different from other classroom experiences they were accustomed to (1248), including $4.26 \%$ of Jigsaw passages and $3.97 \%$ of No Jigsaw passages with this code. The following are illustrative quotations from students who saw this as strength:

Student \#24411: [This was] probably the only class that I've taken that's done the Web Quest or anything like that. So it [was a] a pretty unique class in that aspect, in regards to the way it was conducted [with the] 
group and so forth...Pretty much it's like a hands-on experience. You learn from the class without a teacher having to teach us much. (1248)

Student \#25172: [The WebQuest] was a change of pace from class. I'm the kind of person that likes to see more...I want to be able to apply what I've learned or actually do stuff to make myself motivated to do something. I don't want to sit in class for 2 hours [listening to lecture]...Nothing against [the instructor], but...sometimes it's just the change of pace from class where you look forward to come to class... [With the WebQuest], we're doing this project, it's different, it's out of the norm [rather than] going to lecture and write and write and write.

However, one student perceived this as a weakness, noting, "I would have liked to have been warned about it before hand. I'm a history major so I'm very familiar with the history classes, and [this class with the WebQuest] was really different than what I was used to."

\section{Likelihood of Participating in the Future}

During the interviews, students were asked, "what would you think about participating in another class with a WebQuest?" Nine out of ten students interviewed from each class made positive remarks about taking another class with a WebQuest. However, whereas the Jigsaw group had only one student who made a negative remark, nine out of ten students in the No Jigsaw group made negative comments about taking another class with a WebQuest. For example, some students from the No Jigsaw class had difficulty finding resources for their WebQuest project, others didn't like not being allowed to choose their own teammates, others thought the WebQuest was too time consuming or saw it as "extra work on top of the whole class," and a few students thought it should have been "more spread out throughout the semester." One student in particular from the No Jigsaw class was unhappy and felt that the WebQuest was too dissimilar from what she has come to expect in a college course, stating: 
Student \#19360: If [the WebQuest] was more standard throughout the university [and] if you could expect to have a course like that every once in a while [that would be okay, but] this was kind of a first time thing. So it was kind of different and it was kind of annoying at times...As it gets brought in and introduced into the curriculum, I'm sure that [students] would get used to it and then expect it and then it would be [more wellreceived]. (1248)

\section{Assignment timing}

The sub-theme coded most frequently $(3.60 \%)$ as a weakness was "assignment timing" (1241), including $1.64 \%$ of Jigsaw passages and $5.56 \%$ of No Jigsaw passages with this code. Some students would have preferred more time to complete the WebQuest, or that the three-weeks allotted for the WebQuest would have been spread out throughout the semester. Others said they would have preferred to have the WebQuest assignment earlier in the semester when there would have been less conflict with other final exams and assignments. One student described the WebQuest as seeming "fractured" from the rest of the course. The following are illustrative quotes from students:

Student \#12708: I found that if [the WebQuest] were put at a different time in the course it would have been a little bit less stressful and I think a lot of people in my group shared that [feeling] with me too because they had a lot of midterms going on because it was towards the end [of the semester] and everyone just felt a little rushed about it...And we just felt like because we were given a three-week period to get the research together, that maybe that wasn't enough time. (1241)

Student \#28866: The time frame that [we were given] to do [the WebQuest] wasn't [adequate.] There was so much information and so much condensing that had to go on. There was so little time, I feel, and we were just rushing, and it was right in the middle of other finals and papers that had to be done. And it was just kind of...the wrong timing and not enough time. (1241) 


\section{Instructor observations}

Table 4.18 presents the course instructor's verbatim responses in which he reflects on the class session immediately following the class. This journal entry was recorded during week two just after the Jigsaw activity, which was used in one class and not in the other.

Table 4.18 Instructor Case Notes Regarding the WebQuest Experience (Week 2)

\begin{tabular}{|l|l|}
\hline $\begin{array}{l}\text { Journal Reflection } \\
\text { Prompt }\end{array}$ & Instructor Response \\
\hline $\begin{array}{l}\text { What went well in the } \\
\text { session: }\end{array}$ & $\begin{array}{l}\text { Jigsaw: Students are taking it seriously. It's amazing to me } \\
\text { how much smoother it is this semester, [pilot test] was last } \\
\text { year, and how much less anxiety students have this semester. } \\
\text { Not a single student complained this semester. } \\
\text { No Jigsaw: It went very smoothly. Students took to their } \\
\text { roles well and took it seriously. Students were so engaged } \\
\text { that 90\% didn't take their break (unheard of!). }\end{array}$ \\
\hline $\begin{array}{l}\text { What I would have done } \\
\text { differently: }\end{array}$ & $\begin{array}{l}\text { Jigsaw: All fine. } \\
\text { No Jigsaw: Nothing. }\end{array}$ \\
\hline $\begin{array}{l}\text { What I learned about my } \\
\text { students: }\end{array}$ & $\begin{array}{l}\text { Jigsaw: They have a lot of compassion. } \\
\text { No Jigsaw: They are even more seriously engaged than I had } \\
\text { thought. }\end{array}$ \\
\hline $\begin{array}{l}\text { What I think and feel } \\
\text { about how engaged the } \\
\text { class was: }\end{array}$ & $\begin{array}{l}\text { Jigsaw: Very engaged. } \\
\text { No Jigsaw: Warm fuzzy feeling. I am very gratified. }\end{array}$ \\
\hline What questions I have: & $\begin{array}{l}\text { Jigsaw: More WebQuest in other areas of class - less lecture? } \\
\text { I am envisioning more ways to integrate WebQuest in more } \\
\text { of the classes, lessening the lecture component and assigning } \\
\text { the WebQuest to other areas of study...It also amazes me how } \\
\text { it took me two years to see how valuable a component this is } \\
\text { and how it will radically change my teaching style (I have } \\
\text { been teaching for 39 years). }\end{array}$ \\
No Jigsaw: What can I do with this next year?
\end{tabular}

Research Question \#3: Will student performance on an HIV/AIDS Semantic

Relationship Test and HIV/AIDS Relationship Judgment test, as well as writing in 
response to a final (essay) test question exhibit greater depth of understanding concerning "living with AIDS" for those students exposed to a role-specific Jigsaw activity within a WebQuest than for students exposed to the same WebQuest without a role-specific Jigsaw activity?

In order to examine whether the Jigsaw method significantly increased students' depth of understanding, the researcher used both quantitative and qualitative data from the Knowledge Check (including the Semantic Relationship and Relationship Judgment sub-scores), the final essay, student journals, and interview data.

\section{Quantitative Data}

Table 4.19 presents the descriptive statistics and the analyses of variance for the Knowledge Check total score, the Semantic Relationship and Relationship Judgment subscores, and the final essay total score. Table 4.20 presents the correlations between the Knowledge Check total, its sub-scores, and demographic variables. Tables 4.21 and 4.22 present the linear associations between Class, Grade Status, WebQuest Prior, Midterm Score, and the Semantic Relationship sub-score. Each table is preceded by a brief description of the results.

The means and standard deviations for the No Jigsaw and Jigsaw groups are similar, with students in the No Jigsaw group performing slightly better on average on all knowledge outcome measures (Table 4.19). No statistically significant differences were found for the Essay Total or the five sub-scores that comprise the total by Class. No statistically significant differences were found for the Knowledge Check total, the Semantic Relationship sub-score or the Relationship Judgment sub-score by Class. The 
only noteworthy difference was a trend for the Semantic Relationship sub-score $[F(1,84)$ $=3.815, \mathrm{p}=.054]$, with the No Jigsaw class scoring higher than the Jigsaw class. Table 4.19 Knowledge Outcomes by Class

\section{Class}

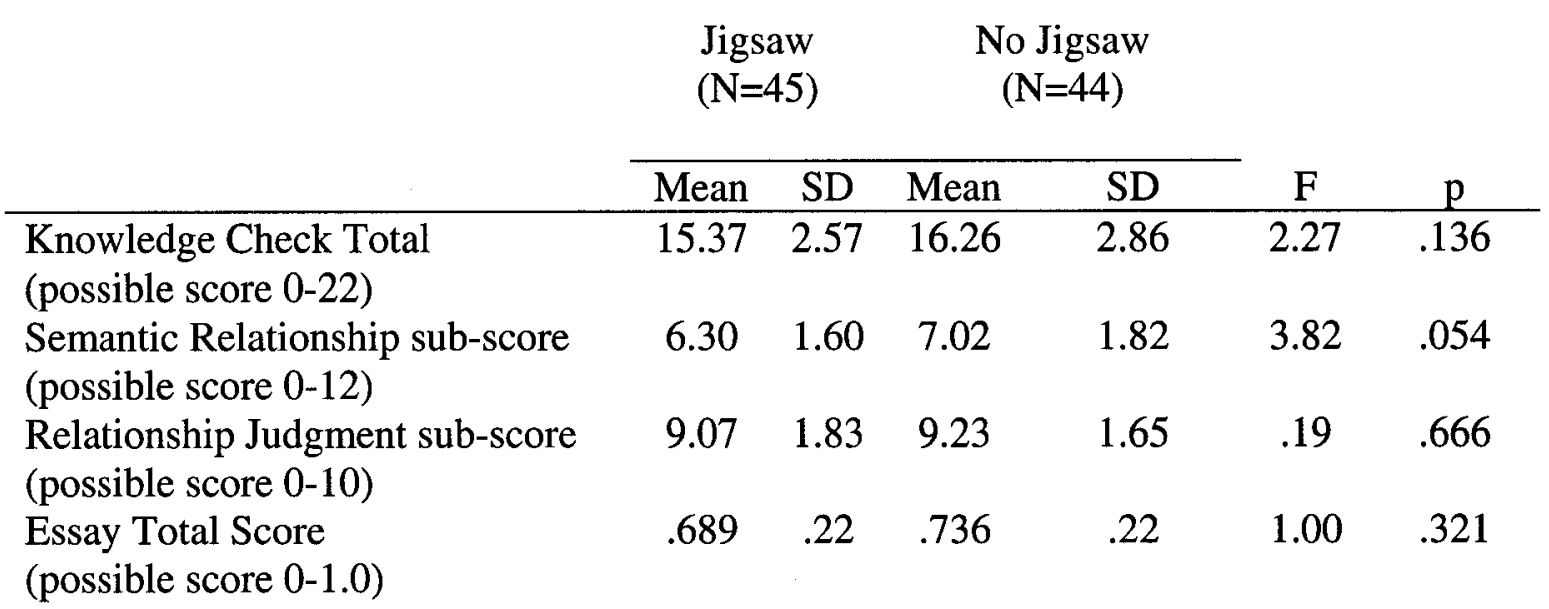

Because midterm score was significantly different by Class (as presented earlier in Table 4.2) with No Jigsaw greater than Jigsaw, the researcher wanted to control for this and other potentially confounding demographic variables. Correlations were calculated between the demographic variables and the Knowledge Check total, the Semantic Relationship sub-score, and the Relationship Judgment sub-score shown in Table 4.20.

A statistically significant correlation was found between Knowledge Check total and Midterm score ( $\mathrm{p}=.001)$, Relationship Judgment sub-score and Midterm score ( $\mathrm{p}=.000)$, Midterm score and Class ( $\mathrm{p}=.017)$, and Relationship Judgment sub-score and Grade Status $(\mathrm{p}=.031)$. Students who took the class for credit performed significantly better on the Relationship Judgment sub-scale. Students in the No Jigsaw class scored significantly higher on the Midterm. The Knowledge Check total and the Relationship Judgment sub-score were positively correlated to Midterm Score. Approaching 
significance at the .05 level, scores on the Semantic Relationship sub-scale were correlated to Class, with students in the No Jigsaw class scoring higher $(\mathrm{r}=-.208, \mathrm{p}=.054)$.

Table 4.20 Knowledge Check Correlations with Demographic Variables

\begin{tabular}{|c|c|c|c|c|c|c|}
\hline & DAY & $\begin{array}{c}\text { GRADE } \\
\text { Status }\end{array}$ & MIDTERM & GS340 & $\begin{array}{c}\text { WebQuest } \\
\text { PRIOR }\end{array}$ & UNITS \\
\hline \multicolumn{7}{|l|}{ Class } \\
\hline Grade Status & $\mathrm{ns}$ & & & & & \\
\hline $\begin{array}{l}\text { Midterm } \\
\text { Score }\end{array}$ & $-.254^{*}$ & ns & & & & \\
\hline GS340 & $\mathrm{ns}$ & $\mathrm{ns}$ & $\mathrm{ns}$ & & & \\
\hline $\begin{array}{l}\text { WebQuest } \\
\text { Prior }\end{array}$ & $\mathrm{ns}$ & ns & ns & $\mathrm{ns}$ & & \\
\hline Units & $\mathrm{ns}$ & $\mathrm{ns}$ & ns & ns & ns & \\
\hline $\begin{array}{l}\text { Knowledge } \\
\text { Check }\end{array}$ & $\mathrm{ns}$ & $\mathrm{ns}$ & $.355^{* *}$ & $\mathrm{~ns}$ & $\mathrm{~ns}$ & $\mathrm{~ns}$ \\
\hline $\begin{array}{l}\text { Semantic } \\
\text { Relationship } \\
\text { sub-score }\end{array}$ & ns & ns & ns & ns & $\mathrm{ns}$ & ns \\
\hline $\begin{array}{l}\text { Relationship } \\
\text { Judgment } \\
\text { sub-score }\end{array}$ & ns & $-.246^{*}$ & $.465^{* *}$ & $\mathrm{~ns}$ & $\mathrm{~ns}$ & $\mathrm{~ns}$ \\
\hline
\end{tabular}

$* \mathrm{p}<0.05$ level (2-tailed).

$* * \mathrm{p}<0.01$ level (2-tailed).

ANCOVA and linear regression techniques were used to determine the relative effect of Class on the Knowledge Check total and its sub-scales while controlling for Midterm score. When controlling for Midterm score, there were no statistically significant differences in the Knowledge Check total, or the Relationship Judgment subscale by Class. Though not significant, the Semantic Relationship sub-scale was the only one for which Class made a marginal difference. Therefore, linear regression techniques were used to determine the relative effect of Class and other demographic variables on the Semantic Relationship sub-scale. The best fitting model, presented in Tables 4.21 and 4.22, included Class, Grade Status, WebQuest Prior and Midterm Score, but was not a 
good predictor of the Semantic Relationship subscale $[F(4,70)=2.029, p=.091, \mathrm{R}$ square $=$ $.107]$.

Table 4.21 Model Predicting Semantic Relationship Score

\begin{tabular}{|l|l|l|l|}
\hline $\mathrm{R}$ & R Square & $\mathrm{F}$ & $\mathrm{p}$ \\
\hline $.327(\mathrm{a})$ & .107 & 2.092 & .091 \\
\hline
\end{tabular}

(a) Predictors: (Constant), Midterm Score, Grade Status, WebQuest Prior, Class

Table 4.22 Model Coefficients of Variables Predicting Semantic Relationship Score

\begin{tabular}{lccc} 
& \multicolumn{2}{c}{$\begin{array}{c}\text { Standardized } \\
\text { Coefficients }\end{array}$} & \\
\cline { 2 - 3 } & Beta & $\mathrm{t}$ & $\mathrm{p}$ \\
\hline (Constant) & & 2.218 & .030 \\
Midterm Score & -.197 & -1.695 & .094 \\
Grade Status & -.118 & -1.031 & .306 \\
WebQuest Prior & -.167 & -1.467 & .147 \\
Class & .144 & 1.246 & .217 \\
\hline
\end{tabular}

In summary, based on the quantitative data the Jigsaw made no significant difference in learning outcomes, as indicated by students' performance on the Knowledge Check and the final essay. Furthermore, results indicated that students in the No Jigsaw group performed slightly better on average than students in the Jigsaw class on the Knowledge Check total and its two sub-scales, with the difference on the Semantic Relationship sub-scale approaching significance.

\section{Learning Outcomes by Grade Status}

Table 4.23 presents the descriptive statistics and the analyses of variance for the Essay score, WebQuest Total Score, Knowledge Check total score, and the Group Presentation score by Grade Status. In terms of academic performance, the students taking the course for a letter grade significantly outperformed the students taking the course for credit on the major academic performance indicator associated with the 
WebQuest, the final essay question $(\mathrm{F}=4.079, \mathrm{p}=.047)$, and performed better on the WebQuest total project score, though not significantly. Though not statistically significant, the students taking the course for credit performed better on the group presentation $(\mathrm{F}=3.969, \mathrm{p}=.050)$ and the knowledge check $(\mathrm{F}=3.951, \mathrm{p}=.051)$, indicating a trend.

Table 4.23 Performance Outcomes by Grade Status

\section{Class}

$\begin{array}{cc}\text { Credit } & \text { Letter } \\ (\mathrm{N}=16) & (\mathrm{N}=65)\end{array}$

\begin{tabular}{lcccccc}
\cline { 2 - 5 } & Mean & SD & Mean & SD & F & p \\
\hline Essay score & .62 & .20 & .75 & .22 & 4.079 & .047 \\
WebQuest Total score & 15.70 & 2.05 & 16.78 & 2.16 & 3.64 & .060 \\
Knowledge Check score & 17.00 & 1.41 & 15.44 & 2.96 & 3.951 & .051 \\
Group Presentation score & 91.88 & 3.86 & 88.77 & 5.92 & 3.969 & .050
\end{tabular}

\section{Qualitative Data}

While the interviews and journals did not contain questions directly related to depth of understanding of the topic, some students made comments having to do with learning a great deal, or having more of a global perspective, or that their views had changed for the better due to this experience. The following are illustrative quotations from students:

Student \#18493: I learned a lot just by being around [the group and] conversing with the group. (1120)

Student \#15882: [The WebQuest] seemed to be useful to get people involved and [give them] a world perspective on HIV and AIDS.

Student \#24752: [Upon reflecting about my response to the final essay question], I think overall, my answer [to the essay question]... has been changed by this whole experience...I'm one of those [people who feels like] we have enough problems here [in the United States, and that] we need to keep our money here [in the United States]...But [the AIDS 
epidemic requires] a global picture, [and] we can't fight it [solely in the United States].

\section{Instructor's Perception of Student Academic Performance}

When asked, the instructor shared that he was disappointed by students' performance on the academic measures in both classes, including their scores on the knowledge checks, and the two essay questions as part of the final exam. The instructor was particularly surprised at how poorly the Jigsaw class performed on the non-AIDS related essay question, though they seemed better prepared (i.e., the essay that addressed material covered prior to the WebQuest "living with AIDS" assignment). He went on to say that the timing of the exam may have had something to do with the Jigsaw students' mediocre performance. In his opinion, because students in the No Jigsaw class took their final on the Monday of finals week, they were presumably "fresher," whereas students in the Jigsaw class took their final on Wednesday, in the middle of finals week.

\section{Summary of Findings}

This chapter presents the results of data analyses and findings from the sample of 89 students from two undergraduate history classes, with class as the unit of analysis. Both quantitative and qualitative analyses were used to examine the ways in which the Jigsaw affected students' personal agency beliefs, engagement, and learning. Interviews with 10 students from each class were analyzed and coded as strengths or weaknesses and categorized according to major themes and sub-themes that corresponded with the three driving research questions using constant comparative analysis. Quantitative data was analyzed using analyses of variance, chi-square, and linear regression techniques. The results revealed: 
- no significant differences by Class in demographic and academic variables including Gender, Grade Status, WebQuest Prior, GS430, Major College, and Units;

- a significant difference by Class in Midterm Score, with the No Jigsaw class having higher scores;

- a statistically significant difference by Grade Status in Essay score, with students taking the course for a letter grade scoring higher;

- a statistically significant positive correlation between Midterm Score and Knowledge Check total, Midterm Score and Relationship Judgment sub-score;

- a statistically significant positive correlation between Grade Status and Relationship Judgment sub-score.

- no significant differences by Class in academic self-efficacy as measured by quantitative data from the Collaboration Rubric for self;

- no significant differences by Class in context beliefs as measured by quantitative data from the Collaboration Rubric for others;

- no statistically significant differences by Class in weekly Time on Task as measured by quantitative data from the weekly time sheets;

- a statistically significant difference by Class in Time on Task post-Jigsaw when controlling for Midterm Score and GS340, with the Jigsaw class spending significantly less time on task post-Jigsaw;

- a significant difference by Class for quality of interaction with teammates as measured by qualitative data from the student journals comparing current group experience versus ideal group experience post-Jigsaw, with the No Jigsaw class significantly more likely to use a negative word to describe their group experience; 
- no statistically significant differences by Class for quality of interaction with teammates as measured by quantitative data from the Group Work sub-scale totals and change scores from the student journals;

- a significant difference in perceived strengths and weakness with the WebQuest experience by Class as measured by qualitative data from the student interviews, with the Jigsaw class reporting more strengths and fewer weaknesses than the No Jigsaw class;

- a statistically significant difference by Class for satisfaction with access to technology as measured by quantitative data from the student journals, with students in the No Jigsaw class having great satisfaction with access to technology;

- no statistically significant difference by Class for satisfaction with the WebQuest experience as measured by quantitative data from the WebQuest Satisfaction subscale totals and change scores from the student journals;

- qualitative differences between classes in satisfaction with the WebQuest experience as indicated by comparing positive and negative student remarks, with students in the Jigsaw class sharing more positive and fewer negative remarks;

- no statistically significant difference by Class for learning outcomes as measured by quantitative data from the Knowledge Check total, Semantic Relationship sub-score, Relationship Judgment sub-score, and Essay; 


\section{CHAPTER V: DISCUSSION}

Typically, the spread of new instructional approaches that use technologies is often propelled more by anecdotal praise than by data. This study helps practitioners (teachers, instructional designers, school leaders, resource specialists, and the larger educational technology professional community of practice) make research-based judgments as to the effectiveness and efficiency of different WebQuest design strategies that embrace cooperative learning techniques.

The purpose of this study was to develop understanding of WebQuests that use cooperative learning techniques by measuring the impact of such strategies on students' personal agency beliefs, engagement, and learning. Once these strategies are understood, it may be possible to help practitioners design, develop and implement WebQuest activities that maximize positive cooperative learning elements and limit the negatives. The research also raises issues that may not have been previously addressed in the literature.

This chapter is organized around the three major research questions which address personal agency beliefs, student engagement, and learning outcomes.

Overview of Major Findings

Quantitative data yielded significant results in two areas: changes in students' perceptions of the WebQuest group work process and changes in the amount of time students reported working on the WebQuest task. These results are intriguing because of their relationship to student engagement and personal agency beliefs which in turn affect effort and achievement. Qualitative data revealed differences between classes in 
satisfaction with the WebQuest experience, perceptions of the group experience, and academic self-efficacy beliefs.

\section{Conclusions and Implications}

Conclusions and recommendations are based on the convergence of information from different sources of evidence, not on qualitative or quantitative data alone. Given the authentic classroom setting in which this study took place the results are promising for educators interested in effective WebQuest design strategies.

$$
\text { Personal Agency Beliefs }
$$

\section{Academic Self-Efficacy}

One measure of academic self-efficacy in this study included students' confidence regarding their individual contribution to the group. Researchers have found that when reporting confidence, students have a tendency to overestimate the amount and quality of their individual contribution to a group product (Linblom-Ylanne, Pihlajamaki, \& Kotkas, 2003; Staudinger, 1996). This appeared to be the case in the current study, with students in both classes rating their individual contributions to the group quite positively, a factor which may have contributed to the lack of significant differences between classes. However, students in the Jigsaw class rated their individual contribution to the group lower than that of their teammates on the Collaboration Rubric. One explanation for this difference may be that exposure to other student expert opinions made the students in the Jigsaw class more aware of just how much information was available in addition to what they had found on their own. Thus, when they compared their own knowledge to that of the other student experts, students may have realized how little they actually knew about the topic and their role in the WebQuest group. 
Conversely, the qualitative data appears to indicate that the Jigsaw was successful in positively impacting the academic self-efficacy beliefs held by the students, with students in the Jigsaw class sharing positive comments more frequently than students in the No Jigsaw class. Based on the qualitative data, rather than the student expert groups having a negative effect on confidence, a rival hypothesis would suggest that the "expert" relationships had a confidence-building effect within the Jigsaw class. Perhaps the students exposed to the Jigsaw were afforded the opportunity for greater elaboration of content, allowing more meaningful, in-depth processing to occur (Anderson, 2000), as well as validation of their own ideas as they exchanged resources and shared information with their fellow student experts.

Though the qualitative and quantitative data seem to present opposing results regarding the effect of the Jigsaw, these findings are consistent with aspects of Motivational Systems Theory. The fact that students in the Jigsaw class rated their individual contributions lower than those of their teammates could be seen as an indication of modest personal agency beliefs (i.e., placing a moderate estimate on one's abilities). Such beliefs are ideal for learning contexts because self is regarded as fallible, and the context is seen as a source of strength (Ford, 1992). This belief pattern can effectively be the "green light" a learner needs to embrace the cooperative notion that "I can get by with a little help from my friends" (p. 135), which would support the qualitative findings that suggest the Jigsaw positively impacted academic self-efficacy beliefs.

Another measure of academic self-efficacy in this study included students' confidence regarding knowledge of topic. Students in both classes were confident in their 
preparation for the final essay question, and expressed many positive statements about how much they learned through the WebQuest experience. During the course of the interviews, several students expressed the belief that the final essay was simply an "opinion question" with "no one right answer," and, therefore, was not very difficult. This belief could have also added to students' confidence that they would perform well on the final WebQuest essay.

While students in both classes reported confidence about their performance on the final essay, students in the No Jigsaw class were more likely to report lower confidence than those in the Jigsaw class. This could be related to the fact that the No Jigsaw students were also more likely to report a bad WebQuest group experience during the week of the presentations, which could have left them feeling ill-prepared.

After five student interviews were completed, one new question emerged as a result of student remarks about confidence going into the final essay. Therefore, only the remaining fifteen interviewees were asked the question, "How confident did you feel going into the essay?" The first five interviewees who did not receive this question specifically were all from the No Jigsaw group, which may have confounded the findings.

\section{Context beliefs}

One measure of context beliefs in this study was collective efficacy, or students' beliefs about the nature and quality of their group work experiences. The means and standard deviations on the Collaboration Rubric for others were similar for the No Jigsaw and Jigsaw classes, with students in both classes rating their teammates and group work experience quite positively. In addition, there were no significant differences by Class, 
which would imply that the Jigsaw had no significant impact on confidence regarding the group work experience. However, the extremely high mean scores may have contributed to the lack of significant differences between classes. The extremely high mean scores may be attributed to students over-estimating their teammates' contributions, or students being in a hurry to complete the Collaboration Rubric, marking "all fours" instead of putting forth much effort into their ratings. In their 2001 study, Hanrahan \& Isaacs reported that it is difficult for students to be objective when rating peers. According to their findings, there is a tendency for students to over-inflate their estimates of others, and to not take the process of peer rating seriously.

\section{Student Engagement}

\section{Group work satisfaction}

One measure of student engagement in this study included satisfaction with the group work experience. Based on the Group Work subscale of the weekly journals, students in both classes rated their group work experience positively post-Jigsaw, with no statistically significant differences by Class. For both classes, satisfaction with the group experience increased over the three-week period of the WebQuest. When rating their teammates' effort relative to their own, students in both classes reported that they rarely put forth more effort than others in their groups, which would further support the idea that students in both classes were satisfied with their group work experiences.

Another measure of group work satisfaction was a qualitative item asking students to compare their current group experience versus ideal group experience postJigsaw. Satisfaction is associated with an individual's belief that things are going well and that the task is within the limits of competency (Bandura, 1986), which facilitates 
engagement by the maintenance of positive personal agency beliefs (Ford, 1992). According to Martin Ford's Motivational Systems Theory (1992) and D. Ford's Living Systems Framework (1987), satisfaction is the primary emotional component necessary for achievement, competence, and learning. When comparing satisfaction by Class, a significant difference was found, with the No Jigsaw class significantly more likely to use a negative word to describe their group experience. These findings suggest that the Jigsaw method had a positive effect on students' group work satisfaction. This may be an indicator of deeper levels of student engagement and more positive academic selfefficacy for students in the Jigsaw class. On the contrary, for students in the No Jigsaw class, undergoing a negative group experience may have led to decreases in engagement which could have had a detrimental effect on academic self-efficacy going into the final essay.

When examining the qualitative data for indications of the nature and quality of group work satisfaction, two notable exceptions stood out. For the majority of students in the Jigsaw class, the expert group experience was seen positively. However, some students were not satisfied with their expert group experience. In such cases, it seemed that there was interaction and information exchange happening within the expert group, but the particular individual was not included in that interchange.

Another notable exception emerged indicating that at least one student from each class perceived the group experience as individualistic rather than cooperative. For instance, one student interviewed from the No Jigsaw class believed the WebQuest project was primarily an individual effort, and that it was too "independent" for her liking. This student also expressed a strong preference for a more traditional lecture 
approach, with definitive answers from the instructor, and said that she was not comfortable with the ambiguity of the task

Time on task

Another measure of engagement included the amount of time students spent working on the WebQuest outside of class. Weekly measures of time on task showed similar mean totals for the No Jigsaw and Jigsaw classes, with students in both classes reporting an increase in time on task from week one through week three. Quantitative measures revealed that there was no significant difference in time on task by Class. Because there was a significant difference in Midterm score by Class, the researcher performed an analysis of covariance to account for the effect of Midterm score on time on task, and found a significant difference by Class in week three, with students in the Jigsaw spending significantly less time on task post-Jigsaw when controlling for Midterm Score. Linear regression also revealed a significant difference when controlling for Midterm Score and GS340 (i.e., prior experience with similar content). The restricted model predicting time on task post-Jigsaw (Time) is presented below, using unstandardized coefficients:

Time $=30.672-2.930$ Class $($ Jigsaw $=1 ;$ No Jigsaw $=0)-.216$ Midterm $3.895 \mathrm{GS} 340(\mathrm{Yes}=1 ; \mathrm{No}=0$ )

The final model may be interpreted as follows: Students in the Jigsaw class spent 2.93 fewer hours in week three than students in the No Jigsaw class, holding midterm score and prior experience (GS340) constant; For every extra point on the midterm, students spent .216 fewer hours in week three, holding class and prior experience (GS340) constant; Students who had prior experience with the content (taken course 
GS340) spent 3.895 fewer hours in week three than students who had no prior experience, holding class and midterm score constant. For example, using this model to predict time on task in week three, a student who was in the Jigsaw class, and has taken GS340, and received a 90 on the midterm likely spent 4.41 hours outside of class on the WebQuest. A student who was in the No Jigsaw class and had not taken GS340, and received a score of 90 on the midterm likely spent 11.23 hours outside of class on the WebQuest.

Using the standardized coefficients, presented in Table 4.11, the effect of the Jigsaw on time spent was slightly stronger than the effect of having taken GS 340. When controlling for midterm score and whether or not the student had taken another course focusing on same the content domain, this quantitative data appears to indicate that the Jigsaw (Class) decreased the amount of time that students spent working on the WebQuest outside of class by several hours. If time on task outside of class is a measure of engagement, then these findings would indicate that the Jigsaw actually decreased engagement. Alternatively, another plausible explanation is that students in the Jigsaw class gained so much information from participating in their expert groups that they were able to spend less time outside of class on the WebQuest in week three. This supports findings from previous research (e.g., Kagan, 1994) which suggests that the cooperative Jigsaw method is more efficient than more traditional teacher-centered instruction, as well as Aronson's position that the Jigsaw method is a "remarkably efficient way to learn" (2000, Overview section, para. 6).

Another measure of engagement included sub-themes that emerged from the qualitative data regarding time on task relative to what they had anticipated, as well as the 
level of difficulty of the task. For instance, some students felt that the WebQuest took more time than expected, while other students perceived the WebQuest as a relatively easy assignment (i.e., low level of difficulty), requiring less time than expected. As one student from the Jigsaw class said:

Student \#24411: By meeting in group [and] sharing information, you...tend to learn much faster from a peer than...from the professor. (1244)

While the quantitative data revealed differences by Class, there were no major differences in time on task as a result of the Jigsaw based on the qualitative data. Again, if time on task is a measure of engagement, the qualitative data would suggest that the Jigsaw students were no less engaged. An important study by Astin (1993) identified time on task as a critical success factor undergraduate education. Therefore, the results of this study are important to consider when examining the growing body of literature about educational technology methods.

Though there was little difference indicated by Class, there were differences in students' perception of the level of difficulty and amount of time spent on the WebQuest task which seemed to be related to the city of focus for the WebQuest assignment. For instance, there was a trend that indicated groups assigned a city outside the United States, such as Cairo or Dubai, may have found it more difficult and needed more time to conduct research and find resources for their WebQuest assignment than students who were assigned a city in the United States.

Astin (1993) posits that time on task is important in undergraduate education, and Chickering and Gamson (1994) support the idea that greater time on task is an indication of greater engagement. However, this study had mixed findings regarding time on task and engagement. When using time on task as a measure of engagement, the researcher in 
this study found that students in the Jigsaw class spent less time on task which would suggest that they were less engaged than students in the No Jigsaw class. Conversely, when examining interview and open-ended journal data, the researcher found that students in the Jigsaw class were more engaged and achieved similar learning outcomes in less time. Therefore, this researcher suggests that time on task is a complex concept that warrants further examination, especially as time on task relates to designing collaborative learning strategies such as the WebQuest.

\section{WebQuest satisfaction}

Another indicator of engagement in this study was students' satisfaction with the WebQuest experience as measured quantitatively by the WebQuest Satisfaction sub-scale from the weekly journals. Students in both classes were quite satisfied with the WebQuest experience, and the Jigsaw did not appear to produce a significant difference in WebQuest satisfaction. Based on the results indicating no significant differences for weekly WebQuest Satisfaction scores or change scores, it would appear that the Jigsaw had no significant impact on satisfaction with the WebQuest experience. Yet the qualitative data tells us a different story.

During the interviews, students were asked, "what would you think about participating in another class with a WebQuest?" Interview passages were coded as either being a strength or weakness, and the number of students making either positive or negative comments was tallied for each class. In addition, when examining one item from the interview that asked about taking another class with a WebQuest, both classes had nine out of ten students who made positive remarks. While the Jigsaw class had only one student who made a negative remark in response to this question, nine out of ten students 
in the No Jigsaw class made negative comments about taking another class with a WebQuest. This could be an indication that the students who participated in the Jigsaw felt more positively overall about the experience.

Another comparison was made by counting the total number of positive and negative student remarks regarding the WebQuest experience overall, based on the interview data. A Chi-square analysis revealed a significant difference by class, with students in the Jigsaw class sharing more positive and fewer negative remarks than students in the No Jigsaw. This is further evidence that the WebQuest with a Jigsaw component produced greater student satisfaction than the WebQuest alone.

Upon further examination of the qualitative data, several notable themes emerged regarding student engagement and their perceptions of the WebQuest experience. First, several students felt that the WebQuest included more active learning than they were used to in their college courses. For most, this was a positive aspect of the WebQuest. Others were not satisfied with the active learning approach, and would have preferred a more traditional lecture format, similar to other typical general education courses and the majority of this course (HIST406) in particular. For instance, when asked, "What would you tell a new student about your experience with the WebQuest over the last 7 days," one student from the No Jigsaw class responded by saying that "it was okay, but if I had a choice I would not choose to participate. I enjoy the traditional classroom environment better." This statement indicates that this student clearly preferred the traditional lecture method to more active approaches to instruction.

Some students from both classes shared negative feelings about student-centered learning, but a review of the post-Jigsaw qualitative data indicated that this was less 
prevalent in the Jigsaw class. Students in the Jigsaw class were also less likely to criticize the implementation and logistics of the WebQuest. One source of dissatisfaction included the timing or placement of the WebQuest assignment within the semester. Several students said they would have preferred the WebQuest to have happened earlier in the semester, so as not to overlap with other high-stakes course deliverables that are typically due at the end of the semester. Other students would have preferred the assignment to be spread out over a longer time-frame, allowing them to get to know their group members earlier in the semester. Another source of dissatisfaction included the random assignment of groups and roles. Many of those who were dissatisfied with the random assignment said that they had established relationships with classmates who were seated nearby at the beginning of the course, and that they felt uprooted when they were assigned to work in the WebQuest groups, which occurred late in the semester.

Another theme regarding student engagement that stood out was related to the basic structure of the WebQuest model, which was seen as a major strength of the instructional experience by students from both classes. Most students appreciated the structure provided by assigned roles with specific and associated tasks, resource links to jumpstart their individual research, web-based access to the WebQuest materials and resources anytime, anywhere, and the opportunity to present their findings back to the class in the form of an electronic presentation. However, several students complained about the fact that they were limited to a seven-minute group presentation which did not allow them to comfortably cover all the required material. Students also felt that these short group presentations began to seem similar, and thus repetitive when listening to ten group presentations in one sitting. When designing WebQuests or other collaborative 
learning projects that include a culminating group presentation, instructors may want to consider how to address these concerns. For instance, groups could be given more time, and group tasks could be assigned in such a way that each group is covering different information so that the audience experience is more interesting.

Several students enjoyed having time in class to work in their WebQuest or expert groups as opposed to having to meeting solely outside of class. One student described how having Internet resources available during the in-class group meetings added to her academic self-efficacy, as the following quotation illustrates.

Student \#21646. [Having the Internet-enabled laptops during the in-class expert group meeting] allowed you to be able to read through [the resources I had gathered] and feel confident [about] what I read, and you never had people looking at you [saying], 'are you sure you're on the right [track],' because you can show them right then and there too... That made a huge difference...so I didn't feel like I was the weak link of the group [because] I couldn't meet them... and so by having the resources [in class] it was really easy. (1110)

The researcher examined how Grade Status might have affected student engagement. One reason to look at Grade Status is because some students said that this factor influenced their class effort. One student from the Jigsaw class said that while he "made a wholehearted effort to do a good job out of respect for [the instructor] and out of respect for the group," he also shared, "I could have skipped the WebQuest and still gotten my grade. It's not going to help me because I'm credit/no credit and I've already received my points." In terms of satisfaction with the group work and with the WebQuest experience overall, students taking the course for a letter grade consistently reported higher satisfaction over time, although no significant difference was found by Grade Status. Perhaps the "letter" students expressed greater satisfaction because they had 
added motivation to engage in the experience in order to get a good grade. In short, maybe they cared more, and this might have led to greater engagement.

\section{Learning Outcomes}

\section{Cognitive outcomes}

In order to examine learning outcomes in terms of depth of understanding in the content domain, this study relied primarily on the Knowledge Check, including the Semantic Relationship sub-score and the Relationship Judgment sub-score, as well as a final essay exam. Students in both classes performed similarly on all three measures, and no statistically significant differences were found. This data would suggest that the Jigsaw had no influence on learning outcomes.

However, the data indicated that there were pre-existing differences between classes on midterm measures of learning. As shown in Table 5.1, there were significant differences in midterm scores by Class prior to the WebQuest, with students in the No Jigsaw class exhibiting a significantly higher level of understanding of the course material than students in the Jigsaw class. Significant differences in depth of understanding were no longer present after the WebQuest, as measured by the Knowledge Check and final essay. In other words, students in the Jigsaw class made cognitive gains, thereby bringing their performance nearly to the same level as students in the No Jigsaw class. Alternatively, perhaps the measures used in this study were not as sensitive in detecting the cognitive differences that were picked up in the Midterm. 
Table 5.1 Midterm Score and WebQuest Cognitive Outcomes by Class ( $\mathrm{N}=89$ )

\begin{tabular}{cc}
\hline \multicolumn{2}{c}{ Class } \\
\hline Jigsaw & No Jigsaw \\
$(\mathrm{N}=45)$ & $(\mathrm{N}=44)$
\end{tabular}

\begin{tabular}{|c|c|c|c|c|c|c|}
\hline & Mean & SD & Mean & SD & $\mathrm{F}$ & $p$ \\
\hline $\begin{array}{l}\text { Midterm Score } \\
\text { (possible score 0-100) }\end{array}$ & 83.0 & 10.2 & 87.2 & 5.1 & 5.89 & .017 \\
\hline $\begin{array}{l}\text { Knowledge Check Total } \\
\text { (possible score 0-22) }\end{array}$ & 15.37 & 2.57 & 16.26 & 2.86 & 2.27 & .136 \\
\hline $\begin{array}{l}\text { Semantic Relationship sub- } \\
\text { score } \\
\text { (possible score } 0-12 \text { ) }\end{array}$ & 6.30 & 1.60 & 7.02 & 1.82 & 3.82 & .054 \\
\hline $\begin{array}{l}\text { Relationship Judgment sub- } \\
\text { score } \\
\text { (possible score } 0-10 \text { ) }\end{array}$ & 9.07 & 1.83 & 9.23 & 1.65 & .19 & .666 \\
\hline $\begin{array}{l}\text { Essay Total Score } \\
\text { (possible score } 0-1.0 \text { ) }\end{array}$ & .689 & .22 & .736 & .22 & 1.00 & .321 \\
\hline
\end{tabular}

\section{Beliefs and attitudes}

While the qualitative data did not contain questions directly related to depth of understanding of the topic, students from both classes made comments having to do with learning a great deal, or having more of a global perspective, or that their views had changed for the better due to this experience. The instructor's comments echoed students' perspectives when he reported that in his view, students from both class exhibited a great deal of compassion and a global perspective regarding the WebQuest topic. These findings indicate that students from both classes were able to articulate a broad understanding including changes in beliefs and attitudes that went beyond the cognitive measures in place.

In summary, instructors who wish to use a WebQuest in their courses may wonder whether or not to incorporate the Jigsaw method. Findings from this study suggest that using the Jigsaw method had a positive effect on students' personal agency beliefs and 
engagement, while the evidence was less certain regarding learning outcomes. However, in light of the literature regarding motivation and learning (e.g., Ford, 1992), the Jigsaw's positive impact in the affective domain should lead to gains in achievement and learning.

Strengths and Limitations of the Study

Power of the study

According to a meta-analysis by Johnson and Johnson (1989) which compared the impact of cooperative, competitive and individualistic efforts on achievement, students in a cooperative situation performed approximately two-thirds a standard deviation above those in an individualistic situation (critical effect size $=.61$ ).

With a critical effect size of .61 , to have 99 percent power (i.e., probability of obtaining a significant result) for a 5\% one-tailed test, one would need approximately 34 subjects, or approximately 40 subjects for a two-tailed test (Kraemer \& Thiemann, 1987). Therefore, this study had a sufficient sample size, which substantiates the researcher's findings.

\section{Instrumentation}

Tables 4.3 and 4.4 showed that the ratings of Self and Others on the Collaboration Rubric were very high for both classes, with little variation in scores. This could be related to a lack of sensitivity of the instrument, which may have not picked up differences that may have been present.

\section{Interrater reliability}

Six essays (7\%), three from each class, were randomly selected for scoring by the researcher and another rater in order to determine interrater reliability before proceeding with scoring the other essays. Correlations calculated for the essay total scores resulted in 
a high inter-rater reliability $(\mathrm{r}=.961)$. This result was considered to be a strong correlation, and therefore, the 87 essays from both classes were randomly distributed so that the researcher and another rater each scored approximately half of the essays. Even though there was high interrater reliability, it was based on only seven percent of the essays. A more robust sample could have been used to enhance the reliability of the raters' scores.

\section{Contamination}

One explanation for the lack of significant differences between classes may be that some students in the No Jigsaw class formed their own ad hoc expert groups with students outside their WebQuest group, some of whom had the same role or city, in order to discuss the deliverables and share Web sites and resources. This was revealed by one of the interviewees, and could have been indicative of other student groups in the No Jigsaw class.

\section{Confounding variables}

Several independent factors may have been present which could have confounded the findings of this study. For instance, the students were not randomly assigned to classes. Rather, students self-selected whether they would register for the class scheduled on Monday or Wednesday. At the university where the study took place, priority registration is given to a subset of students that includes athletes, those for whom English is a second language, and those identified as having learning disabilities. Data on these individual factors was not collected for this study, and may have had an influence on the findings. 


\section{Historical context}

Unforeseen circumstances could have affected student's experiences, and thus distorted the findings in this study (Creswell, 1998). In this case, two obvious events occurred during the course of the case study. First, the course instructor was called away for jury duty, missing the second week of the WebQuest assignment. Secondly, and more consequential, were the Southern California wild fires of fall 2003 that burned over 3,500 homes and blackened more than 280,000 acres, killing over a dozen people and displacing hundreds of families from their homes (Associated Press, November 6, 2003). Due to the wildfires, the entire campus was closed, and classes at the university were cancelled for one week, affecting both the Jigsaw and No Jigsaw classes.

While both classes were affected by these events, it is impossible to determine the extent to which these events affected individual students within each class. For instance, there was at least one student who lost her home due to the wildfires.

Student \#15882: I had looked at the website previously to being assigned the actual work. And then when we got the assignment, the feeling from beginning to end was very much rushed, and that was my biggest problem with it. It [was] very rushed because I knew we had missed that class because of the [disastrous county-wide] fire, and then the professor had jury duty [and missed the second week of the WebQuest]. The only thing is that I would [have liked to] have a little more time than we did. And I think if it was like a normal semester it would have been fine. But again, there [are] unforeseen things that happen. (2110)

\section{External generalizability}

The students in the study were undergraduates enrolled in a humanities elective course. The results found, therefore, may not generalize to younger students or to other areas. Clearly, additional research investigating the WebQuest model is needed with different age populations and with different subject matter areas. The research findings above have clear implications for educators interested in effective WebQuest design 
strategies. However, these results are specific to the context under investigation and may not be applicable to other settings.

\section{Suggestions for Future Research}

In conclusion, the research literature on the WebQuest is sparse and it is this researcher's opinion that more empirical studies examining the model are warranted. Regrettably, the study reported here was not designed to investigate individual differences related to culture, ethnicity or gender. Hence, additional research is needed to examine the variations related to these important factors. For instance, one area for future research would include taking a more in-depth examination of the group process including individual factors that may affect collaborative work such as age, major, and preferences and expectations about teaching and learning methods (e.g. student reactions to the uncertainty that comes with ill-structured authentic, complex tasks). In order to compare the effectiveness of various WebQuest design strategies, future researchers might focus on other key components of the WebQuest, one of which is the structure provided by the assigned roles. For instance, future researchers could look at a WebQuest with and without individual roles.

In future studies, researchers who choose to use this same WebQuest could examine differences in engagement, including satisfaction and time on task, based on the city of focus for this specific WebQuest task. Furthermore, the weekly time report could include a multiple choice question asking, "How would you rate the amount of time you spent this week," with possible responses including less than I expected, about what I expected, more than I expected." In addition, researchers might include an item that asks 
students whether or not they have any first hand experience with HIV/AIDS, which might influence how personally meaningful the assignment was and, thus, affect engagement.

This study challenged the researcher to critically analyze just how much studentstudent interaction should take place within a WebQuest. And further, how much social interdependence is best for increasing students' personal agency beliefs, engagement, and learning? These questions are not easily answered, but engaging in this type of reflective dialogue is critical to the growth of the WebQuest model. It is also clear that discourse about effective (student-centered) WebQuest design strategies will benefit from the comment and critique by other researchers and educational technologists.

Finally, this study was firmly grounded in Martin Ford's Motivational Systems Theory (1992), which emphasizes the integration of different motivational constructs including goals, emotions, and personal agency beliefs. In particular, this study focused on learning goals and outcomes, and how those were affected by students' emotional arousal related to satisfaction with the learning process, as well as their beliefs about their own capabilities and confidence in their group's ability to successfully complete the WebQuest task. There is considerable research evidence that suggests satisfaction with instructional materials can enhance student motivation to learn, and that there is a strong positive relationship between motivation and achievement (e.g., NRC, 2002). This study presented findings supporting Ford's theory, such as the link between satisfaction with the learning process and positive academic self-efficacy beliefs in the Jigsaw class. Other trends that were noted in this study suggest future research that could explore the links between goal salience (e.g., major of study, grade status) and motivation and learning outcomes. 


\section{REFERENCES}

AACE. (2003, March). Society for Information Technology and Teacher Education (SITE) Annual International Conference Proceedings, Albuquerque, NM.

Abrami, P. C., Chambers, B., Poulsen, C., DeSimone, C., d'Apollonia, S., \& Howden, J. (1995). Classroom connections: Understanding and using cooperative learning. Toronto: Harcourt-Brace.

Achtenhagen, F. (2000). Reality, models and complex teaching learning environments. In J. M. Spector \& T. M. Anderson (Eds.), Integrated and holistic perspectives on learning, instruction and technology: Understanding complexity. (pp. 159-174). Boston: Kluwer Academic Publications.

AECT. (2003, October). Association for Educational Communications and Technology (AECT) Annual Conference Proceedings, Anaheim, CA.

American Heritage Dictionaries (Ed.). (2000). The American Heritage ${ }^{\circledR}$ Dictionary of the English Language, $\left(4^{\text {th }}\right.$ ed.) Houghton Mifflin Company.

Anderson, J. R. (2000). Cognitive psychology and its implications (5th ed.). New York: Worth Publishers.

Anderson, L. W., \& Krathwohl (Eds.). (2001). A taxonomy for learning, teaching, and assessing: A revision of Bloom's taxonomy of educational objectives. New York: Longman.

Aronson, E. (2000). Jigsaw classroom: Overview of the technique. Retrieved November 10, 2003, from http://www.jigsaw.org/overview.htm

Aronson, E., Blaney, N., Stephan, C., Sikes, J., \& Snapp, M. (1978). The jigsaw classroom. Beverly Hills, CA: Sage Publications. 
Aronson, E., \& Goode, E. (1980). Training teachers to implement jigsaw learning: A manual for teachers. In S. Sharan, P. Hare, C. Webb \& R. Hertz-Lazarowitz (Eds.), Cooperation in Education (pp. 47-81). Provo, UT: Brigham Young University Press.

Aronson, E., \& Patnoe, S. (1997). The jigsaw classroom: Building cooperation in the classroom (2nd ed.). New York: Addison Wesley Longman.

Associated Press (November 6, 2003). Firefight continues on SoCal blazes; death toll stands at 24. North County Times. Retrieved on April 3, 2004 from http://www.nctimes.com/articles/2003/11/07/news/top_stories/11_6_0320_17_18.txt ATPC. (2003, June). Expanding academic technology in the CSU: The report of the Academic Technology Planning Committee. Long Beach, CA: California State University.

Baldwin, J. D., Ebert-May, D., \& Burns, D. (1999). The development of a college biology self-efficacy instrument for non-majors. Science Education, 83(4), 397-408.

Bandura, A. (1969). Principles of behavior modification. New York: Holt, Rinehart \& Winston.

Bandura, A. (1986). Social foundations of thought and action: A social cognitive theory. Englewood Cliffs, NJ: Prentice Hall.

Bandura, A. (1997). Self-efficacy: The exercise of control. New York: W. H. Freeman.

Bandura, A. (2001). Social cognitive theory: An agentic perspective. Annual Review of Psychology, 52, 1-26. 
Benson, J. B. (2002). Teaching with technology and generation e. National Teaching and Learning Forum, 11(2). Retrieved August 26, 2003, from http://www.pitt.edu/AFShome/n/t/ntlforum/public/html/v11n2/.

Bloom, B. S. (1956). A taxonomy of educational objectives: Handbook 1: The cognitive domain. New York: Longmans, Green.

Brewster, C., \& Fager, J. (2000). Increasing student engagement and motivation: From time-on-task to homework. Portland, OR: Northwest Regional Educational Laboratory. Retrieved August 20, 2003, from http://www.nwrel.org/request/oct00/index.html

Brown v. Board of Educ., 347 U.S. 483 (1954).

Bruner, J. (1960). The process of education. Cambridge, MA: Harvard University Press.

Bruner, J. (1986). Actual minds, possible worlds. Cambridge, MA: Harvard University Press.

Chickering, A. W., \& Gamson, Z. F. (1994). Seven principles for good practice in undergraduate education. In K. A. Feldman \& M. B. Paulsen (Eds.), Teaching and learning in teh college classroom (pp. 255-263). Needham Heights, MA: Ginn.Clark, R. (1983). Reconsidering research on learning from media. Review of Educational Research, 53(4), 445-459.

Cohen. (1994). Designing group work: Strategies for the heterogeneous classroom. New York: Teachers College Press.

Creswell, J. W. (1998). Qualitative inquiry and research design: Choosing among the five traditions. Thousand Oaks, CA: Sage Publications. 
Csikszentmihalyi, M. (1990). Flow: The psychology of optimal experience. New York: Harper Perennial.

Denzin, N. K., \& Lincoln, Y. S. (2000). Handbook of qualitative research (2nd ed.). Thousand Oaks, CA: Sage Publications.

Dewey, J. (1924). The school and society. Chicago: University of Chicago Press.

Diekhoff, G. M. (1983). Relationship judgments in the evaluation of structural understanding. Journal of Educational Psychology, 75, 227-233.

Dodge, B. (1995). WebQuests: A technique for internet-based learning. Distance Educator, 1(2), 10-13.

Dodge, B. (1997). Some thoughts about WebQuests. Retrieved August, 26, 2002, from San Diego State University, Department of Educational Technology Web site: http://edweb.sdsu.edu/courses/edtec596/about_webquests.html

Dodge, B. (1998). The WebQuest page. Retrieved August 26, 2003, from http://webquest.sdsu.edu

Dodge, B. (2001). FOCUS: Five rules for writing a great WebQuest. Learning and Leading with Technology., 28(8), 6-9, 58.

Dodge, B. (2003a). WebQuest Portal. Retrieved Sept. 1, 2003, from http://webquest.org.

Dodge, B. (2003b, March). WebQuest symposium. Annual Conference of the Society for Information Technology and Teacher Education (SITE): Albuquerque, NM.

Ford, D. (1987). Humans as self-constructing living systems: A developmental perspective on behavior and personality. Hillsdale, NJ: Lawrence Erlbaum. 
Ford, M. (1992). Motivating humans: Goals, emotions, and personal agency beliefs. London: Sage Publications.

Ford, M., \& Ford, D. (1987). Overview of the heuristic utility of the living systems framework for guiding research and professional activities. In M. Ford \& D. Ford (Eds.), Humans as self-constructing living systems: Putting the framework to work (pp. 377-393). Hillsdale, NJ: Lawrence Erlbaum.

Fraenkel, J. R., \& Wallen, N. E. (1996). How to design and evaluate research on education (3rd ed.). New York: McGraw-Hill, Inc.

Geffner, R. A. (1978). The effects of interdependent learning on self-esteem, interethnic relations, and interethnic attitudes of elementary school children: A field experiment. Unpublished doctoral dissertation, University of California, Santa Cruz.

Geraghty, C. L. (2004). Learning (and teaching) in the technological age. SDSUniverse. Retrieved: February 3, 2004, from San Diego State University Web site: http://www.sdsuniverse.info/print.asp?id=13378.

Guba, E., \& Lincoln, Y. S. (1988). Do inquiry paradigms imply inquiry methodologies? In D. M. Fetterman (Ed.), Qualitative approaches to evaluation in education (pp. 89-115). New York: Praeger.

Hanrahan, S. J., \& Isaacs, G. (2001). Assessing self- and peer-assessment: The students' views. Higher Education Research and Development, 20(1), 53.

Hayes, J. (1996). A new framework for understanding cognition and affect in writing. In C. Levy \& S. Ransdell (Eds.), The science of writing. Mahwah, NJ: Lawrence Erlbaum Associates. 
ISTE. (2003). National Education Computing Conference (NECC) Annual Conference Proceedings, Seatlle, WA.

Johnson, D. W., \& Johnson, R. (1976). Student perceptions of and preferences for cooperative and competitive learning experiences. Perceptual and Motor Skills, 42, 989 990.

Johnson, D. W., \& Johnson, R. (1981). Effects of cooperative and individualistic learning experiences on interethnic interaction. Journal of Educational Psychology, 73, 444-449.

Johnson, D. W., \& Johnson, R. (1989). Cooperation and competition: Theory and research (3rd ed.). Edina, MN: Interaction Book Co.

Johnson, D. W., \& Johnson, R. (1994). Cooperative learning in the classroom. Alexandria, VA: Association for Supervision and Curriculum Development.

Johnson, D. W., Johnson, R., \& Holubec, E. (1992). Advanced cooperative learning. Edina, MN: Interaction Book Company.

Johnson, D. W., Johnson, R., \& Smith, K. (1998). Active learning: Cooperation in the college classroom. Edina, MN: Interaction Book Company.

Johnson, D. W., Maruyama, G., Johnson, R., Nelson, D., \& Skon, L. (1981). Effects of cooperative, competitive and individualistic goal structures on achievement: A meta-analysis. Psychological Bulletin, 89, 47-63.

Jonassen, D. (1999). Designing constructivist learning environments. In C. M. Reigeluth (Ed.), Instructional-design theories and models: A new paradigm of instruction theory (Vol. II, pp. 215-239). New Jersey: Lawrence Erlbaum Associates. 
Jonassen, D., Beissner, K., \& Yacci, M. (1993). Structural knowledge techniques for representing, conveying, and acquiring structural knowledge. Hillsdale, $\mathrm{NJ}$ : Lawrence Erlbaum Associates.

Jonassen, D.H., Howland, J., Moore, J., \& Marra, R.M. (2003) Learning to solve problems with technology: A constructivist perspective, 2nd. Ed. Columbus, $\mathrm{OH}$ : Merrill/Prentice-Hall.

Jonassen, D.H., \& Wang, S. (1993). Acquiring structural knowledge from semantically structured hypertext. Journal of Computer Based Instruction, 20(1), 1-8.

Kagan, S. (1994). Cooperative Learning. San Juan Capistrano, CA: Kagan Cooperative Learning.

Keller, J.M. (1983). Motivational design of instruction. In C. M. Reigeluth (ed.) Instructional Theories and Models: An Overview of Their Current Status (pp. 383-434). NY: Lawrence Erlbaum Associates.

Kortecamp, K., \& Bartoshesky, A. (2003, March 24-29). WebQuest: An instructional tool that engages adult learners, promotes higher level thinking and deepens content knowledge. Annual Conference of the Society for Information Technology and Teacher Education (SITE): Albuquerque, NM.

Lexico Publishing Group, L. (2004). Dictionary.com. Retrieved August 20, 2003, from http://dictionary.reference.com/.

Linblom-Ylanne, S., Pihlajamaki, H., \& Kotkas, T. (2003). What makes a student group successful? Student-student and student-teacher interaction in a problem-based learning environment. Learning Environments Research, 6(1), 59-76. 
Logan, K. R., \& Keefe, E. B. (1997). A comparison of instructional context, teacher behavior, and engaged behavior for students with severe disabilities in general education and self-contained elementary classrooms. JASH, 22, 16-27.

Malone, T. W., \& Lepper, M. K. (1987). Making learning fun: A taxonomy of intrinsic motivation for learning. In R. E. Snow \& M. J. Farr (Eds.), Aptitude Learning and Instruction, Cognitive and Affective Process Analysis, Vol. 3 (pp. 223-253). Hillsdale, NJ: Lawrence Erlbaum.

Menchaca, M., \& Vicker, B. (2003). Scaffolding WebQuest creation for experienced teachers. Annual Conference of the Society for Information Technology and Teacher Education (SITE): Albuquerque, NM.

March, T. (1998). OzLine: Helping educators work the web. Retrieved August 26, 2003, from http://ozline.com/

March, T. (2003, December/January). The learning power of WebQuests. Educational Leadership, (60), 42-47.

Marchionini, G. (1999). Educating responsible citizens in the information society. Educational Technology, 39(2), 17-26.

Marzano, R. J., Pickering, D. J., \& Pollock, J. E. (2001). Classroom instruction that works: Research-based strategies for increasing student achievement. Alexandria, VA: Association for Supervision and Curriculum Development.

Merriam, S. (1988). Case study research in education: A qualitative approach. San Francisco: Jossey-Bass.

Millis, B. J. (2002). Enhancing learning and more through cooperative learning (Paper \#38). Kansas State University, IDEA Center. 
Monroe, \& Orme. (2003). The nature of discourse as students collaborate on a mathematics WebQuest. National Educational Computing Conference, 2003, Seattle, WA.

National Commission on Excellence in Education. (1983). A nation at risk: The imperative for educational reform. Washington, DC: U.S. Department of Education. Retrieved June 20, 2002, from http://www.ed.gov/pubs/NatAtRisk/index.html.

National Research Council (2002). Enhancing undergraduate learning with information technology: A workshop summary (M. Hilton, Ed.). Washington, DC: National Academy Press.

National Survey of Student Engagement (2000). The NSSE 2000 Report: National benchmarks of effective educational practice.Bloomington, IN: Indiana University Center for Postsecondary Research and Planning.

SBC. (2004). Knowledge Network Explorer. Retrieved Jan. 15, 2004, from http://www.kn.pacbell.com.

Pajares, F. (2002). Overview of social cognitive theory and of self-efficacy. Retrieved May, 12, 2002, from the Emory Web site: http://www.emory.edu/EDUCATION/mfp/eff.html.

Palloff, R., \& Pratt, K. (1999). Building learning communities in Cyberspace. San Francisco: Jossey-Bass.

Peterson, C.L., Caverly, D.C., \& MacDonald, L. (2003). Developing academic literacy through WebQuests. Journal of Developmental Education, 26(3), 38-39.

Piaget, J. (1954). The construction of reality in the child. (M. Cook, Trans.). New York: Basic Books. 
Piaget, J. (1971). The construction of reality by the child. New York: Ballantine.

Pintrich, P. R., \& DeGroot, E. V. (1990). Motivational and self-regulated learning components of classroom academic performance. Journal of Educational Psychology, 82, $33-40$.

Prensky, M. (2002). The motivation of game play: Or the REAL 21 st century learning revolution. On The Horizon, 10(1), 14.

Shavelson, R. J. (1972). Some aspects of the correspondence between contentstructure and cognitive structure in physics education. Journal of Educational Psychology, 63(3), 225-234.

Slavin, R., Sharan, S., Kagan, S., Lazarowitz, R. H., Webb, L., \& Schmuck, R. (1985). Learning to cooperate, cooperating to learn. New York: Plenum Press.

Slavin, R. E. (1983). Cooperative learning. New York: Longman.

Solomon, G. (2003). Project-based learning: A primer. Technology and Learning, $23(6), 20-26$.

Stake, R.E. (1995). The art of case study research. Thousand Oaks, CA: Sage Publications.

Stake, R. E. (2000). Case studies. In N. K. Denzin \& Y. S. Lincoln (Eds.), Handbook of qualitative research (2nd ed., pp. 435-454). Thousand Oaks, CA: Sage Publications.

Staudinger, U. (1996). Wisdom and the social-interactive foundation of the mind. In P.B. Baltes \& U.M. Staudinger (Eds.), Interactive minds: Life span perspectives on the social foundation of cognition (pp. 276-315). New York: Cambridge University Press. 
Steinbroner, F. (2000). Hyperhelper.org and jigsawhelper.org: Design of the first free web-based cooperative learning community of practice for writing and using jigsaw cooperative grouping methods. Unpublished Dissertation Proposal, Pepperdine University, Malibu, CA.

Streufert, S., \& Streufert, S. C. (1978). Behavior in the complex environment. New York: John Wiley.

Thomas, M. M. (2001). Proficient reader characteristics: Relationships among text-dependent and higher-order literacy variables with reference to intellectual development. Unpublished Dissertation, University of Missouri-Kansas City, Kansas City, MO.

U.S. Department of Labor, The Secretary's Commission on Achieving Necessary Skills (SCANS). (1992). Learning a living: A blueprint for high performance. Washington, DC: U.S. Government Printing Office.

Vroom, V. H. (1964). Work and motivation. New York: John Wiley \& Sons.

Vygotsky, L. S. (1978). Mind in society: The development of higher psychological processes. Cambridge, MA: Harvard University Press.

Vygotsky, L. S. (Ed.). (1986). Thought and language. Cambridge, MA: MIT Press.

Wang, M. J. (2001). The construction of shared knowledge in an Internet-based shared environment for Expeditions (iExpeditions): A study of external factors implying knowledge construction. Unpublished doctoral dissertation, University of Missouri, Columbia.

WordNet 1.6. (Version 1.6) (1997). Princeton University. 
Wlodkowski, R. J. (1993). Enhancing adult motivation to learn. San Francisco: Jossey-Bass.

Yin, R. K. (1994). Case study research: Design and methods (2nd ed.). Thousand Oaks, CA: Sage Publications

Yin, R. K. (2003). Case study research design and methods (3rd ed.). Thousand Oaks, CA: Sage Publications. 


\author{
APPENDICES \\ Appendix A - Comparative Case Study Logic \\ Appendix B - Research Script/Protocol \\ Appendix C - WebQuest Fact Sheet \\ Appendix D - Presentation Handouts \\ Appendix E - Collaboration Tips \\ Appendix F - Group Process Guides \\ Appendix G - Weekly Journal \\ Appendix H - Weekly Time Record \\ Appendix I - Presentation Rubric \\ Appendix J - Collaboration Rubric \\ Appendix K - Essay Rubric \\ Appendix L - Data Collection Protocol
}

Appendix M - HIV/AIDS Semantic Relationship Test and Relationship Judgment Test

Appendix N - Living with AIDS final essay

Appendix O - Interview Guide

Appendix P - Human Subjects Approvals

Appendix Q - Number of Interview Passages Coded as Strength by Sub-Themes by Class Appendix R - Number of Interview Passages Coded as Weakness by

Sub-Themes for each Class 


\section{APPENDIX A - COMPARATIVE CASE STUDY LOGIC}

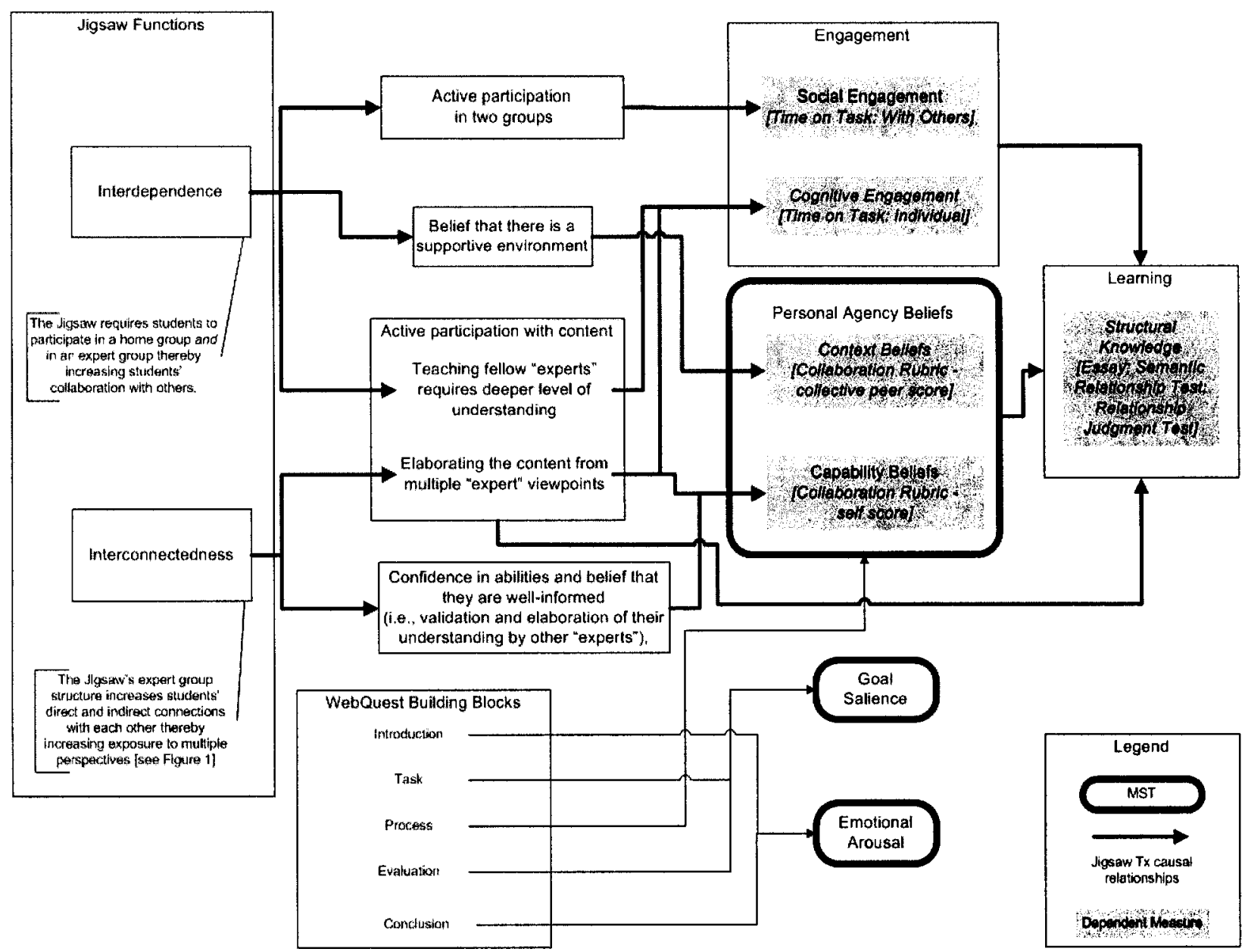




\section{APPENDIX B - RESEARCH SCRIPT/PROTOCOL}

My name is James Frazee and I am a student studying educational technology in the Joint Doctoral Program with San Diego State University and the University of San Diego. Under the guidance of Dr. Bernie Dodge, a professor in the Educational Technology Department here at SDSU, I am conducting research on technologies for teaching.

- This study focuses using the Web as part of instruction.

- The researchers are interested in answering questions such as: How is the learning process different for students exposed to variations of Web-based instructional design strategies?

- The purpose of the study is to advance knowledge about technologies for teaching, and more specifically, the WebQuest model.

- Ten students will be selected at random (i.e., by chance) for interviews in order to get feedback about student perceptions regarding the teaching and learning process. The audio taped interviews will be conducted outside of class and should not take longer than 30 minutes from start to finish. Interviewees will receive a $\$ 10$ gift certificate (to choice of either Aztec Shops, Blockbuster or Starbucks).

- Your participation is entirely voluntary, and you have no obligation to participate.

- You will need to use the last four digits of your student ID number, but neither I nor your instructor will see any identifying information from students and all data will be analyzed and summarized by the researchers and reported in aggregate.

- Your ratings will be most helpful if you answer thoughtfully and honestly.

- Measures are in place to prevent your responses from being linked to your name.

- Your feedback will NOT impact your grade.

- Your data (WebQuest-related journals, performance on essays / exams, and electronic presentations) will be used for course improvement.

- You must be 18 years of age or older to participate.

If you have any questions or want to learn more about the study, please call the principal researcher, James Frazee at (619) 594-2893, the SDSU Institutional Review Board at (619) 594-6622, or the University of San Diego's Office of the Vice President and Provost at (619) 260-4553.

If you would like to participate, please indicate your permission below, and fill in the necessary information.

Thank You for Your Time! (-) 
APPENDIX C - WEBQUEST FACT SHEET \& SYLLABUS LANGUAGE

This capstone unit for the History of Sexuality (HIST 406) course deals with people "living with AIDS," and your goal (quest), is to work together to provide multimedia solutions to the "real" problems they are facing. It is heavily focused on building skills such as teamwork, collaboration, problem solving, and self/peer assessment in order to assist in the smooth development of the product (solution system). Each student team consists of about four students who are responsible for different aspects of the project / product development. Teamwork is necessary in order to design and develop a highquality multimedia product aimed at helping a friend or loved-one who is either HIV+ or diagnosed with AIDS. Students will utilize 32 Internet-ready laptop computers (16 Mac / 16 PC) while discussing multiple AIDS-related issues (e.g., historical, biological, psychological, and economic).

Final grade on WebQuest (worth $20 \%$ of overall course grade) is a combination of:

- Project Team Grade (30 points) that involves teams of four students acting out the roles of historian, doctor, psychologist, and economist in order to create and deliver an electronic presentation (e.g., PowerPoint or web page) that presents a brief analysis of the problem from multiple perspectives, with a focus on "living" with AIDS.

a Individual Journal/Collaboration Rubric (20 points) reflections represent individual students' comments about the WebQuest, and the group work process (collected by the researcher and scored credit / no credit).

Instructor only sees whether or not students completed the reflections. Time on task and other journal data is purposefully witheld from the instructor until after final course grades are submitted for all students! Instructor will only have access to aggregated data, and all identifying information will be stripped away.

- Essay Grade (50 points) based on a problem-solving question related to AIDS, done on the day of the final exam.

$$
\text { TOTAL }=100 \text { Points }
$$




\section{Syllabus Language}

\section{Living with AIDS WebQuest}

At the end of the semester you will participate in a team project focusing on the AIDS epidemic. Students will conduct research on the Internet (using the laptops with wireless Internet-connectivity provided for you in class) as well as using non-Internet materials. You will investigate the history of the disease, such as the demographics, epidemiological issues, treatment options, economics, politics, and social support services available in different parts of the world. By the last day of class each four-person team will present a five-to-seven minute electronic presentation on the topic, and each individual student will complete three brief electronic journal entries (one per week, for three weeks). In addition, each individual student will respond to one of three possible essay questions relating to the Living with AIDS WebQuest. The entire project will make up $20 \%$ of your grade in the course.

You will use the theoretical models we will have studied for the analysis of sexuality in history by Jeffery Weeks and D'Emilio and Freedman to inform your research. Further, you will explain how the research you have done has informed your position on the essay. The materials explaining the unit in more detail will be handed-out to students in class one week before the project begins.

\section{Research Effort}

Because student learning is the central purpose of teaching, I will be working with a doctoral student to investigate how I am using technology in this course. Your participation is entirely voluntary, and you have no obligation to participate. Your confidentiality and anonymity is assured as I will not see any identifying information from students and all data will be analyzed and summarized and reported back to me in aggregate. Your feedback will not impact your grade and your data will be used for course improvement. 


\title{
APPENDIX D - PRESENTATION HANDOUTS
}

\author{
Living with AIDS \\ A WebQuest for History of Sexuality
}

\section{The Challenge}

You have a loved-one or friend who has been diagnosed with AIDS. To help this individual and other members of the family, you will used the Internet to find out all you can about the disease, and then share this information with them.

\section{The Deliverables}

1. For the specific area of the world you are assigned to research (i.e., the fictitious home town of your friend or loved-one), you will work with a team to develop and deliver an electronic presentation that will summarize information on:

- History and origin of the disease

- Treatment options

- Community support services

- Global consequences

2. You will individually complete three electronic journal entries about your experience with the WebQuest

3. You will work with your four-person team to create and deliver an electronic presentation about what you found (more details below)

4. You will individually write a response to an AIDS-related essay exam question on the day of the final

Week 13 (November 24, 2003)

Instructors review WebQuest during the last half of class.

- Introduce WebQuest (PowerPoint explaining process)

- Demo web site (visit URL)

- Deliver WebQuest Handouts

- Form WebQuest Teams

- Class breaks into four-person WebQuest teams

- Each team is assigned a city to focus their research

- Each individual picks a role (topic area of expertise)

- Historian - focus is on the history and origin of the disease

- Doctor - focus is on biological treatment options

- Psychologist - focus is on psychological support services

- Economist - focus is on economic consequences

- Students will begin in-class research on laptops based on their individual roles.

- Students will begin to devise plan for creating presentation together

- Remind students to (before week 13)

- Review WebQuest resources 
- Complete journal entry number one

Week 14 (December 1, 2003)

This class session will focus on the WebQuest.

- Remind students to Complete journal entry number two (before week 14)

Week 15 (December 8, 2003)

Team Presentations

- See Guidelines for Group Presentation

Week 16 (December 15, 2003)

Individual Essay Exam

- See Guidelines for Final Essay

Journal Entry Number Three Due

- See Guidelines for Electronic Journal

INSTRUCTOR NOTES

In Week 14, Jigsaw class will:

- Meet with Expert Groups during the first half of class (with laptops) to:

- Share information about the topic

- Discuss strategies for teaching topic to WebQuest teams

- Meet with WebQuest Teams during second half of class to:

- Take turns teaching each other about topic areas

In Week 14, Control class will:

- Work in WebQuest Teams (with laptops)

\section{Living with AIDS Roles}

Historian - Individual responsibilities:

- List the symptoms of the disease

- Explain the history and origin

- Describe current demographic and statistical information for the area of the world your team will to research.

Psychologist - Individual responsibilities:

- Beyond Psychology-based treatment, such as psychotherapy, report at least two sources of "community" support for individuals living with AIDS (and/or their family members):

o One of the support organizations should be within a fifty-mile radius of where the person lives

- One of the support groups should be an online support group, such that the individual or another individual can obtain information and support electronically. 
- Both support groups should be described and you should report detailed instructions as to how to access each one. (E.g., address, telephone number; URL, etc.)

\section{Doctor - Individual responsibilities:}

- Describe a minimum of three types of treatments for living with AIDS including the following information:

- How it works

- Means of obtaining it (e.g. cost, paid for by insurance, illegal means, experimental treatments from overseas, etc.)

- Success rates and statistics

- Common side effects and drug interactions

- Treatments might include

- Pharmacological-based treatment, such as medication

- Nutritionally-based, such as healthy diet.

\section{Economist - Individual responsibilities:}

- Discuss the consequences of the global spread of AIDS

- Individual (e.g. relationships with family, friends, coworkers)

- Political (e.g. HIV screening, needle and condom programs)

- Economic (e.g. for the individual, community, state, feds, etc.)

- Societal (e.g. fear, prejudiced, impact on behavior such as increased "safe" sex practices, monogamy, etc.)

\section{WebQuest Deliverables \\ Guidelines for Group Presentation \\ (Worth $6 \%$ of final grade in course)}

You have a loved-one or friend who has been diagnosed with AIDS. To help this individual and other members of the family, you want to find out all you can about the disease, and then share this information with them in the form of a 5-7 minute small group presentation. Your presentation will summarize information on the specific area of the world you are assigned to research. The presentation must include current information on AIDS, and might focus on:

1. Describing the symptoms of the disease and explaining the history and origins as well as current demographic and statistical information for the area of the world you are assigned to research.

2. Describing different types of treatment for the disease (e.g.):

a. A biologically based treatment, such as medication, and report information such as:

(1) how it works

(2) the percentage of users significantly helped

(3) any common side effects

(4) major drug interactions 
(5) contraindications

b. A psychology based treatment, such as psychotherapy for coping with the disease. Report such information as:

(1) how it works

(2) the percentage of users helped

(3) any contraindications

c. A nutritionally based treatment, such as diet modification for living longer. Report such information as:

(1) how it works

(2) the percentage of users helped

(3) any contraindications

3. Reporting at sources of "community" support for individuals living with AIDS (and/or their family members):

a. One of the supportive organizations could be within a fifty-mile radius of where the person lives

b. One of the support groups could be an online support group, such that the individual or another individual can obtain information and support electronically.

c. Both support groups should be described and you should report detailed instructions as to how to access each one. (e.g., address, telephone number; URL, etc.)

4. Discussing the consequences of the global spread of AIDS (economic, political, societal). Prevention measures such as HIV-screening, condom and needle programs, and other ways to avoid the spread of the disease.

\section{Important Notes about the Presentation}

- You must include a "References" section at the end of your presentation, listing all sources of information in sufficient detail, such that your instructor could easily obtain/consult these sources.

- The presentation must be coordinated so that each team member speaks about the same amount of time, and the organization must follow elements from the outline above. Please refer to the attached scoring rubric for grading criteria.

- Your instructor will collect and keep a copy of handouts, so if you want a copy, keep one for yourself. 


\section{APPENDIX E - COLLABORATION TIPS}

During this semester you are going to be working together in groups for the WebQuest. Here are a few pointers to help you make your collaborative efforts successful.

Why is learning to collaborate important for me?

- Employers are increasingly looking for employees who can work effectively together; the success of many projects in the "real world" calls for the collaboration of many people. Your experience in this class will give you the expertise you need in order to work cooperatively on group projects. It is a skill that you can include on your resume.

- Research suggests that people who are actively engaged in the learning process learn more. By working with your teammates to solve the WebQuest task, you will be able to ask questions about the things you don't understand. You will also be able to clarify your thinking and help others learn by explaining concepts and ideas to them.

\section{What things can I do to make my collaboration effective?}

1. Participate \& contribute: In order to be engaged in the learning process, you need to participate in all the group activities and contribute towards completing the group goals.

2. Listen \& reflect: Listen accurately to your group members and reflect on what they are saying; one of the objectives of the collaboration exercises is to learn from each other.

3. Explain \& clarify: Remember that part of your job is to make sure that everyone in the group understands the material; so, explain and clarify when necessary.

4. Discuss \& reach a consensus: This is a group effort so it's important to discuss the answers before you input them into the computer. Strive to reach a consensus.

5. Be tactful: Be tactful if you don't agree with someone. Criticize the ideas and not the person. Remember that this is about learning, not about who is right or wrong. 


\section{APPENDIX F - GROUP PROCESS GUIDE}

When working in a group it is important that all members of the group play a role. While the simple majority rules concept works for our nation, in smaller groups it could leave members feeling slighted or out of the loop. Consensus is a strategy that involves everyone playing a role in the decision making of the group. In order for this to be successful it is important to be open to compromise!

According to the Merriam-Webster dictionary the definition of consensus is:

1) a : general agreement $b$ : the judgment arrived at by most or all of those concerned

2) group solidarity in sentiment and belief

\section{Guidelines}

- Trust each other. This is not a competition; everyone must not be afraid to express their ideas and opinions.

- Make sure everyone understands the topic/problem. While building a consensus make sure everyone is following, listening to, and understanding each other.

- All members should contribute their ideas and knowledge related to the subject.

- Stay on the task. You may disagree, that is OK and healthy. However, you must be flexible and willing to give something up to reach an agreement.

- Separate the issue from the personalities. This is not a time to disagree just because you don't like someone.

- Spend some time on this process. Being quick is not a sign of quality. The thought process needs to be drawn out some.

\section{Procedure}

- Agree on your objectives for the task/project, expectations, and rules (see guidelines above).

- Define the problem or decision to be reached by consensus.

- Figure out what must be done to reach a solution.

- Brainstorm possible solutions

- Discuss pros and cons of the narrowed down list of ideas/solutions.

- Adjust, compromise, and fine tune the agreed upon idea/solution so all group members are satisfied with the result.

- Make your decision. If a consensus isn't reached, review and/or repeat steps one through six.

- Once the decision has been made, act upon what you decided.

Adapted from http://projects.edtech.sandi.net/staffdev/tpss99/processguides/consensus.html. 


\section{APPENDIX G - WEEKLY JOURNAL}

\section{Remember to complete this WebQuest Weekly Journal and return it in to the researcher at the start of the next class session to get credit!!}

Date:

Last 4 Digits of Student ID:

Group \#: Role:

Part 1: The WebQuest

Think about your experiences over the last seven (7) days as they related to the WebQuest.

\begin{tabular}{|c|c|c|c|c|c|}
\hline & Never & Rarely & Occasionally & Usually & $\begin{array}{c}\text { Most } \\
\text { Always }\end{array}$ \\
\hline 1. The WebQuest was interesting. & 1 & 2 & 3 & 4 & 5 \\
\hline 2. The WebQuest was frustrating. & 1 & 2 & 3 & 4 & 5 \\
\hline $\begin{array}{l}\text { 3. I had easy access to equipment, technology, etc. } \\
\text { that I needed to work on the WebQuest. }\end{array}$ & 1 & 2 & 3 & 4 & 5 \\
\hline 4. The WebQuest was too time consuming. & 1 & 2 & 3 & 4 & 5 \\
\hline 5. The WebQuest did not feel like busy work. & 1 & 2 & 3 & 4 & 5 \\
\hline
\end{tabular}

6. What would you tell a new student about your experiences with the WebQuest? $\sim$ Please use other side of paper to answer.

\section{Part 2: Group Work}

Now, specifically think about your group experiences over the last seven (7) days as they related to the WebQuest.

\begin{tabular}{|c|c|c|c|c|c|}
\hline & Never & Rarely & Occasionally & Usually & $\begin{array}{c}\text { Most } \\
\text { Always }\end{array}$ \\
\hline $\begin{array}{l}\text { 7. My group discussions did not raise interesting new } \\
\text { ideas or insights. }\end{array}$ & 1 & 2 & 3 & 4 & 5 \\
\hline $\begin{array}{l}\text { 8. Challenging questions were raised in my group } \\
\text { discussions. }\end{array}$ & 1 & 2 & 3 & 4 & 5 \\
\hline $\begin{array}{l}\text { 9. My group discussions did not stimulate me to } \\
\text { discuss new ideas. }\end{array}$ & 1 & 2 & 3 & 4 & 5 \\
\hline $\begin{array}{l}\text { 10. As a rule, I put forth more effort than other } \\
\text { students in my group work. }\end{array}$ & 1 & 2 & 3 & 4 & 5 \\
\hline 11. Not everyone in the group participates. & 1 & 2 & 3 & 4 & 5 \\
\hline 12. We try to make each other feel good. & 1 & 2 & 3 & 4 & 5 \\
\hline 13. We are not able to talk and say what we think. & 1 & 2 & 3 & 4 & 5 \\
\hline 14. We try to listen and pay attention to each other. & 1 & 2 & 3 & 4 & 5 \\
\hline $\begin{array}{l}\text { 15. It seems like one person is talking most of the } \\
\text { time. }\end{array}$ & 1 & 2 & 3 & 4 & 5 \\
\hline
\end{tabular}

16. What one word would you use to describe your group experience over the last seven (7) days?

17. What one word would you use to describe how you would like the group experience to be?

Part 3: Time on WebQuest

Think about the time you have spent outside of class working on the WebQuest over the last seven (7) days. 
Approximately how many hours have you spent:

- $\quad$ Reading Web pages? (Fill in) ___ hours

- Reading print materials? (Fill in) _ hours

- Talking with your teammates? (Fill in) ___ hours

- Talking with people from outside your team? (Fill in) ___ hours

\section{Part 4: Comments}




\section{APPENDIX H - WEEKLY TIME RECORD}

\section{Fall 2003 HIST 406 WebQuest Weekly Time Record}

The Week Starting

With:

[Date]

\section{Student: \\ last 4 digiits of \\ ID\#:}

Instructions:

Fill in shaded cells.

Enter time you spend working on the WebQuest each day on various activities, round to the nearest quarter hour. Total hours will be calculated automatically if you use Excel.

\begin{tabular}{|c|c|c|c|c|c|}
\hline Day/Date & $\begin{array}{l}\text { Hours spent reading } \\
\text { web pages }\end{array}$ & $\begin{array}{c}\text { Hours } \\
\text { spent } \\
\text { reading } \\
\text { print } \\
\text { material }\end{array}$ & $\begin{array}{l}\text { Hours } \\
\text { spent } \\
\text { talking } \\
\text { with } \\
\text { people in } \\
\text { my project } \\
\text { group }\end{array}$ & $\begin{array}{c}\text { Hours spent } \\
\text { talking with } \\
\text { people outside } \\
\text { my project group }\end{array}$ & $\begin{array}{l}\text { Total hours } \\
\text { per day }\end{array}$ \\
\hline (2) Monday & & & & & \\
\hline Y Tuesday & & & & & \\
\hline Wednesday & & & & & \\
\hline Thursday & & & & & \\
\hline Friday & & & & & \\
\hline - Saturday & & & & & \\
\hline Sunday & & & & & \\
\hline & & & & $\begin{array}{l}\text { Total hours per } \\
\text { week }\end{array}$ & \\
\hline
\end{tabular}




\title{
APPENDIX I - PRESENTATION RUBRIC
}

\author{
Assessment Rubric / Scoring Criteria \\ "Living with AIDS" Team Presentation
}

\begin{tabular}{|c|c|c|c|}
\hline Component & Poor & Good & Excellent \\
\hline Introduction & $\begin{array}{l}5 \text { to } 6 \text { points } \\
\text { Introduction does not } \\
\text { make explicit reference } \\
\text { to the problem that is to } \\
\text { be examined. }\end{array}$ & $\begin{array}{l}7 \text { to } 9 \text { points } \\
\text { Introduction adequately } \\
\text { presents the problem, } \\
\text { who is involved, and on } \\
\text { what the presentation } \\
\text { will focus. }\end{array}$ & $\begin{array}{l}10 \text { points } \\
\text { Introduction clearly and explicitly } \\
\text { explains the problem, who is } \\
\text { involved (audience(s), and the } \\
\text { focus of the report. Grabs attention } \\
\text { of the audience - puts us in the } \\
\text { middle of the problem. }\end{array}$ \\
\hline $\begin{array}{l}\text { Sources of } \\
\text { Information }\end{array}$ & $\begin{array}{l}5 \text { to } 6 \text { points } \\
\text { The sources of } \\
\text { information are not } \\
\text { listed, or listed but not } \\
\text { described in any detail. }\end{array}$ & \begin{tabular}{|l}
7 to 9 points \\
Some explanation of \\
both sources and the \\
target audience is \\
provided. Data sources \\
are listed and minimally \\
described. The need for \\
additional sources is \\
evident and/or pertinent \\
sources have been \\
overlooked.
\end{tabular} & $\begin{array}{l}\text { 10 points } \\
\text { A variety of relevant individuals } \\
\text { and data are identified and } \\
\text { described (in detail where } \\
\text { appropriate), taking into account } \\
\text { those sources best able to } \\
\text { illuminate the problem. } \\
\text { Appropriate sources (Web-based } \\
\text { data, course texts, and other } \\
\text { resources) are included. A clear } \\
\text { and complete description of the } \\
\text { sources helps the audience picture } \\
\text { those directly involved in the } \\
\text { problem addressed. }\end{array}$ \\
\hline \begin{tabular}{|l} 
Symptoms of the \\
Disease, the \\
History and \\
Orlgins as well \\
as Current \\
Demographic \\
and Statistical \\
Information
\end{tabular} & \begin{tabular}{|l||}
5 to 6 points \\
Symptoms, history and \\
origins of the disease \\
remain unclear. Current \\
demographic and \\
statistical information \\
missing.
\end{tabular} & $\begin{array}{l}7 \text { to } 9 \text { points } \\
\text { Information about } \\
\text { symptoms, history and } \\
\text { origins of the disease } \\
\text { has been identified, yet } \\
\text { additional clarity is } \\
\text { warranted. The } \\
\text { information is vague or } \\
\text { ambiguous. Insufficient } \\
\text { or inappropriate } \\
\text { identification of current } \\
\text { demographic and } \\
\text { statistical information. }\end{array}$ & $\begin{array}{l}10 \text { points } \\
\text { Symptoms, history and origins of } \\
\text { the disease are clearly identified } \\
\text { and defined. Misinformation is } \\
\text { compared with credible, } \\
\text { appropriate information. Current } \\
\text { demographic and statistical } \\
\text { information for the area of the } \\
\text { world you are assigned to research } \\
\text { is listed with rationale for their } \\
\text { inclusion. }\end{array}$ \\
\hline $\begin{array}{l}\text { Treatment for } \\
\text { the disease }\end{array}$ & \begin{tabular}{|l|}
5 to 6 points \\
Little or no information \\
concerning potential \\
treatment options for \\
living with the disease is \\
identified. Missing one \\
or more potential \\
treatment options.
\end{tabular} & $\begin{array}{l}7 \text { to } 9 \text { points } \\
\text { Information on } \\
\text { biological, } \\
\text { psychological or } \\
\text { nutritionally based } \\
\text { treatment included. It } \\
\text { appears that most } \\
\text { treatment options have } \\
\text { been considered. }\end{array}$ & $\begin{array}{l}\text { 10 points } \\
\text { Information on biological, } \\
\text { psychological or nutritionally } \\
\text { based treatment is all included. A } \\
\text { rich variety of treatment options } \\
\text { have been described in detail and } \\
\text { all are related to a comprehensive } \\
\text { treatment system. A multi-pronged } \\
\text { treatment system is presented. }\end{array}$ \\
\hline
\end{tabular}




\begin{tabular}{|c|c|c|c|}
\hline Component & Poor & Good & Excellent \\
\hline $\begin{array}{l}\text { Community } \\
\text { Support for } \\
\text { Individuals } \\
\text { "Living with } \\
\text { AIDS" (and/or } \\
\text { their family } \\
\text { members) }\end{array}$ & $\begin{array}{l}5 \text { to } 6 \text { points } \\
\text { Lacks a clear description } \\
\text { about the availability of } \\
\text { face-to-face or online } \\
\text { support groups or } \\
\text { organizations. }\end{array}$ & \begin{tabular}{|l|}
7 to 9 points \\
The description about \\
the availability of face- \\
to-face or online support \\
groups or organizations \\
is adequate. Some lack \\
of detail or justification \\
for the support resource \\
may exist.
\end{tabular} & $\begin{array}{l}10 \text { points } \\
\text { Recommendations about potential } \\
\text { face-to-face or online support } \\
\text { groups or organizations are clear } \\
\text { and comprehensive. The writer } \\
\text { identifies community support } \\
\text { options that are realistic and make } \\
\text { sense. We are optimistic that the } \\
\text { community support options } \\
\text { presented have a good chance of } \\
\text { being utilized by the individual or } \\
\text { their friends or family members. }\end{array}$ \\
\hline $\begin{array}{l}\text { Global } \\
\text { Consequences } \\
\text { of AIDS }\end{array}$ & $\begin{array}{l}5 \text { to } 6 \text { points } \\
\text { Insufficient information } \\
\text { on the consequences of } \\
\text { the global spread of } \\
\text { AIDS (e.g., missing } \\
\text { economic, political, or } \\
\text { societal implications) }\end{array}$ & \begin{tabular}{|l}
7 to 9 points \\
Description of the \\
economic, political and \\
societal consequences \\
associated with the \\
spread of the disease, as \\
well as the need for \\
prevention measures.
\end{tabular} & $\begin{array}{l}\text { 10 points } \\
\text { Clear articulation of the global } \\
\text { (economic, political and societal) } \\
\text { consequences associated with the } \\
\text { unchecked spread of the disease, as } \\
\text { well as a strong call for action } \\
\text { regarding the need for prevention } \\
\text { measures and other steps one (with } \\
\text { or without the disease) can take to } \\
\text { be part of the solution. }\end{array}$ \\
\hline $\begin{array}{l}\text { Clarity of } \\
\text { Writing; } \\
\text { information } \\
\text { Organization and } \\
\text { Display }\end{array}$ & $\begin{array}{l}10 \text { to } 19 \text { points } \\
\text { It is hard to know what } \\
\text { the team is trying to say. } \\
\text { Presentation is } \\
\text { convoluted. Misspelled } \\
\text { words, incorrect } \\
\text { grammar, and improper } \\
\text { information evident and } \\
\text { distracting. Information } \\
\text { presentation lacks } \\
\text { organization. }\end{array}$ & \begin{tabular}{|l|}
20 to 30 points \\
Presentation is \\
adequate, but \\
unnecessary information \\
used. Meaning is \\
sometimes unclear. \\
Concepts or ideas are \\
misused. A few errors \\
have been found. \\
Information displays \\
could be improved, is \\
improper, or is \\
confusing. The \\
presentation could profit \\
from better \\
organization.
\end{tabular} & $\begin{array}{l}31 \text { to } 40 \text { points } \\
\text { Presentation is crisp, clear, and } \\
\text { succinct. The audience is guided } \\
\text { from a broad and general view of } \\
\text { the situation (Introduction) to } \\
\text { actionable specifics } \\
\text { (Recommendations/Solution } \\
\text { System). No mistakes are evident. } \\
\text { Presentation is organized logically } \\
\text { and effectively (headers, sections, } \\
\text { etc.) The team takes advantage of } \\
\text { information displays such as } \\
\text { tables, flow charts, graphics etc. } \\
\text { when appropriate. }\end{array}$ \\
\hline & & TOTAL SCORE & \\
\hline
\end{tabular}


APPENDIX J - COLLABORATION RUBRIC

Your Name

Your Team Member's Name

Group Number

Class Day $\square$ Monday $\square$ Wednesday

\begin{tabular}{|c|c|c|c|c}
\hline $\begin{array}{c}\text { Beginning } \\
1\end{array}$ & $\begin{array}{c}\text { Developing } \\
2\end{array}$ & $\begin{array}{c}\text { Accomplished } \\
3\end{array}$ & $\begin{array}{c}\text { Exemplary } \\
4\end{array}$ & Score \\
\hline
\end{tabular}

1. Contribution

\begin{tabular}{|c|c|c|c|c|}
\hline $\begin{array}{l}\text { 1.a } \\
\text { Research \& } \\
\text { Gather } \\
\text { Information }\end{array}$ & $\begin{array}{l}\text { Does not } \\
\text { collect any } \\
\text { information } \\
\text { that relates to } \\
\text { the topic. }\end{array}$ & $\begin{array}{l}\text { Collects very } \\
\text { little } \\
\text { information-- } \\
\text { some relates } \\
\text { to the topic. }\end{array}$ & $\begin{array}{l}\text { Collects some } \\
\text { basic } \\
\text { information-- } \\
\text { most relates to } \\
\text { the topic. }\end{array}$ & $\begin{array}{l}\text { Collects a } \\
\text { great deal of } \\
\text { information-- } \\
\text { all relates to } \\
\text { the topic. }\end{array}$ \\
\hline $\begin{array}{l}1 . b \\
\text { Share } \\
\text { Information }\end{array}$ & $\begin{array}{l}\text { Does not } \\
\text { relay any } \\
\text { information } \\
\text { to teammates. }\end{array}$ & $\begin{array}{l}\text { Relays very } \\
\text { little } \\
\text { information-- } \\
\text { some relates } \\
\text { to the topic. }\end{array}$ & $\begin{array}{l}\text { Relays some } \\
\text { basic } \\
\text { information-- } \\
\text { most relates to } \\
\text { the topic. }\end{array}$ & $\begin{array}{l}\text { Relays a } \\
\text { great deal of } \\
\text { information-- } \\
\text { all relates to } \\
\text { the topic. }\end{array}$ \\
\hline $\begin{array}{l}\text { 1.c } \\
\text { Confidence } \\
\text { in Topic } \\
\text { Expertise }\end{array}$ & $\begin{array}{l}\text { I did not feel } \\
\text { confident } \\
\text { about his/her } \\
\text { topic } \\
\text { expertise }\end{array}$ & $\begin{array}{l}\text { I felt } \\
\text { somewhat } \\
\text { confident } \\
\text { about his/her } \\
\text { topic } \\
\text { expertise }\end{array}$ & $\begin{array}{l}\text { I felt confident } \\
\text { about his/her } \\
\text { topic expertise }\end{array}$ & $\begin{array}{l}\text { I felt very } \\
\text { confident } \\
\text { about his/her } \\
\text { topic } \\
\text { expertise }\end{array}$ \\
\hline \multicolumn{5}{|c|}{ 2. Take Responsibility } \\
\hline $\begin{array}{l}\text { 2.a } \\
\text { Be Punctual }\end{array}$ & $\begin{array}{l}\text { Does not } \\
\text { hand in any } \\
\text { assignments. }\end{array}$ & $\begin{array}{l}\text { Hands in } \\
\text { most } \\
\text { assignments } \\
\text { late. }\end{array}$ & $\begin{array}{l}\text { Hands in most } \\
\text { assignments on } \\
\text { time. }\end{array}$ & $\begin{array}{l}\text { Hands in all } \\
\text { assignments } \\
\text { on time. }\end{array}$ \\
\hline
\end{tabular}




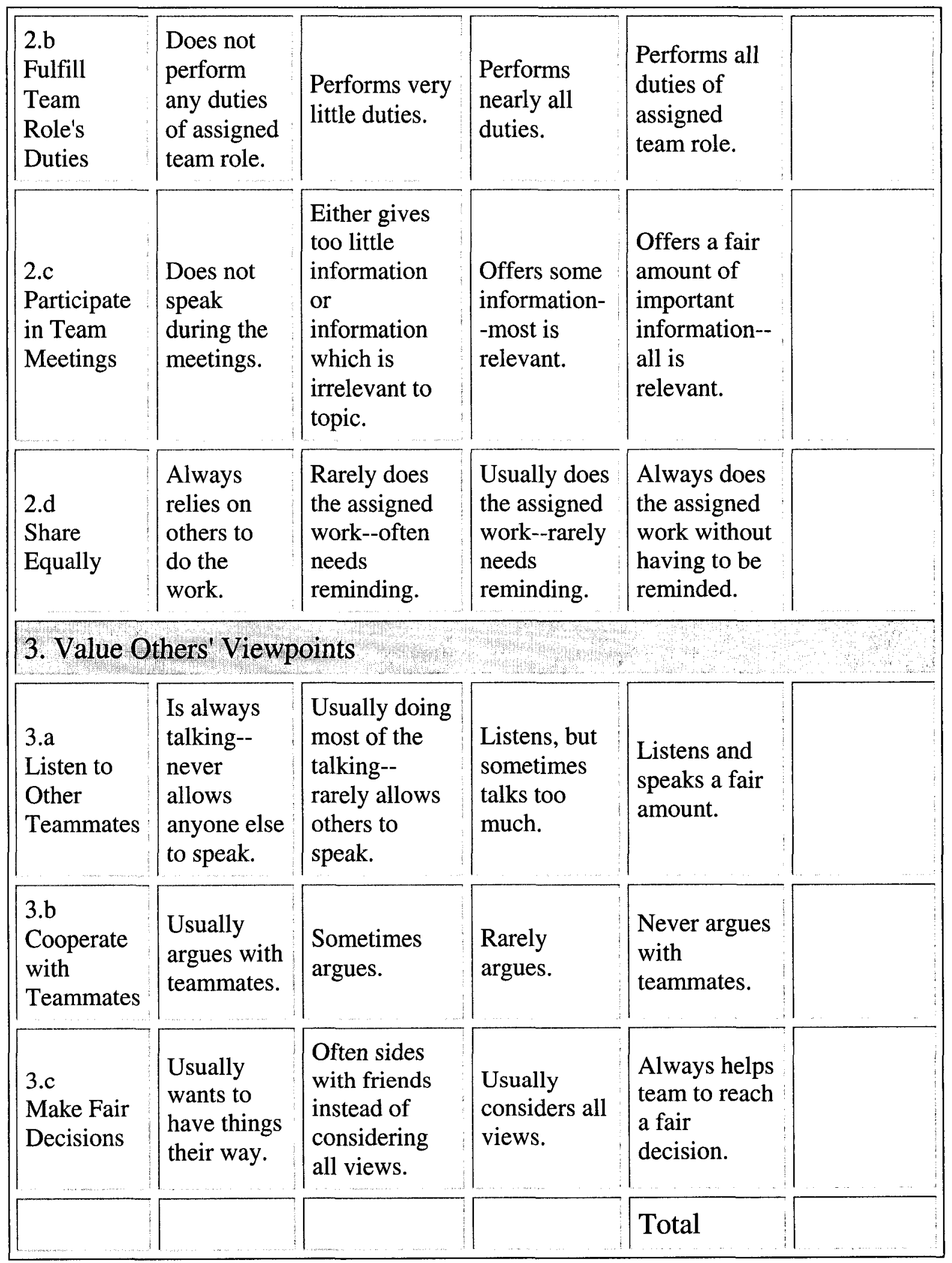


APPENDIX K - ESSAY RUBRIC

\begin{tabular}{|c|c|c|c|}
\hline & 2 & 1 & 0 \\
\hline Focus & $\begin{array}{l}\text { The proposed solution } \\
\text { includes two or more of the } \\
\text { following prevention areas } \\
\text { and depicts their } \\
\text { "connectedness." } \\
\text { - Research (e.g., cause / } \\
\text { cure / prevention of } \\
\text { spread) } \\
\text { - Education (e.g., } \\
\text { awareness and outreach) } \\
\text { Containment (e.g., } \\
\text { needle exchange, } \\
\text { condom giveaway, } \\
\text { testing) }\end{array}$ & $\begin{array}{l}\text { The proposed solution } \\
\text { includes only one area, or } \\
\text { includes two or more of the } \\
\text { following prevention areas } \\
\text { but does NOT depict their } \\
\text { "connectedness." } \\
\text { - Research (e.g., cause / } \\
\text { cure / prevention of } \\
\text { spread) } \\
\text { - Education (e.g., } \\
\text { awareness and outreach) } \\
\text { Containment (e.g., } \\
\text { needle exchange, } \\
\text { condom giveaway, } \\
\text { testing) }\end{array}$ & $\begin{array}{l}\text { The proposed solution } \\
\text { includes none of the } \\
\text { following prevention areas: } \\
\text { - Research (e.g., cause / } \\
\text { cure / prevention of } \\
\text { spread) } \\
\text { - Education (e.g., } \\
\text { awareness and outreach) } \\
\text { - Containment (e.g., } \\
\text { needle exchange, } \\
\text { condom giveaway, } \\
\text { testing) }\end{array}$ \\
\hline $\begin{array}{l}\text { Supporting } \\
\text { Data }\end{array}$ & $\begin{array}{l}\text { Several areas of supporting } \\
\text { data are mentioned, including } \\
\text { two or more of the following } \\
\text { areas AND there are clear } \\
\text { connections or linkages } \\
\text { between the program(s) they } \\
\text { propose and the } \\
\text { data/evidence: } \\
\text { Data Areas: History, } \\
\text { disease stages, statistics } \\
\text { on the spread, } \\
\text { economical impact, } \\
\text { social impact, etc. }\end{array}$ & $\begin{array}{l}\text { Minimal supporting data is } \\
\text { mentioned, including only } \\
\text { one or two of the following } \\
\text { areas AND no link is made } \\
\text { between the program(s) they } \\
\text { propose and the } \\
\text { data/evidence: } \\
\text { Data Areas: History, } \\
\text { disease stages, statistics } \\
\text { on the spread, } \\
\text { economical impact, } \\
\text { social impact, etc. }\end{array}$ & $\begin{array}{l}\text { No sup } \\
\text { mentio }\end{array}$ \\
\hline $\begin{array}{l}\text { Global } \\
\text { Perspective }\end{array}$ & $\begin{array}{l}\text { Solution includes two or } \\
\text { more countries/continents } \\
\text { with explanation of how they } \\
\text { are related (e.g. how the } \\
\text { situation in Africa directly } \\
\text { affects the U.S. and other } \\
\text { western nations). }\end{array}$ & $\begin{array}{l}\text { Solution includes two or } \\
\text { more countries/continents } \\
\text { with no mention of how they } \\
\text { are related. }\end{array}$ & $\begin{array}{l}\text { Solution includes only local, } \\
\text { city, state, or U.S. } \\
\text { perspective. }\end{array}$ \\
\hline $\begin{array}{l}\text { Target } \\
\text { Group(s) }\end{array}$ & $\begin{array}{l}\text { Target group(s) identified } \\
\text { and clearly defined with } \\
\text { supporting rationale or } \\
\text { justification. }\end{array}$ & $\begin{array}{l}\text { Target group(s) identified } \\
\text { and clearly defined but no } \\
\text { supporting rationale or } \\
\text { justification is given. }\end{array}$ & $\begin{array}{l}\text { Target group(s) not } \\
\text { mentioned or is not clearly } \\
\text { defined. }\end{array}$ \\
\hline $\begin{array}{l}\text { Systemic } \\
\text { Plan of } \\
\text { Action }\end{array}$ & $\begin{array}{l}\text { Solution considers the larger } \\
\text { context, and includes a plan } \\
\text { for two or more of the } \\
\text { following: } \\
\text { - Linkages/connections } \\
\text { between and among } \\
\text { multiple agencies. } \\
\text { - Evaluation / data-driven } \\
\text { decision making } \\
\text { - Dissemination/marketing }\end{array}$ & $\begin{array}{l}\text { Solution considers the larger } \\
\text { context, and includes a plan } \\
\text { for one of the following: } \\
\text { - Linkages/connections } \\
\text { between and among } \\
\text { multiple agencies. } \\
\text { Evaluation / data-driven } \\
\text { decision making } \\
\text { Dissemination/marketing } \\
\text { about available services }\end{array}$ & $\begin{array}{l}\text { Solution does not consider } \\
\text { the larger context, and lacks } \\
\text { a plan for any of the } \\
\text { following: } \\
\text { - Linkages/connections } \\
\text { between and among } \\
\text { multiple agencies. } \\
\text { - Evaluation / data-driven } \\
\text { decision making } \\
\text { - Dissemination/marketing }\end{array}$ \\
\hline
\end{tabular}




\begin{tabular}{|l|l|l|l|}
\hline & $\begin{array}{l}\text { about available services } \\
\text { and results of funding } \\
\text { Program sustainability }\end{array}$ & $\bullet \begin{array}{l}\text { and results of funding } \\
\text { Program sustainability }\end{array}$ & $\begin{array}{l}\text { about available services } \\
\text { and results of funding } \\
\text { Program sustainability }\end{array}$ \\
\hline
\end{tabular}

Total points out of 10 . 


\section{APPENDIX L - DATA COLLECTION PROTOCOL}

\begin{tabular}{|c|c|c|c|}
\hline Week & Instrument & Data Collected & $\begin{array}{c}\text { Research } \\
\text { Question/Purpose }\end{array}$ \\
\hline 12 & $\begin{array}{l}\text { Weekly Journal \#1 (survey) } \\
\text { - Closed-ended (Likert-type, } \\
\text { quantitative) } \\
\circ \quad \text { WebQuest items } \\
\circ \quad \text { Group work items } \\
\text { - Open-ended "reflection" } \\
\text { type questions } \\
\text { Journal to be completed at end } \\
\text { of week, or in-class next week if } \\
\text { necessary. }\end{array}$ & $\begin{array}{l}\text { Context beliefs about and perceptions } \\
\text { of group process and interaction } \\
\text { quality } \\
\text { Context beliefs about and perceptions } \\
\text { of satisfaction with learning process }\end{array}$ & $\begin{array}{l}\text { RQ\#1(b); } \\
\text { RQ \#2(b) } \\
\text { RQ \#1(b); } \\
\text { RQ \#2(c) }\end{array}$ \\
\hline 12 & $\begin{array}{l}\text { Weekly Time Record \#1 (time } \\
\text { sheet) }\end{array}$ & $\begin{array}{l}\text { Time-on-Task Out-of-class } \\
\text { - } \quad \text { Reading Web pages } \\
\text { - } \quad \text { Reading print materials } \\
\text { - } \quad \text { Talking with people in group } \\
\text { Talking with people outside of } \\
\text { group }\end{array}$ & RQ \#2(a) \\
\hline 12 & Researcher case notes \#1 & $\begin{array}{l}\text { Researcher's reflections throughout the } \\
\text { WebQuest process }\end{array}$ & $\mathrm{RQ} \# 1-3$ \\
\hline 12 & Instructor case notes \#1 & $\begin{array}{l}\text { Instructor's reflections throughout the } \\
\text { WebQuest process }\end{array}$ & RQ\#1-3 \\
\hline & Repeat all of above for week 13 & & \\
\hline & Repeat all of above for week 14 & & \\
\hline 15 & $\begin{array}{l}\text { HIV/AIDS Semantic } \\
\text { Relationship Test } \\
\text { HIV/AIDS Relationship } \\
\text { Judgment Test } \\
\begin{array}{l}\text { Researcher and other raters } \\
\text { will score tests }\end{array}\end{array}$ & $\begin{array}{l}\text { Performance on HIV/AIDS Semantic } \\
\text { Relationship Test and HIV/AIDS } \\
\text { Relationship Judgment Test will reveal } \\
\text { students' depth of understanding } \\
\text { (structural knowledge) about the } \\
\text { disease. }\end{array}$ & RQ \#3 \\
\hline 16 & $\begin{array}{ll}\text { HIV/AIDS Essay Test } \\
\begin{array}{l}\text { Researcher and one other } \\
\text { rater will score essays }\end{array}\end{array}$ & $\begin{array}{l}\text { Researcher-rated level structural } \\
\text { knowledge based on final independent } \\
\text { writing assignment. }\end{array}$ & RQ\#3 \\
\hline 16 & $\begin{array}{ll}\text { Semi-structured interviews } \\
- & \text { Researcher will use in- } \\
\text { person semi-structured } \\
\text { interviews to triangulate } \\
\text { information gathered } \\
\text { from journals, time } \\
\text { records and rubrics } \\
\text { Ten students per class } \\
\text { were randomly chosen } \\
\text { to participate, with no } \\
\text { more than one student } \\
\text { per group } \\
\end{array}$ & $\begin{array}{l}\text { Time on task } \\
\text { Perceptions of group process and } \\
\text { interaction quality } \\
\text { Perceptions of satisfaction with } \\
\text { learning process } \\
\text { Perceptions of academic self-efficacy }\end{array}$ & RQ \#1-3 \\
\hline
\end{tabular}




\section{APPENDIX M - HIV/AIDS SEMANTIC RELATIONSHIP TEST AND \\ RELATIONSHIP JUDGMENT TEST}

\section{Part 1: Background}

1. Have you taken or are you currently taking "Confronting AIDS" Circle One [GS340] at SDSU?

2. Have you had any prior experience with the WebQuest Model before Yes $\quad$ No this course?

3. How many units are you taking this semester, including the 3 units for \# of units = this course?

\section{Part 2: True / False}

Directions: Please judge the strength of the relationships between the following important HIV/AIDS concepts by answering TRUE or FALSE for each of the following relationship statements.

\begin{tabular}{|l|c|c|}
\hline & \multicolumn{2}{|c|}{ Circle One } \\
\hline 4. HIV is not related to AIDS & True & False \\
\hline 5. Definition of homosexuality is highly related to the definition of AIDS & True & False \\
\hline 6. AIDS is highly related to chronic health problems & True & False \\
\hline 7. Low income is highly related to AIDS & True & False \\
\hline 8. Self-management is not related to living with AIDS & True & False \\
\hline 9. Smoking is highly related to living with AIDS & True & False \\
\hline 10. Entering into drug or alcohol treatment programs is not related to decreasing & True & False \\
\hline 11. Safer sex is not related to decreasing the spread of HIV & & \\
\hline 12. Returning to work is highly related to living with AIDS & True & False \\
\hline 13. Taking medication is not related to brushing teeth & True & False \\
\hline 14. Confidentiality is highly related to HIV/AIDS treatment & True & False \\
\hline 15. Contracting HIV is highly related to getting an animal or mosquito bite & True & False \\
\hline
\end{tabular}

Part 3: Fill in the blank

Directions: Please classify the nature of the relationships between the following important HIV/AIDS concepts.

\begin{tabular}{|c|c|}
\hline Answer & \\
\hline & $\begin{array}{c}16 . \mathrm{HIV}+ \\
\text { a. is caused by }\end{array}$ \\
\hline
\end{tabular}




\begin{tabular}{|c|c|}
\hline & $\begin{array}{l}\text { b. causes } \\
\text { c. is the same as } \\
\text { d. precedes }\end{array}$ \\
\hline & $\begin{array}{l}\text { 17. Simian virus } \\
\text { a. is similar to } \\
\text { b. comes after } \\
\text { c. is caused by } \\
\text { d. causes }\end{array}$ \\
\hline & $\begin{array}{l}\text { 18. Condom give-away ___ needle exchange. } \\
\text { a. assists } \\
\text { b. models } \\
\text { c. justifies } \\
\text { d. is opposite of }\end{array}$ \\
\hline & $\begin{array}{l}\text { 19. Exercise } \\
\text { a. is example of } \\
\text { b. comes after } \\
\text { c. precedes } \\
\text { d. is as important as }\end{array}$ \\
\hline & $\begin{array}{l}\text { 20. AIDS a gay man's disease. } \\
\text { a. is part of } \\
\text { b. is mistaken as } \\
\text { c. causes } \\
\text { d. is the same as }\end{array}$ \\
\hline & $\begin{array}{l}\text { 21. AIDS compassion. } \\
\text { a. is assisted by } \\
\text { b. is opposite of } \\
\text { c. is example of } \\
\text { d. is kind of }\end{array}$ \\
\hline & $\begin{array}{l}\text { 22. HAART } \\
\text { a. is part of } \\
\text { b. comes after } \\
\text { c. is caused by } \\
\text { d. precedes }\end{array}$ \\
\hline & $\begin{array}{l}\text { 23. HIV } \\
\text { a. is caused by } \\
\text { b. is assisted by } \\
\text { c. is part of } \\
\text { d. justifies }\end{array}$ \\
\hline & $\begin{array}{l}\text { 24. Injecting non-prescription drugs } \quad \text { sexual intercourse without a condom. } \\
\text { a. justifies } \\
\text { b. causes } \\
\text { c. is same as } \\
\text { d. precedes }\end{array}$ \\
\hline
\end{tabular}




\begin{tabular}{|c|c|}
\hline & \\
\hline & $\begin{array}{c}\text { 25. Taking daily medication } \\
\text { a. is the same as } \\
\text { b. is opposite of } \\
\text { c. describes } \\
\text { d. is modeled by }\end{array}$ \\
\hline
\end{tabular}

\section{APPENDIX N - LIVING WITH AIDS FINAL ESSAY}

"How would you choose to spend money to fight the spread of AIDS if money was not an object? When explaining your solution system, consider the following:

- What would be your main emphasis and/or target population, and why?

- What else might you do?

- What is your rationale for how you would prioritize spending the money" 


\section{APPENDIX O - INTERVIEW GUIDE}

My name is James Frazee and I am a student studying educational technology in the Joint Doctoral Program with San Diego State University and the University of San Diego. Under the guidance of Dr. Bernie Dodge, a professor in the Educational Technology Department here at SDSU, I am conducting research on technologies for teaching.

- This study focuses on using the Web as part of instruction.

- The researchers are interested in answering questions such as: How is the learning process different for students exposed to variations of Web-based instructional design strategies?

- The purpose of the study is to advance knowledge about technologies for teaching.

- Your participation is entirely voluntary, and you have no obligation to participate.

- Your answers will be most helpful if you respond thoughtfully and honestly.

- Ten students will be selected at random (i.e., by chance) for interviews in order to get feedback about student perceptions regarding the teaching and learning process. The audio taped interviews will be conducted outside of class and should not take longer than 30 minutes from start to finish.

- Measures are in place to prevent your responses from being linked to your name.

- Your feedback will NOT impact your grade.

- Your data (WebQuest-related journals, final essays and electronic presentations) will be used for course improvement.

- You must be 18 years of age or older to participate.

\section{Interview Questions}

1. Describe your experience with the WebQuest.

2. Describe the group aspect of the project. Tell me about how much time it took for you? For your group?

3. How does this class (WQ) compare to other classes you've taken at SDSU?

4. How much time did you spend working on the WebQuest?

5. Describe your experience in your expert group.

6. How confident were you going into the essay?

7. How confident were you with your group members?

8. What you think about participating in another class with a WebQuest?

9. What advice would you give another student if they were going to be doing a WQ?

10. Anything else you want to add? 


\section{APPENDIX Q - EXPERT INTERVIEW RECRUITMENT LETTER}

\section{Dear $>$ :}

My name is James Frazee and I am a doctoral student studying educational technology in the joint program between San Diego State University and the University of San Diego. Formerly, I was the Director of Information Technology for the Sweetwater Union High School District and am now the Associate Director of Instructional Technology Services at San Diego State University. The reason I am writing you is because I am working on my dissertation research study and was hoping for 10-20 minutes of your time to discuss "living with AIDS." This is the content for a Web-enhanced instructional unit that I am investigating as part of my research and because you teach the "Confronting AIDS" course for [institution of higher education], I would like your help with a measure of students' structural knowledge as it relates to your area of expertise. And, to sweeten the pot, I would like to give you $\$ 20$ in appreciation for your thoughtful time and careful consideration.

Because time is of the essence (i.e., I begin my data collection in November) I would very much appreciate getting together with you, wherever it may be convenient for you, sometime in the next few weeks.

See attached for an abstract describing my research study.

Looking forward to hearing from you as soon as possible. Thank you in advance for your help and expertise.

Sincerely,

James P. Frazee 
Appendix Q - Number of Interview Passages Coded as Strength by Sub-Themes by Class

\begin{tabular}{|c|c|c|c|c|c|c|}
\hline \multirow[b]{3}{*}{ Code } & \multirow[b]{3}{*}{ Sub-Theme Description } & \multirow{2}{*}{\multicolumn{2}{|c|}{$\begin{array}{c}\text { Jigsaw } \\
(\mathrm{N}=305)\end{array}$}} & \multirow{2}{*}{\multicolumn{2}{|c|}{$\begin{array}{l}\text { No Jigsaw } \\
(\mathrm{N}=252)\end{array}$}} & \multirow{3}{*}{$\begin{array}{c}\text { Total } \\
(\mathrm{N}=557) \\
\%\end{array}$} \\
\hline & & & & & & \\
\hline & & $\mathrm{n}$ & $\%$ & $\mathrm{n}$ & $\%$ & \\
\hline 1212 & $\begin{array}{l}\begin{array}{l}\text { GRP - Collaboration/Communication (e.g., } \\
\text { shared resources) }\end{array} \\
\end{array}$ & 48 & $15.74 \%$ & 21 & $8.33 \%$ & $12.04 \%$ \\
\hline 1221 & WebQuest - WebQuest structure & 20 & $6.56 \%$ & 18 & $7.14 \%$ & $6.85 \%$ \\
\hline 1211 & $\begin{array}{l}\text { GRP - Members (e.g, confidence and } \\
\text { satisfaction with teammates' effort, didn't } \\
\text { show up) }\end{array}$ & 14 & $4.59 \%$ & 15 & $5.95 \%$ & $5.27 \%$ \\
\hline 1244 & $\begin{array}{l}\text { LRNG - Active learning (e.g. group work, } \\
\text { research projects, peer to peer learning, } \\
\text { hands on, collaborate) }\end{array}$ & 20 & $6.56 \%$ & 7 & $2.78 \%$ & $4.67 \%$ \\
\hline 1246 & $\begin{array}{l}\text { LRNG - Challenge/Difficulty level (e.g., it } \\
\text { was easy, hard, difficult, simplistic, essay } \\
\text { question opinion only) }\end{array}$ & 14 & $4.59 \%$ & 10 & $3.97 \%$ & $4.28 \%$ \\
\hline 1110 & PAB - Confidence & 21 & $6.89 \%$ & 4 & $1.59 \%$ & $4.24 \%$ \\
\hline 1248 & LRN & 13 & $4.26 \%$ & 10 & $3.97 \%$ & $4.12 \%$ \\
\hline 1120 & 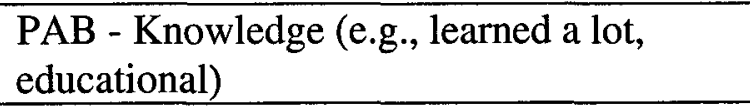 & 15 & $4.92 \%$ & 8 & $3.17 \%$ & $4.05 \%$ \\
\hline 1249 & LRNG - Individual aspect / effort & 8 & $2.62 \%$ & 9 & $3.57 \%$ & $3.10 \%$ \\
\hline 1213 & GRP - Experts / Expert & 12 & $3.93 \%$ & 5 & $1.98 \%$ & $2.96 \%$ \\
\hline 1222 & WebQu & 7 & $2.30 \%$ & 9 & $3.57 \%$ & $2.93 \%$ \\
\hline 1226 & WebC & 9 & $2.95 \%$ & 7 & $2.78 \%$ & $2.86 \%$ \\
\hline 1225 & WebQ & 3 & $0.98 \%$ & 10 & $3.97 \%$ & $2.48 \%$ \\
\hline 1235 & $\begin{array}{l}\text { ENV - Web b } \\
\mathrm{Bb})\end{array}$ & 5 & $1.64 \%$ & 7 & $2.78 \%$ & $2.21 \%$ \\
\hline 1130 & $\begin{array}{l}\text { PAB - Technology savvy (e.g., v } \\
\text { computers) }\end{array}$ & 8 & $2.62 \%$ & 4 & $1.59 \%$ & $2.11 \%$ \\
\hline 1234 & ENV - Email & 9 & $2.95 \%$ & 3 & $1.19 \%$ & $2.07 \%$ \\
\hline 1242 & LRNG - Preser & 5 & $1.64 \%$ & 1 & $0.40 \%$ & $1.02 \%$ \\
\hline 1224 & WebQuest - City as & 1 & $0.33 \%$ & 4 & $1.59 \%$ & $0.96 \%$ \\
\hline 2140 & tright" & 3 & $0.98 \%$ & 2 & $0.79 \%$ & $0.89 \%$ \\
\hline 3100 & LRN & 3 & $0.98 \%$ & 2 & $0.79 \%$ & $0.89 \%$ \\
\hline 1231 & ENV - Laptops & 2 & $0.66 \%$ & 2 & $0.79 \%$ & $0.72 \%$ \\
\hline 1247 & $\begin{array}{l}\text { LRNG - Dedicated in-clas } \\
\text { research }\end{array}$ & 2 & $0.66 \%$ & 2 & $79 \%$ & $0.72 \%$ \\
\hline 1100 & PAB- & 2 & $0.66 \%$ & 1 & $0.40 \%$ & $0.53 \%$ \\
\hline 1230 & ENV - Er & 1 & $0.33 \%$ & 1 & $0.40 \%$ & $0.36 \%$ \\
\hline 2120 & $\begin{array}{l}\text { ENG - Less time than student expected; a } \\
\text { little }\end{array}$ & 1 & $0.33 \%$ & 1 & $0.40 \%$ & $0.36 \%$ \\
\hline 1233 & ENV - Resea & - & 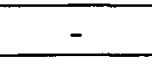 & 1 & $0.40 \%$ & $0.20 \%$ \\
\hline 1240 & LRNG - Lear & - & - & 1 & $0.40 \%$ & $0.20 \%$ \\
\hline 1241 & LRNG - Assignment timing & - & - & 1 & $0.40 \%$ & $0.20 \%$ \\
\hline
\end{tabular}




\begin{tabular}{|l|l|c|c|c|c|c|}
1243 & LRNG - Essay & - & - & 1 & $0.40 \%$ & $0.20 \%$ \\
\hline 2100 & ENG - Time on task & - & - & 1 & $0.40 \%$ & $0.20 \%$ \\
\hline & ENG - More time than student expected; a & & & & & \\
2110 & lot & - & - & 1 & $0.40 \%$ & $0.20 \%$ \\
\hline 1140 & PAB - Major same as role & 1 & $0.33 \%$ & - & - & $0.16 \%$ \\
\hline 1232 & ENV - Room layout & 1 & $0.33 \%$ & - & - & $0.16 \%$ \\
\hline
\end{tabular}

Appendix R - Number of Interview Passages Coded as Weakness by Sub-Themes for each Class

\begin{tabular}{|c|c|c|c|c|c|c|}
\hline & \multirow{2}{*}{\multicolumn{2}{|c|}{$\begin{array}{c}\text { Jigsaw } \\
(\mathrm{N}=305)\end{array}$}} & \multirow{2}{*}{\multicolumn{2}{|c|}{$\begin{array}{c}\text { No Jigsaw } \\
(\mathrm{N}=252)\end{array}$}} & \multirow{3}{*}{$\begin{array}{c}\text { Total } \\
(\mathrm{N}=557) \\
\%\end{array}$} \\
\hline \multirow[b]{2}{*}{ Code } & \multirow[b]{2}{*}{ Sub-Theme Description } & & & & & \\
\hline & & $\mathrm{n}$ & $\%$ & $\mathrm{n}$ & $\%$ & \\
\hline 1241 & LRNG - Assignment timing & 5 & $1.64 \%$ & 14 & $5.56 \%$ & $3.60 \%$ \\
\hline 1212 & $\begin{array}{l}\text { GRP - Collaboration/Communication (e.g., } \\
\text { shared resources) }\end{array}$ & 12 & $3.93 \%$ & 8 & $3.17 \%$ & $3.55 \%$ \\
\hline 1211 & $\begin{array}{l}\text { GRP - Members (e.g, confidence and } \\
\text { satisfaction with teammates' effort, didn't } \\
\text { show up) }\end{array}$ & 7 & $2.30 \%$ & 9 & $3.57 \%$ & $2.93 \%$ \\
\hline 1242 & LRNG - Presentations & 8 & $2.62 \%$ & 5 & $1.98 \%$ & $2.30 \%$ \\
\hline 2110 & $\begin{array}{l}\text { ENG - More time than student expected; a } \\
\text { lot }\end{array}$ & 3 & $0.98 \%$ & 7 & $2.78 \%$ & $1.88 \%$ \\
\hline 1221 & WebQuest - WebQuest structure & 3 & $0.98 \%$ & 6 & $2.38 \%$ & $1.68 \%$ \\
\hline 1249 & LRNG - Individual aspect / effort & 4 & $1.31 \%$ & 4 & $1.59 \%$ & $1.45 \%$ \\
\hline 1246 & $\begin{array}{l}\text { LRNG - Challenge/Difficulty level (e.g., it } \\
\text { was easy, hard, difficult, simplistic, the } \\
\text { essay question was only opinion) }\end{array}$ & 1 & $0.33 \%$ & 5 & $1.98 \%$ & $1.16 \%$ \\
\hline 1110 & PAB - Confidence & 1 & $0.33 \%$ & 5 & $1.98 \%$ & $1.16 \%$ \\
\hline 1233 & ENV - Research Setting & 2 & $0.66 \%$ & 4 & $1.59 \%$ & $1.12 \%$ \\
\hline 1225 & WebQuest - Role assignments & 2 & $0.66 \%$ & 2 & $0.79 \%$ & $0.72 \%$ \\
\hline 1213 & GRP - Experts / Expert group & 4 & $1.31 \%$ & - & - & $0.66 \%$ \\
\hline 1224 & WebQuest - City assignments & - & - & 3 & $1.19 \%$ & $0.60 \%$ \\
\hline 1248 & LRNG - New, different & 1 & $0.33 \%$ & 2 & $0.79 \%$ & $0.56 \%$ \\
\hline 1222 & WebQuest - WebQuest links and resources & 1 & $0.33 \%$ & 2 & $0.79 \%$ & $0.56 \%$ \\
\hline 1210 & GRP - Group work & 1 & $0.33 \%$ & 1 & $0.40 \%$ & $0.36 \%$ \\
\hline 1245 & $\begin{array}{l}\text { LRNG - Traditional learning (e.g., lecture, } \\
\text { usual way) }\end{array}$ & 1 & $0.33 \%$ & 1 & $0.40 \%$ & $0.36 \%$ \\
\hline 1244 & $\begin{array}{l}\text { LRNG - Active learning (e.g. group work, } \\
\text { research projects, peer to peer learning, } \\
\text { hands on, collaborate) }\end{array}$ & - & - & 1 & $0.40 \%$ & $0.20 \%$ \\
\hline 1120 & $\begin{array}{l}\text { PAB - Knowledge (e.g., learned a lot, } \\
\text { educational) }\end{array}$ & - & - & 1 & $0.40 \%$ & $0.20 \%$ \\
\hline 1226 & WebQuest - Topic/Content domain & - & - & 1 & $0.40 \%$ & $0.20 \%$ \\
\hline 3100 & LRNG - Global awareness & - & - & 1 & $0.40 \%$ & $0.20 \%$ \\
\hline 1240 & LRNG - Learning Process & - & - & 1 & $0.40 \%$ & $0.20 \%$ \\
\hline 1234 & ENV - Email & 1 & $0.33 \%$ & - & - & $0.16 \%$ \\
\hline
\end{tabular}

